\title{
Methodios und die Studiten.
}

\section{Strömungen und Gegenströmungen in der Hagiographie des 9. Jahrhunderts.}

Der Bilderstreit hat der Kirche des Ostens eine große Zahl kraftvoller Gestalten, gefeierter Heiligen geschenkt. Selten ist eine Zeit so reich an ausfährlichen Heiligenleben wie das 9. Jahrhundert. Selten bieten Heiligenleben auch dem Historiker so viel interessanten Stoff. Man hat diese Leben bisher meist im guten Glauben ausgenutzt, es mit gleichzeitigen, höchstens durch die panegyrische Art der Byzantiner etwas getrübten Quellen zu tun zu haben.1) Nur langsam und schwer brach sich bei den einzelnen die Erkenntnis Bahn, daB sie beträchtlich später abgefaBt seien. Ebrhard weist darauf hin, daB auch die Viten aus der ersten Periode des Bilderstreits unter den Isauriern in der uns vorliegenden Form meist erst dem 9. Jahrhundert angehören ${ }^{8}$ ), doch ohne daraus irgend welche Konsequenzen zu ziehen. Ich glaube, man' kann leicht weiter kommen und zeigen,

1) Bezeichnend ist in dieser Hinsicht Ehrhards Urteil bei Krumbacher, Gesch. d. byz. Lit.2 194.

2) a. a. O. 197: Die Auffindung der Reliquien der zehn Märtyrer von der Chalke, Maria Patrikia, Georgios Spatharios usf. († 9. Aug. 730) hängt zusammen mit dem Erdbeben 9. Jan. 869 unter Kaiser Basilios und Patr. Ignatios. Der Text (AS Aug. II 434-447) scheint noch unter Ignation ( +28 . Okt. 878) ontstanden. Die Auffindung des Märtyrers Paulos des Nouen aus Kreta ( $\dagger$ CP 8. Juli 745? unter Kopronymos) wird unter Patr. Antonios Kauleas (893-901) gesetzt, 122 (1. 152?) Jahre nach dem Martyrium (=897?); aber der Verfasser des in AS Juli II 635-639 nur lat. gegebenen Textes redet so konfuse von dem Patriarchen Ignatios, daB er jedenfalls noch später zu setzen ist. In dem unter Leon $d$. Weisen zusammengestellten Synaxar von Konstantinopel haben jene zehn Märtyrer am 9. Aug. noch Aufnahme gefunden; Paulos nicht mehr. In beiden Texten wird Photios einfach übergangen. Für Andreas in Crisi $(\dagger 20.0$ kt. unter Kopronymos 741-775) fehlt noch der älteste Text, auf den die Synaxarlektion (besser in $\mathrm{Cb}$ als in S p. 151 Synaxarium eccl. CPtanae ed. Delehaye), der Metaphrast (AS Oct. VIII 152-159= MSG 115, 1109-28) und der gleichfalls jüngere, die Menäenverse voraussetzende Text AS Oct. VIII 135-149 zurückgehen. Es erhellt nicht, ob er gleich nach dem Martyrium oder auch orst nach seiner A.uffindung gefeiert wurdc. Das Synaxar stellt ihn meist mit Stephanos, Petros und Paulos zusammen. 
wie starke kirchenpolitische Tendenzen diese Literatur beherrschen, wenn man einmal die ganze Masse, soweit sie vorliegt, einheitlich untersucht. DaB dabei wichtige Stücke, von deren Existenz wir wissen, nicht herangezogen werden können, weil sie noch unveröffentlicht sind, ist dem Bearbeiter der gröBte Schmerz. Möge diese Studie dazu beitragen, Helfer für die Arbeit zu gewinnen.

I.

Wir gehen aus von Dokumenten, die von der Forschung bisher fast nicht beachtet worden sind und doch in dieser Frage von der gröBten Tragweite sein dürften. Es sind Erlasse des Patriarchen Methodios an und gegen die Studiten. Leon Allatios hatte von ihnen Kunde und gab eine kleine Probe in seinem Werk de Methodiis. Bereits 1841 machte Angelo Mai sie aus vatikanischen Handschriften bekannt, leider in seiner Art Stücke von hier und von dort mitteilend, so daB man nur schwer ein richtiges Bild der Überlieferung erhält. ${ }^{2}$ ) Hergenröther in seinem Photios (1867, I 353) hat sie erwähnt, ebenso E. Marin in seiner sorgfältigen Arbeit über Studion. ${ }^{2}$ ) Sonst schweigen die Werke über Theodor, auch das glänzend geschriebene von Miss Alice Gardner (1905): sie springt S. 259 von der Restitution der Bilder gleich über zu den photianischen Streitigkeiten mit dem Westen; es schweigt Hefele in seiner Konziliengeschichte ( ${ }^{8}$ IV $108 \mathrm{f}$.) und die gesamte kirchengeschichtliche Literatur der neueren Zeit. $\left.{ }^{3}\right)$

Wir geben die Stücke hier in deutscher Übertragung, wobei jedoch bemerkt sein muB, daB nichts schwieriger ist, als diese Produkte byzantinischer Rhetorik einigermaßen sachgemäB und formentsprechend zu übersetzen. Die griechischen Texte folgen unten.

Methodios schreibt den Studiten: „Wenn ihr nicht das gegen Nikephoros den hochheiligen und Tarasios den dreimalseligen Geschriebene

1) Spicilegium Romanum VI p. XXII aus Vatic. Ottob. gr. 225 (saec. XVII), womit Script. vet. nova coll. III 256 aus Vat. gr. Ottob. 213 (saec. XV) zu vergleichen ist; ibd. IV 168 ist aus Vat. arab. 176 die Aufnahme der Stücke in das Typicon Nikons nachgewiesen. Alles ist abgedruckt bei Migne Ser. gr. 100, 1293-98 und 140, 793f. Bei Krumbacher-Ehrhard 167 sind diese Stücke nicht erwähnt.

2) De Studio coenobio Constantinopolitano, Paris 1897, 58 . In seiner populären Biographie Saint Théodore, Paris 1906, geht auch Marin darüber hinweg.

3) Die russische Literatur über den Bilderstreit und die Synode von 843 (A. P. Lebedev 1888, V. Preobraženskij 1890, Th. Uspenskij, Journ. Min. 1891) ist mir unzugănglich. Das Werk von Nic. Grossu über Theodoros Studites, Kiew 1907, erwähnt (nach freundl. Mitteilung von Prof. Nath. Bonwetsch) den Konflikt zwischen Methodios und den Studiten nur kurz S. 62. 153. 162. 
verdammt: entweder heute vor den Brüdern und Mitpriestern oder an einem festgesetzten Tage wenn sie in euer Kloster kommen und hören, und den BeschluB ausführt es zu verbrennen und zu verdammen, wie wir das geschrieben haben in der Verteidigung der kirchlichen Verwaltung, so wiBt, Brüder, daB wir euch selbst und die sich daran halten

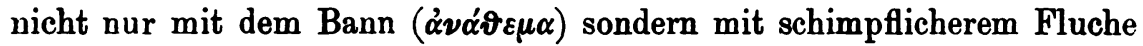
$\left(\varkappa \alpha \tau \alpha^{\prime} \vartheta \varepsilon \mu \alpha\right)$ belegen werden. Denn euer seliger Abt und Lehrer hat, indem er am seligen Ende seines Lebens mit uns Gottesdienst hielt, durch die Tat die eignen Worte außer Kraft gesetzt; denn sonst wäre er nicht wohl mit uns zusammen gewesen, wenn er, was er gegen uns geschrieben hatte, innerlich festhielt. Das aber schreiben wir nicht als Vorwurf, auch nicht als wollten oder wünschten wir, dab es so käme. Sondern wir haben, wie wir es im eignen Sinn tragen und es notwendig bekannt zu machen verpflichtet sind, dies ausgesprochen, damit ihr nur wüBtet, wie gar sehr wir gewillt sind, und wenn wir nur wollen, so haben wir Worte der Satzung und richtige Gerichte euch, eurem Widerspruch, entgegenzusetzen and da es viel mehr ist, um nicht größeren Zorn gegen euch zu erregen, haben wir die Menge dessen was damit zusammen euch vorgeworfen wird und damit zugleich gehört werden muB, verschwiegen. Denn wir beten zu dem überguten Herrn Jesus Christus und möchten ferner gar sehr bitten, daB es bei alle dem nur bei den Worten bleibe und er euch und uns seinen Frieden, Eintracht, Einsicht und Gutgesinntheit in Gnaden schenke."

Der Ton läßt bei aller Verklausulierung an Schärfe nichts zu wünschen übrig. Der Patriarch tritt mit allen ihm zu Gebote stehenden Machtmitteln für die Ehre und Anerkennung seiner beiden Amtsvorgänger ein. Er soll (wie an anderer Stelle berichtet wird) den Studiten zugerufen haben: Du bist Mönch und hast nicht zu untersuchen, was die Priester betrifft; du hast zu gehorchen und nicht zu befehlen oder zu prüfen. ${ }^{1}$ ) Die Studiten haben sich offenbar nicht gefügt, und so ist es zu ibrer Exkommunikation gekommen. Wie energisch der Patriarch die Sache anfaßt, ergibt sich aus einer Predigt und einer Enzyklika. In jener warnt er seine Gemeinde: „EBt nicht init ihnen an einem Tisch, noch grüBt sie, denn wenn ihr teil nehmt an ihren Werken, so notwendigerweise auch an ihrer Verdammung; dazu wollen wir erinnern, daB wenn sie sich bekehren und was übel nicht sowohl - gegen die Patriarchen als gegen die Kirche, (denn jene waren die Kirche, die sie damals stützten) geschrieben ist, verdammen, so wird ihnen eine Frist der Buße gewährt werden, doch nicht priesterliche

1) Vgl. MSG 99, $1853 \mathrm{~d}$. 
Funktion." In dieser Enzyklika aber schreibt er: „gegen die Studiten also ist zu sagen: Wenn sie nicht das, was ihr Vater gegen die allerheiligsten Patriarchen Tarasios und Nikephoros geschrieben hat, verdammen - gewiB nicht ihn selbst, das sei ferne, sondern seine Schriften, wie denn auch Theodoret inbezug auf seine Schriften und andere inbezug auf das, was sie in Verführung ${ }^{1}$ ) gesagt oder geschrieben hatten, getan haben -; wenn also nicht, wie gesagt, auch diese das gegen die genannten Heiligen Geschriebene verdammen, so seien sie fern von Vater, Sohn und heiligem Geist Bann und Fluch verfallen; und nicht sie allein, sondern auch alle, die ihnen folgen und sich mit fortreißen lassen und in freundlicher Gemeinschaft und Verkehr ihnen sich verpflichten: auch sie seien fern von diesen (d. h. der Trinität) verflucht, von Christus fern, in des Teufels Bann: sie tretend, auf ihnen schreitend, d. h. ihrer Meinung zugetan, mögen auf ihrer Verfluchung auch, die ihnen folgen, zum Banne ( $\left.\alpha^{\nu} \alpha^{\prime} \varepsilon \mu \alpha\right)$ gehen. Dann aber ist kein Wunder, daB wir die, welche an dem Verderben der ihnen folgenden Schuld sind, dem (schweren) Fluch ( $\alpha \alpha \tau \alpha \dot{\vartheta} \varepsilon \mu \alpha)$ überliefern; vielmehr ist es recht dafür zu halten, daB wir in göttlichem und apostolischem Urteil dies getan haben ob des Übermaßes der Sünde und des Anlasses zur Sünde so urteilend, bestimmend und die Worte wählend: Christus sei dafür gedankt."

Also hat Methodios gegen die Studiten die schwerste Form des

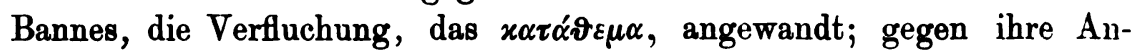
hänger den einfachen Bann, das Anathema.

Aus dem versprengten Stück eines unbekannten Historikers ưber diese Kämpfe ${ }^{2}$ ) entnehmen wir, daß es zweierlei war, was die Studiten jenen beiden Patriarchen vorwarfen: 1. ihr Verhalten in dem sog. moichianischen Streit, 2. das Unkanonische ihrer Wahl vom Laien zum Patriarchen.

Mit ersterem verhielt es sich folgendermaBen:

Kaiser Konstantin VI, Leons IV und Irenes Sohn, hatte seine Frau, eine Armenierin Maria, ins Kloster geschickt und wollte eine neue Ehe mit dem Hoffräulein Theodote eingehen. Das war unkanonisch; der

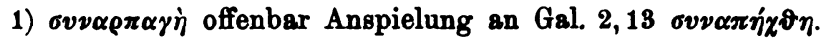

2) Zuerst bei Goar, der es aus Allatios' Papieren durch Combefis erhalten hatte, in den Anmerkungen zu Theophanes ed. Paris (1655) VII 630f. = ed. Bonn II 557-562. Aus Vat. 1137 fol. 27-29 ediert von Mai Spicil. Rom. VII p. XXIXXXXII = MSG 99, 1849-1854. Der Verfasser kennt und benutzt die Methodiosstücke;

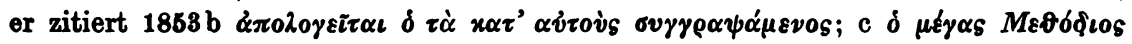

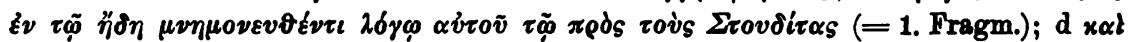

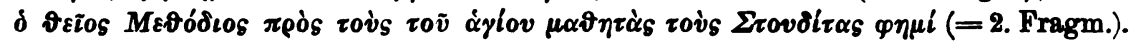
AuBerdem scheint die Theodorvita Michaols benutzt. 
Patriarch Tarasios verweigerte die Trauung, lieB es aber geschehen, laB einer seiner Kleriker, der Oikonomos Joseph, sie vollzog. Die protestierenden Äbte und Mönche verschiedener Klöster ${ }^{1}$ ) wanderten in die Verbannung, aus der sie Irene nach der Blendung ihres Sohnes. zurückberief; Joseph wurde preisgegeben und aus dem Klerus entfernt. Unter Irenes Nachfolger Nikephoros aber lieB sich der gleichnamige Patriarch, Tarasios' Nachfolger, zur Restitution dieses Joseph bewegen: erneuter Protest und abermaliges Exil der Mönche, das erst nach Nikephoros' Tod aufhörte, unter dessen Schwiegersohn Michael Rhangabe die Mönchspartei obenauf war. Theodor von Studion hatte wegen dieses moichianischen Streites nicht weniger als das erstemal ein reichliches Jahr in Thessalonich (796/7), das zweitemal zweieinhalb Jahre auf der Prinzeninsel (809/11) in Exil und Gefängnis zugebracht und seinerseits kräftig gegen die Moichianer, wie er alle mit der unkanonischen Ehe des Kaisers irgendwie BefaBten nannte, gedonnert.") Man versteht, daB das in den Augen seiner Anhänger nichts Geringes war.

Der zweite Punkt war von Theodor und seinem Oheim Platon selbst nicht so betont: das sofortige Aufsteigen von Laien durch alle Weihen hindurch zum Patriarchen war freilich unkanonisch, aber daran war man in Byzanz gewöhnt. Es bedurfte des ganz unbyzantinischen Pochens auf den Buchstaben des kirchlichen Rechts, wie es gerade die Studiten von ihrem großen Abt gelernt hatten, um hieraus eine schwerwiegende Anklage zu machen.

Wir werden die Fragen im einzelnen noch genauer kennen lernen im Verlauf unserer Untersuchung. Hier ist nur noch geltend zu machen, daB es natürlich nicht nur solche alten Differenzen waren, die unter Methodios eine Rolle spielten. Gegenwartsinteressen sind immer das Ausschlaggebende.

Aus der weiterhin noch näher zu besprechenden Lebensbeschreibung des Einsiedlers Joannikios von seinem Schüler Petrus ${ }^{3}$ ) lernen

1) AuBer Platon von Sakkudion und seinen Neffen Theodor und Joseph werden Namen leider nicht genannt.

2) Aus dem Jahre 809 stammt die Vita des jüngern Stephanos von Auxentiû († 28. Nov. 767), auf Wunsch des Einsiedlers Epiphanios, von Auxentiû durch den Diakon Stephanos in Konstantinopel verfaBt (nach Montfaucons Ausgabe in Analecta graeca 1692 bei MSG 100, 1069-1186). Vielleicht klingt die Erregung des

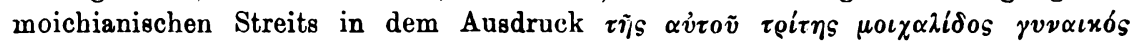
nach, mit dem hier Konstantins V dritte Frau Eudokia bezeichnet wird (1169c); die ('hronisten drücken sich anders aus: Nikephoros der Patriarch sagt einfach (p. 77, 2

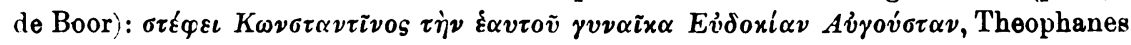

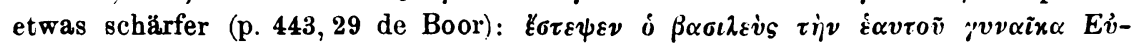

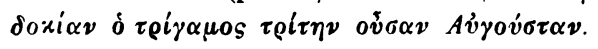

3) S. u. S. $93 \mathrm{ff}$. 
wir, daB es bei den Studiten offenbar gekränkter Ehrgeiz war, der sie gegen Methodios in den Kampf trieb. Sie hatten, wie schon bei der Neubesetzung des Patriarchenstuhls nach Tarasios' Tod (806), so wieder nach der Absetzung des Ikonomachen Johannes 843 darauf gerechnet, daß einer der ihren die Zügel des Kirchenregiments in die Hände nehmen würde. War auch ihr groBer Abt Theodor inzwischen entschlafen, so hatten sie doch an Athanasios, der Sakkudion leitete ${ }^{1}$ ) und dem Abt Naukratios von Studion Männer, die in der schweren Zeit der Verfolgung wacker gekämpft, gelitten und die köstlichen Heiligtümer und Rechte der Kirche energisch verteidigt hatten. ${ }^{\text {) }}$ ? $\mathrm{Zu}$ ihnen gehörte oder hielt sich, wie einst der Erzbischof von Thessalonich, Theodors Bruder Joseph, so jetzt der Erzbischof Johannes Katasambas von Nikomedien und der Metropolit von Kyzikos. ${ }^{3}$ ) Warum sollten sie nicht für einen von diesen den Patriarchenstuhl begehren? Erzählen doch die Biographien verschiedener Heiligen, daB Kaiserin Theodora ihnen denselben angeboten habe, ehe die Wahl auf Methodios fiel. Die Studiten waren die Beichtväter des Manuel, der als Mitglied des Regentschaftsrates an der Neuordnung der Dinge unter Theodora den hervorragendsteu Anteil hatte.4)

Diese Personal- und Machtfragen dürften das eigentlich treibende Motiv gewesen sein. Aber sie bedürfen der Verhüllung: sachliche Gravamina gegen Methodios' Person'und Amtsführung muBten vorgebracht werden. Wir wissen, daB Methodios sich von der Beschuldigung des Ehebruchs vor einem weltlich-geistlichen Gericht zu rechtfertigen hatte: die Anklage soll von den Ikonoklasten ausgegangen sein. ${ }^{5}$ ) Man wird kaum fehlgehen in der Annahme, daB sie nicht so ernst genommen worden wäre, wenn Methodios nicht auch unter den Bilderverehrern heftige Gegner hatte. Die Untersuchung gegen den Patriarchen führt jener Manuel, dessen Beziehungen zu den Studiten wir erwähnten.

Dazu aber kam, daB man ihm Leichtfertigkeit in Erteilung der Bischofsweihen vorwarf. Neuere haben das so verstanden, daB Me-

1) 8. Marin, de Studio 62.

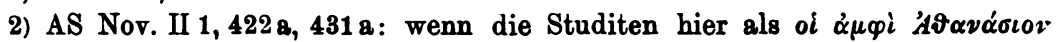

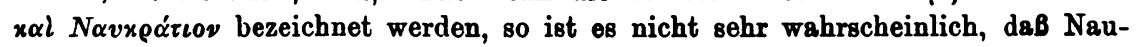
kratios schon vor der Restitution der Bilder, am 8. Apr. 842 starb, wie es nach Marin S. 117 scheint. Die vita des Studiten Nikolaos (MSG 105, 904 b) setzt auch Naukratios' Tod erst nach dem des Methodios (14.Juni 847) an, also 18. Apr. 848, und so Marin selbst S. 52-54.

3) AS Nov. II 1, 432 b. Vgl. schon Le Quien Oriens christ. I 756.

4) Theophanes cont. IV 1 p. 148; Genesios IV p. 79,5.

5) Theophanes cont. IV 10 p. 158 f.; Genesios IV p. 83; Kedr. II 147; Glykas 539. 
thodios nach Meinung der Studiten zu milde (Allatios) oder umgekehrt gerade zu scharf (van den Gheyn) gegen die ikonoklastischen Bischöfe verfahren sei. Diese Meinungen konnten nur entstehen durch unkritische Benutzung der verschiedenen Zeugnisse, von deren wahrer Meinung wir noch zu reden haben werden. Die Ikonoklasten sind erst von der jüngeren Überlieferung hier als Sündenböcke eingeschoben. Ursprünglich handelte es sich um rechtgläubige Einsiedler und Bekenner, die aber nicht dem seit Theodor aufs neue in straffer klösterlicher Disziplin organisierten Mönchtum, sondern dem alten Eremiten-(Hesychasten-)tum angehörten, Vertreter einer ganz anderen Art von Frömmigkeit, Helden weniger im Kampf der Kirche gegen die ketzerischen Kaiser als gegen die bösen Geister, Heroen der Askese, Wundertäter, theologisch oft ungebildet, aber von sehr massiver Art des Glaubéns und Bekennens; Leute, denen die große Kirchenpolitik ganz fern lag, die zufrieden waren, wenn ihnen die kaiserliche Regierung die Freiheit ihres Wirkens lieb und die Orthodoxie schützte, die aber für die studitische Forderung der kirchlichen Freiheiten gegenüber dem Staatskirchenregiment, der Unantastbarkeit der Kirchengesetze- auch vor dem kaiserlichen Willen, gar kein Verständnis zeigten.

Hier liegt - von der Personenfrage abgesehen - der tiefste Grụnd der Differenz. Die strikten Anhänger Theodors vertraten ein hohes kirchenpolitisches Prinzip: Selbständigkeit der Kirche gegenüber dem Staat. Der. Patriarch und seine Leute räumten der Regierung gegen Aufrechterhaltung der Orthodoxie die in Byzanz traditionelle Gewalt über die Kirche ein. Die Mönche waren, wie das auch im Abendland manchmal, besonders bei den Cluniazensern, geschah, päpstlicher als der Papst, kirchlicher als das Oberhaupt der Kirche.

Über den Verlauf des Streites wissen wir leider so gut wie nichts. Er scheint noch vor Methodios' baldigem Tode (14. Juni 847) durch Nachgeben des Patriarchen beigelegt worden zu sein. ${ }^{1}$ ) Andrerseits wurde auch später noch in dem alljährlich verlesenen Synodikon feierlich promulgiert: „Tarasios und Nikephoros, die heiligsten Patriarchen - ewig sei ihr Andenken" und „Was gegen die hochlöblichen Patriarchen Tarasios und Nikephoros gesagt und geschrieben worden ist Anathem!“2) Auch die Studiten waren unter sich nicht einig; neben der durch Athanasios und Naukratios vertretenen strengeren Richtung

1) S. die Vita des Methodios unten S. 52 .

2) MSG 140, 796; in der gleichen Weise ward der Streit zwischen Ignatios und Photios ausgeglichen; s. ebenda. Über das Synodikon hat Th. Uspenskij im

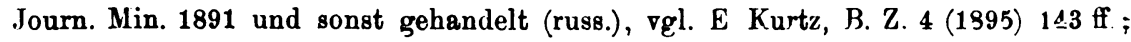
es ist ein Gegenstück zur römischen Nachtmahlsbulle. 
stand eine zu Kompromissen geneigte. Als Abt Naukratios bald nach Methodios starb (18. April 848?), folgte ihm der viel mildere Nikolaos, der mit Patriarch Ignatios auf dem besten FuBe stand. Das Anathem über die Studiten muB schon von Methodios selber aufgehoben worden sein. Unter Ignatios war nicht mehr davon die Rede, obwohl die Hitze des Kampfes in einzelnen Köpfen weiterglühte. Bald kamen die photianischen Wirren und damit ganz andere Erregung.

Es gehört zu den lehrreichsten Tatsachen der Überlieferungsgeschichte, daB die uns erhaltenen byzantinischen Chronisten diesen ganzen Streit mit Stillschweigen übergehen. Es muB doch noch Werke andrer Art gegeben haben, wie jenes oben erwähnte Fragment eines Historikers zeigt, das uns leider ganz isoliert überliefert ist. Wundern kann man sich schlieBlich nicht, daB wir bei der Historiographie dieser Zeit nichts darüber finden: was wir haben, geht doch fast alles auf eine, recht einseitig mönchische Quelle zurück.

Aber auch die Hagiographie geht - wenige Ausnahmen abgerechnet - geschlossenen Auges an diesem peinlichen Anblick der streitenden Heiligen vorüber. Sie kann dabei doch nicht verhüten, daB man ihr anmerkt, welchen Zwang sie sich antut, wie ängstlich sie bemüht ist, nicht unter die Streitenden zu geraten. So verrät sie uns wider ihren Willen gar manches von dem, was sie verschwiegen wissen möchte. Man muß nur ihren etwas unsicheren Gang scharf ins Auge fassen.

Anders stellt sich nur die kanonistische Literatur; ihr verdanken wir jene Methodiosfragmente, die den tiefsten Einblick in die ganze Schärfe des Streites gewähren; in ihr hat das Schismá der Studiten auch weiterhin noch als ein wichtiges Beispiel dessen, was nicht sein soll, figuriert.

Da istazunächst eine dogmatisch-kanonistische Sammlung von dem palästinensischen Mönch Nikon (um 1088) zu nennen, uber die A. Mai in Script. vet. nova coll. IV 168 nach Vat. arab. 176 referiert hat. Hier wird fol. 428 ein Zitat aus Methodios' Schrift gegen die Studiten gegeben. Darauf beruft sich der gleich zu nennende Mönch Methodios im 13. Jahrhundert.

Dieses hat im Zusammenhang mit den Kämpfen zwischen den Orthodoxen und den Latinophrones, den Anhängern des Patriarchen Joseph und des Johannes Bekkos ${ }^{1}$ ), zwei Schriften über das Verhängnisvolle der Schismen hervorgerufen, die offenbar unabhängig von einander, doch fast das gleiche geschichtliche Material benutzen.

1) Hauptquelle hierfür ist Georgios Pachymeres. Vgl. Mansi XXIV $492 \mathrm{ff}$., Hefele 2 VI $162 \mathrm{f}$. 
Die eine stammt von dem Erzbischof Johannes Chilas von Ephe$\operatorname{sos}^{1}$ ), der sie auf einer Synode zu Konstantinopel 1283 selbst vortrug. $\left.{ }^{2}\right)$ Leider sind davon bisher nur Auszüge bekannt, die A. Mai gab; darunter gerade die Methodios-Stücke.

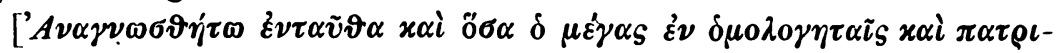

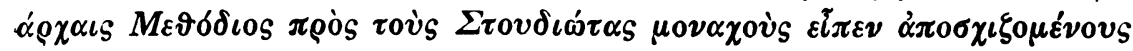

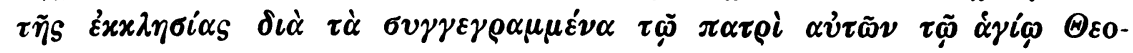

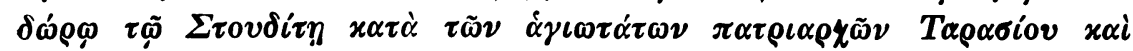

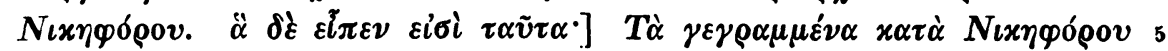

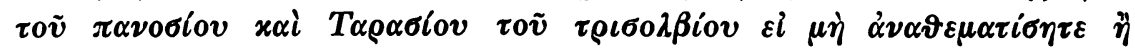

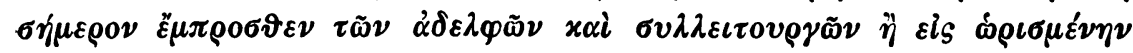

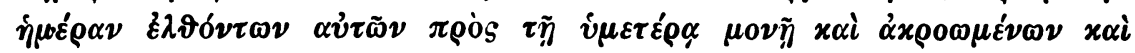

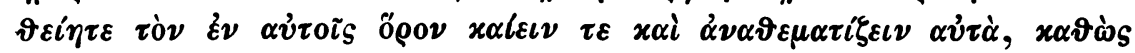

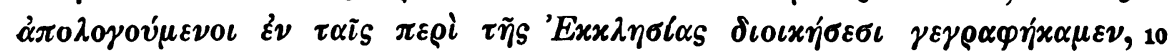

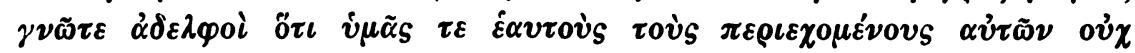

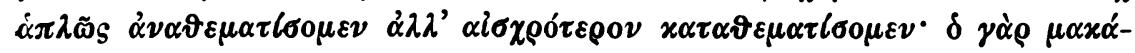

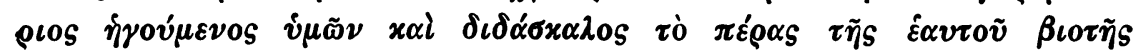

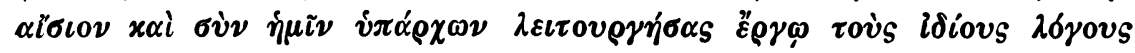

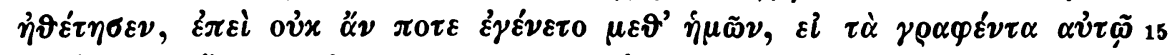

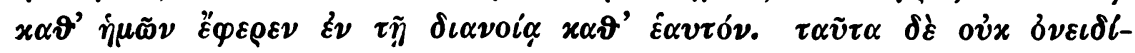

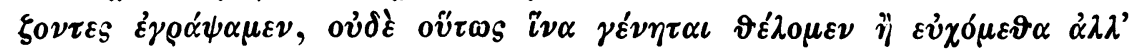

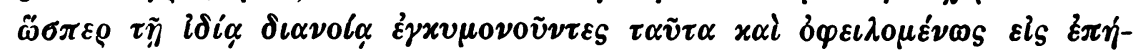

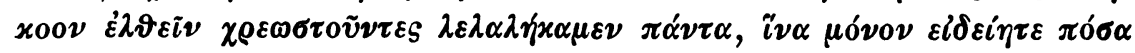

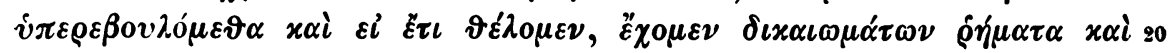

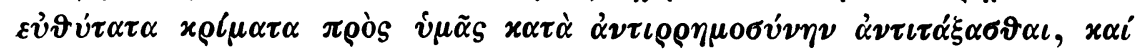

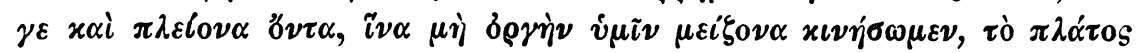

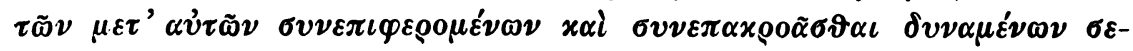

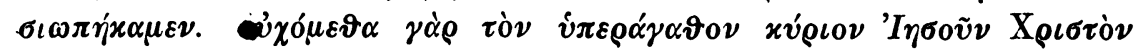

1) Chilas von Fphesos und Daniel von Kyzikos waren die Huuptwortfuhrer beim Sturze des Gregorios Kyprios 1289. Nikeph. Gregoras VI 3.4 p. $177 \mathrm{ff}$.

2) Sie liegt handschriftlich in zwei Formen vor: einer liingeren, wohl ursprünglichen, in Vatic. Ottob. 225 (saec. XVI oder XVII) fol. $1-53=\mathbf{A}$, und einer verkürzten in Vatic. Ottob. 213 (saec. XV) fol. 185-220=B; vgl. den Katalog der Ottoboniani von E. Feron und F. Battaglini (1893) p. 213. 225. Ehrhard bei Krumbacher ${ }^{299}$. Mai hat diese Handschriften in seiner Weise so ausgeschöpft, daB man von keiner ein klares Bild erhält. Seine Praefatio ist zum Teil abgedruckt bei Migne 135, 501-6, der Rest Migne 100, 1293-98.

$1-5$ aus $B$ (wohl auch in $\mathrm{A}$ ).

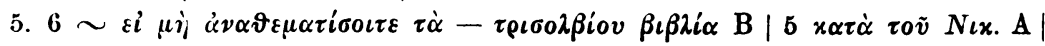

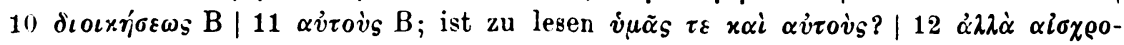

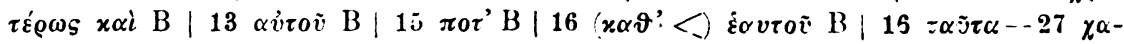
$\rho i \sigma \alpha \sigma \vartheta \alpha \iota<B$. 


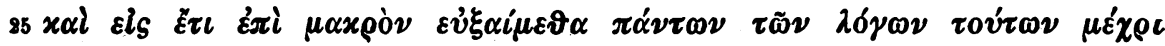

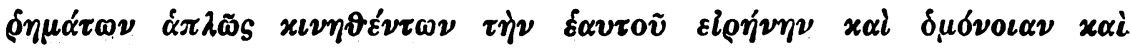

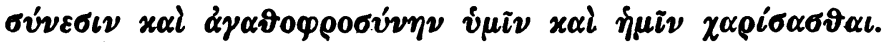

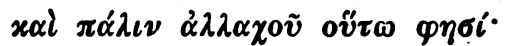

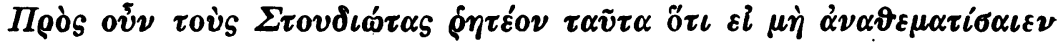

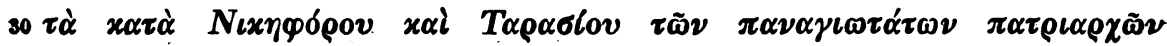

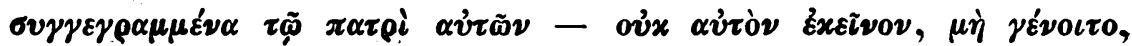

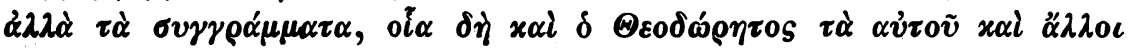

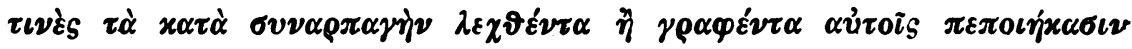

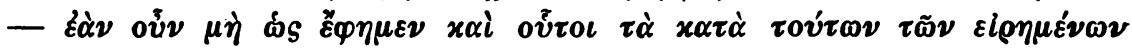

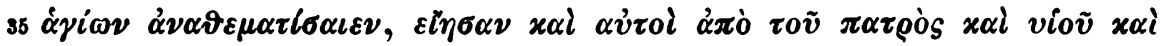

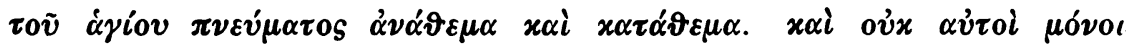

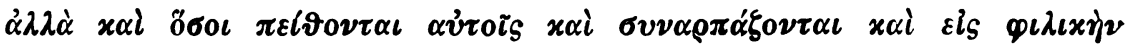

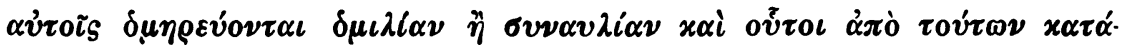

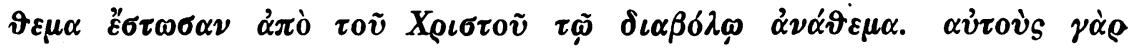
$40 \pi \alpha \tau 0 \tilde{v} \nu \tau \varepsilon S$,

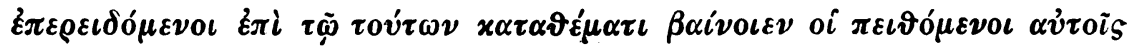

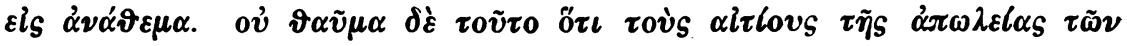

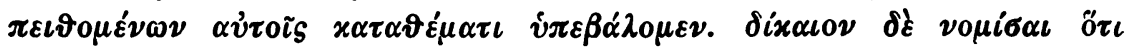

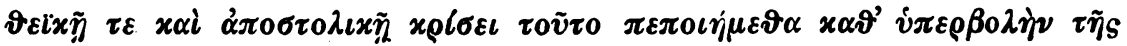

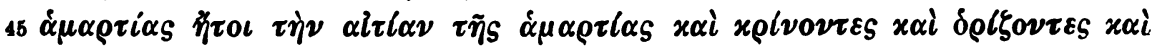

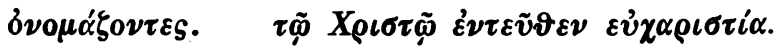

Die andere Schrift stammt von einem Mönch Methodios; A. Mai hat sie 1828 publiziert. ${ }^{1}$ ) Gestützt auf historische und kanonistische Sammlungen ${ }^{2}$ ) geht der Mönch die ganze Patriarchengeschichte auf unregelmäBige Absetzungen und Neubesetzungen hin durch, um zu zeigen, daß sie nie einen Grund für ein dauerndes Schisma abgegeben hätten. Dabei kommen auch die durch den gottlosen Joseph heraufbeschworenen $\sigma x \alpha \dot{v} \delta \alpha \lambda \alpha$ in den Tagen der heiligsten Patriarchen Tarasios und Nikephoros und des Bekenners Theodor des Studiten zur Sprache (c. 10. 11). Der Oikonomos Joseph wird hier auf das schärfste verurteilt. Das Verhalten der Patriarchen wird als ein durch die Verhältnisse gebotenes gerechtfertigt, wie wir das noch kennen lernen werden. Dabei beruft

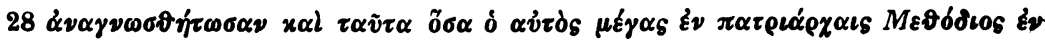

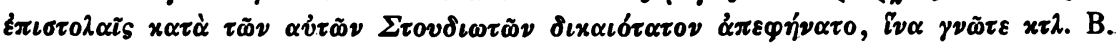

29-36 Soweit dies Fragment schon bei Leon Allatios de Methodiis 94.

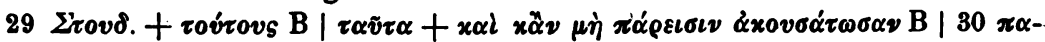

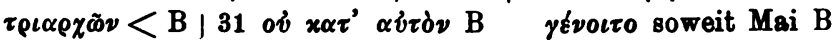

1) A. Mai, Script. vet. nova coll. III 1, 246-264, Migne 140, 779-806.

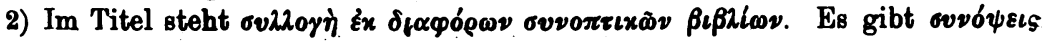

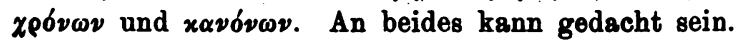


sich der Mönch Methodios für die Herstellung der Gemeinschaft Theodors mit dem Patriarchen nach Josephs AusstoBung anßer auf einen Brief Theodors ${ }^{1}$ ) auch auf ein Leben Theodors, dessen Verfasser er leider nicht nennt, aus dem er aber folgenden Satz zitiert: „Nach der Rückkehr des göttlichen Theodor und des Patriarchen Nikephoros aus der Verbannung legte Theodor seine zank- und streitsüchtige Art ab und war ganz eins mit dem Patriarchen, eine Seele, unter einem Dach, an einem Tisch, und krönte ihn mit vielen Lobsprüchen. “8) Das lesen wir so in keiner der uns erhaltenen Viten (s. u. S. 68). Weiter beruft er sich auf einen Brief des Patriarchen Methodios an die Sakkudianer und Boskytianer ${ }^{3}$ ), der in dem Buch des h. Vaters Nikon (offenbar jener oben S. 48 erwähnten kanonistischen Sammlung) zu finden sei $^{4}$ ); endlich auf das Synodikon, das Tarasios und Nikephoros feiert und alles, was gegen sie gesagt und geschrieben ist, anathematisiert (s. ob. S. 47). Es ist klar, daB diese Darstellung aus offiziellen, von der Patriarchatskanzlei ausgehenden Urkunden geschöpft ist: die Studiten kommen dabei schlecht, ihr gefeierter Abt nicht gerade gut weg. Die Patriarchen werden herausgestrichen.

II.

E. Marin gibt seiner Verwunderung Ausdruck, daB jener Konflikt in keiner der Viten der Nächstbeteiligten, weder der des Patriarchen Methodios noch der des damaligen Studitenabtes Naukratios, irgendwelche Spuren hinterlassen habe. ${ }^{5}$ ) Wir würden uns darüber garnicht so sehr zu wundern haben. Aber die Beobachtung ist auch nicht richtig: man darf nur nicht erwarten, die Gegner mit Namen genannt zu

1) Gemeint ist wohl einer der beiden Briefe an den Patriarchen, s. u. S. 62.

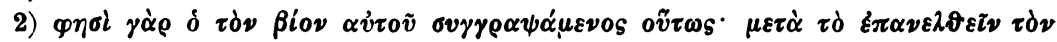

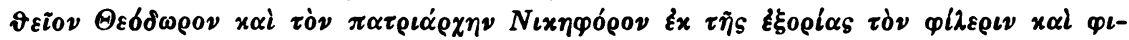

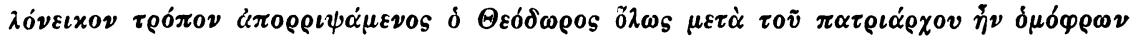

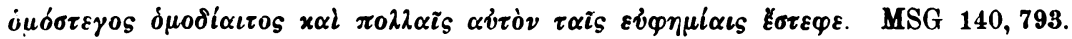

3) Das sind die Studiten, wie die Utberschrift in der anderen Sammlung gelautet zu haben scheint. Jenes waren die Klöster Platons und Theodors vor ihrer ťbersiedlung nach Studion. Es kann aber sein, daB sie hier genannt werden, weil nur ein Teil der Studiten frondierte.

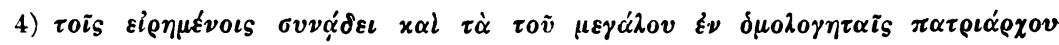

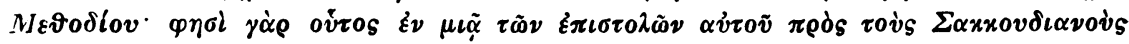

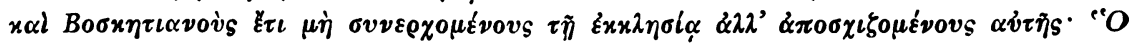

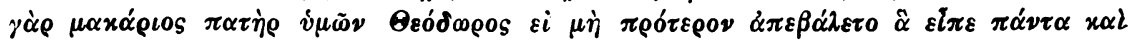

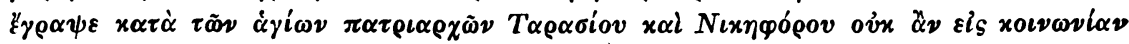

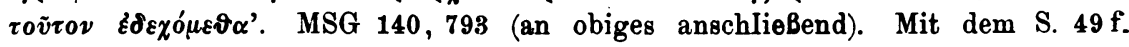
zitierten Schreiben scheint dies nicht identisch zu sein.

5) de Studio p. 54. Eine Nankratiosbiographie gibt es nicht, s. S. 70 A.4. 
sehen. Wenn wir jetzt daran gehen, alle erreichbaren Viten aus dieser Zeit zu durchmustern, so werden' wir mit Erstaunen wahrnehmen, wie tiefe Spuren dieser Konflikt hinterlassen hat; freilich oft mehr in dem, was nicht gesagt wird!

Wir beginnen mit der Biographie des Patriarchen Methodios selbst ${ }^{1}$ ); sie ist wohl nicht zu bald nach Methodios' Tod von einem Anonymus verfaBt. Hier wird, nachdem erst Nikephoros' Exil (nach der offiziösen Version), Methodios' Entweichen nach Rom ${ }^{8}$ ) und seine Rückkehr unter Michael II, sein erstes Martyrium unter diesem Herrscher (neunjährige Kerkerhaft), sein zweites unter Theophilos, der Sieg der Orthodoxie und Methodios' Erhebung zum Patriarchen erzählt ist, der gegen seine Patriarchatsführung erhobene Vorwurf erwähnt: er habe zu unbesehen die Weihen erteilt, auch an solche, die sie nur aus Ehrgeiz begehrten. ${ }^{3}$ ) Sein Biograph scheint das Recht der Anklage zuzugestehen; er sagt entschuldigend: er war kein Petrus, das will sagen kein Herzenskündiger wie dieser im Fall von Ananias und Sapphira (1257b). Er sieht in dem Zwist unter den Orthodoxen ein Werk Satans, beruhigt sich aber durch den Hinweis auf das Zerwürfnis zwischen den Aposteln Paulus, Petrus und Barnabas. Die Meinung des'Patriarchen behält, von der kaiserlichen Macht unterstützt, die Oberhand: die dissentierenden Bischöfe und Äbte werden abgesetzt, das Schisma wird nur größer. Da sendet Gott dem Patriarchen eine Krankheit und von dieser niedergebeugt erkennt er, daB er in seinem Eifer zu weit gegangen, mit seinen Untergebenen zu scharf verfahren sei: er vergibt und erläBt die Strafen, besonders solche für Verachtung und Auflehnung gegen die Patriarchalgewalt. So stirbt er in Frieden und der Verfasser kann ihn als Sieger in allen Kämpfen feiern.

Für den, der lesen kann, sind hier die Kämpfe des Patriarchen mit den renitenten Studiten deutlich genug geschildert: wir lernen dabei, daB die Beförderung nicht ganz einwandfreier Elemente zu Bischöfen ein Hauptgravamen der Mönchspartei bildete. Wir sehen aber

1) Aus Acta Sanct. Juni II bei MSG 100, 1243-1262.

2) Von Methodios' Wirken in Rom spricht Theodor ep. II 35 p. 1209, M. 192 p. 165 mit Anerkennung; an ihn nach Rom gerichtet ist M. 193 p. $166 \mathrm{f}$; vgl. Theophanes cont. 159, 6; Ps. Symeon 652,17; Kedrenos II 148,8; Glykas 539,10.

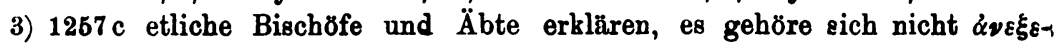

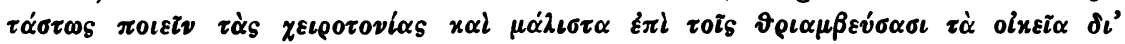
$\xi \xi \alpha \gamma \gamma \varepsilon \lambda \sigma \varepsilon \omega s \pi \alpha \dot{\theta} \eta$. Allatios versteht das von öffentlichem Sündenbekenntnis und denkt an frühere Ikonoklasten. Mir scheint hier Ruhmredigkeit bilderfreundlicher Märtyrer gegeißelt zu sein. So wurde Theophanes Graptos Erzbischof von Nikaia, dessen Martyrion uns bauptsächlich durch seinen von den Biographen aufgenommenen Brief an Johannes von Kyzikos bekannt sind (MSG 116, 672-680). 
auch, daß der Patriarch einen Biographen gefunden hat, der nicht unbedingt auf seiner Seite stand. ${ }^{1}$ )

Von der Vita des Methodios greifen wir zurück auf die seiner beiden gefeierten Vorgänger, für deren ehrenvolles Andenken er kämpfte. Die Viten der Patriarchen Tarasios und Nikephoros stammen beide aus der Feder des Diakon und Skeuophylax Ignatios. ${ }^{2}$ ) Dieser verkörpert in sich die unangenehmen Seiten damaliger byzantinischer Beredsamkeit: er verdankt, wie er selbst sagt, dem Unterricht, den er als Jüngling von Tarasios empfing, die Kenntnis der griechischen Vers$\mathrm{maBe}^{3}$ ): er hat sie $822 / 4$ in Jamben gegen den Prätendenten Thomas,

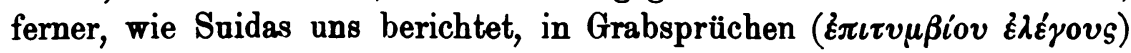
geübt; seine Reden strotzen von rhetorischen Kunstmitteln; wiederholt beruft er sich auf die Kunstregeln des heidnischen Panegyrikus ${ }^{4}$ ); er glänzt in frei erfundenen Reden und Gesprächen, die er einlegt ${ }^{5}$ ); er renommiert gewaltig mit seinen.Kenntnissen klassischer Mythologie und Literatur. ${ }^{6}$ ) Um die Wette mit biblischen Namen schwirren dem Leser alle möglichen geschichtlichen Reminiszenzen um das $\mathrm{Ohr}$. Ja

1) Das Synaxar zum 14. Juni (p. 749 Delehaye) bietet denn auch statt eines Auszugs hieraus nur einen Lobpreis des Wiederherstellers der Orthodoxie.

2) Vgl. Ehrhard bei Krumbacher ${ }^{2} 72$, Krumbacher selbst $312 \mathrm{f}$., 716 f.; auch RE ' XIV 22. Nicephori archiep. CPolitani opuscula historica ed. C. de Boor,

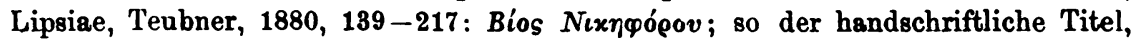
den schon Suidas bezeugt. Ältere Ausgaben in AS März II 704-26, MSG 100, 41-160. - Ignatii diaconi vita Tarasii archiep. CPolitani ed. I. A. Heikel in Acta societatis scientiarum fennicae XVII, Helsingfors 1891, 389-439; vorher nur in lat Übersetzung von Gentianus Hervetus, AS Febr. III 576-590, MGS 98, 1385-1424

3) Tar. 423, $5 \mathrm{ff}$.: hier bezeichnet er sich auch als den Herausgeber der Predigten des Tarasios (vgl. 406,31).

4) Nic. 141, $23 \mathrm{ff}$; Tar. 413,35 .

5) Nic. 168: Rede an den Klerus; 170-186 Disput mit dem Kaiser unter vier Augen (!); 187 Rede eines Bilderverteidigers ror dem Kaisor; 107 Brief an den Kaiser; 199 Gebet. Tar. 398: Rede des Patriarchen Paul IV an Irene und Konstantin; 399f. Rede des Kaisers an Tarasios und Antwort; 409 Strafrede an Kaiser Konstantin; $410 \mathrm{f}$. Verhandlung mit dem Kaiser. Diese Zusammenstellung ergibt zur Genüge, was von dem Quellenwert z. B. der Disputation mit dem Kaiser, die Ehrhard bei Wetzer und Welte ${ }^{2}$ IX 251 gegen Hirsch, byz. Studien 19 als authentisch verteidigt, zu halten ist.

6) Nic. 144, 9 ausonischer Dialekt; 145, 6 paianischer Rhetor; 148, 18 Hof des Alkinoos, 19 goldene Platane des Xerxes, 30 Syrakusische Speisetafel; 150,5 f. Pythagoras, Aristoxenos; 152,j der kynische Philosoph (Diogenes); 164, 26 Proteusgesicht; 165,9 Ogygische Pietät; 165,26 der mythische Aigaion; 166,6 die Strafen des Echetos und Phalaris, 10 die Phantasmen der Empusa; 173,24 Osiris, Typhos, Horos, Isis, 28 ff. ägyptischer Tierdienst: Apis, Hermes, Athena, Pan, Anubis ; 175,27 das Gefilde der Lethe; 188,9 die Sïulen def Herakles - Tar. 296,9 Solon und Lykurg, 18 Gello; 402,22f. Diophantes und Nikomachos; $416 \mathrm{f}$. Zeusmythen. 
Ignatios kann sich nicht enthalten, am Grabe des gefeierten und offenbar geliebten Patriarchen eine ganze Enzyklopädie des grammatischen und mathematischen Wissens vor den Ohren der tiefbekümmerten $\mathrm{Zu}$ hörer auszubreiten. ${ }^{1}$ )

DaB solche rhetorische Prunkstücke nicht eben die besten historischen Quellen sind, liegt auf der Hand. Dazu kommt aber in diesem Falle noch etwas Besonderes: beide Reden haben eine bestimmte kirchliche Tendenz und diese ist in geradezu raffinierter Weise zur Geltung gebracht.

Wir gehen dabei aus von der Leichenrede auf Nikephoros ( $千$ 2. Juni 829); denn das ist der Form nach die sog. vita Nicephori, wie sie zuletzt de Boor in den opuscula historica des Patriarchen Nikephoros ediert hat: sie gibt sich als gleich nach dem Tode des im Exil sterbenden Expatriarchen verfabt und gehalten (vgl. 139,7ff.

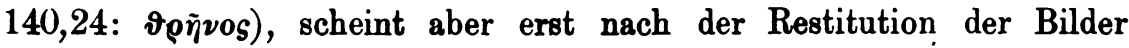
unter Theodora, jedoch vor der Translation der Gebeine des Patriarchen in die Apostelkirche der Hauptstadt, also zwischen 843 und 846 veröffentlicht zu sein: dieser Zeit, den Tagen des Methodios, ist also die endgültige Redaktion zuzuweisen. Und ähnlich wird über die Vita des Tarasios zu urteilen sein: sie ist nicht Rede, sondern Schrift, auf

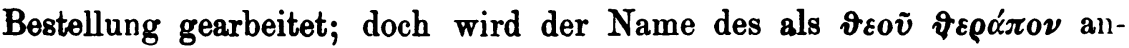
geredeten Auftraggebers nicht genannt. ${ }^{2}$ ) Unter den Wundern des Patriarchen nach seinem Tode wird die Voraussage der Ermordung Kaiser Leos des Armeniers durch Michael Balbus (24. Dez. 820) erzählt, in einer Form, die sicher über Michaels Regierungszeit hinausweist ${ }^{3}$ ): vielleicht in die Zeit des Kaisers Theophilos (829-842), wahrscheinlicher noch in die Theodoras und Michaels III (842-867). Die handschriftlichen Titel nennen Ignatios bei der Vita Tarasii Mönch, bei der Vita Nicephori Diakon und Skeuophylax. ${ }^{4}$ ) Es ist weniger wahrscheinlich, daB er vom Mönch zu dieser kirchlichen Würde avancierte, als daB er nach des Nikephoros Tod auf diese verzichtete und sich ins Kloster

1) Nic. $149-151$.

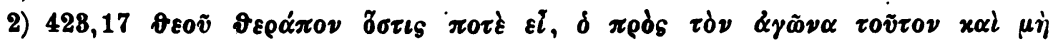

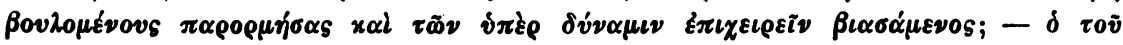

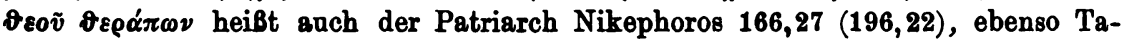
rasios 422,31. Es ist der Mosestitel (Heb. 3,5, I. Clem. 4,12, 43,1 a. o.), der sonst mit Vorliebe großen Monchsheiligen gegeben wird, z. B. Platon, 99, 841 b; Joannikios, AS Nov. II 1, 385 a.

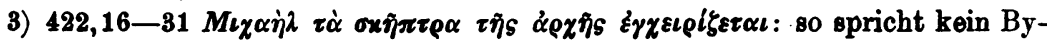
zantiner vom regierenden Kaiser.

4) s. Heikel 391,1; die Identităt der Verfasser steht durch sprachlich-stilistische Beobachtungen fest. 
zurückzog: er klagt am SchluB der Vita Tarasii $(423,25)$, daB or durch Alter und Krankheit gebeugt sei. Also fällt wohl wie die SchluBredaktion und Veröffentlichung der Vita Nicephori, so die Abfassung der Vita Tarasii unter Methodios.

Sehen wir uns nun beide Viten auf ihre Anlage hin etwas näher an. Die Vita des Nikephoros ${ }^{1}$ ) geht aus von einer Schilderung des ersten Bilderstreites, in dem des Nikephoros Vater als hoher Staatsbeamter bereits für den orthodoxen Glauben litt (142f.), erwähnt dann den Anteil, den Nikephoros unter Irene als kaiserlicher Kommissar an der die Bilder restituierenden Synode von Nikaia nahm (146), um endlich, nachdem Nikephoros' Rücktritt aus dem Staatsdienst (147), seine Bildung (149) und seine rege Armenpflege (152) in gebührendes Licht gesetzt ist, sich der Erwählung zum Patriarchen zuzuwenden: anhebend mit einer Verherrlichung des Vorgängers Tarasios und dessen Verdienste um die Orthodoxie, zeigt der Verfasser, wie Gott es war, der auf die Gebete des Tarasios hin des Kaisers Gedanken auf Nikephoros lenkte: die Voten der vorberatenden Klerikerversammlung gehen weit auseinander (einzelnes wird nicht erwähnt, also auch nicht, daB Platon für die Kandidatur seines Neffen eintrat!), der Kaiser aber weiB alle zur Wahl des Nikephoros zu bewegen: man läBt diesen kommen, er kann nicht ausweichen, so wenig er sich geeignet und vorbereitet fühlt, um so weniger, als der Kaiser ihn als Schützer der Orthodoxie aufruft. Nun wird in immer ausführlicher werdender Rede erst die durch des Kaisersohns und Mitregenten Hand vorgenommene Mönchstonsur, dann unter ausdrücklichem Hinweis auf die areopagitischen Stufen der Hierarchie die Priesterweihe, endlich die Inthronisation zum Patriarchen am Osterfest geschildert: dies alles mit einer Breite, die den Leser glauben läßt, es handle sich um eine lange Periode, während doch gerade die unmittelbare Aufeinanderfolge dieser drei Weihen die Grundlage für die Anklage der Studiten auf unkanonische Wahl bildete. ${ }^{8}$ ) Der neue Patriarch wird dann als Sektenbekämpfer (159), Klösterreformer (160) gepriesen und (das ist der Hauptcoup) als Verteidiger der kirchlichen oder vielmehr göttlichen Ehegesetze: einem Taurerfürsten verwehrte er das Eingehen einer zweiten Ehe nach Scheidung der ersten $\left.^{3}\right)$ ! DaB

1) Lehrreich ist ein Vergleich der Analyse bei Hergenröther, Photius I 275.

2) Wie anders stellt in dem analogen Falle des Photios der gegnerische Biograph des Ignatios, Niketas Paphlagon, die rasche Folge dar, MSG 105, 512 a.

3) Dieser Coup gewinnt un so gröBere Bedeutung, wenn man weiß, daB es zu den Anklagepunkten der Studiten gegen die Moichianer gehörte, die unerlaubte Ehe des Römerkaisers habe allen andern Fürsten ein böses Beispiel gegeben: so

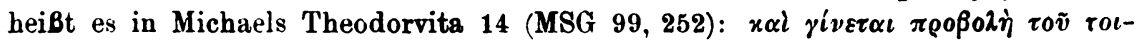


derselbe Patriarch jenen Oikonomos Joseph, der einst die zweite Ehe des Römerkaisers Konstantin eingesegnet hatte, auf Verwendung allerhöchster Gönner, vielleicht des jetzigen Kaisers selbst, wieder in den Klerus aufnahm, davon schweigt der Redner, und ebenso von dem daraus entspringenden Zerwürfnis mit der studitischen Mönchspartei. So kommt er raschen Schrittes über die Patriarchatsführung hinwegschreitend zu dem Wiederausbruch des Bilderstreites unter Leon (162), in dem sich der Patriarch als standhafter Vorkämpfer der Orthodoxie, als Märtyrer bewährt. Seine halbfreiwillige Abdankung, de facto ein Rückzug vor dem überlegenen Feind, wird als Akt prophetischer Voraussicht, seine sichere Überführung nach dem Agathakloster, dann in das von ihm selbst gestiftete Theodorkloster als grausame Exilierung behandelt. Leon, dem der Expatriarch selbst nach seiner Ermordung das Zeugnis eines tüchtigen Regenten ausstellte, ${ }^{1}$ ) erscheint hier in jeder Art als Bestie, seine Ermordung durch Michael als eine Heldentat zur Rettung des Glaubens und der Kirche, die den Redner zu einer widerlichen Apostrophe an den Gestürzten begeistert (208). ${ }^{2}$ ) SchlieBlich ist noch von Nikephoros' erfolglosem Versuch die Rede, den neuen Kaiser zur Anerkennung des Bilderkultes zu bewegen (209): er stirbt, zum Schmerz der Gottgesinnten, zur Freude der Übelgesinnten, die nun ganz offen hervortreten (Verfolgung unter Theophilos); aber der Verfasser ist überzeugt, daB des Heiligen Fürsprache ihren Angriff zunichte machen wird (215), was unter Theodora 843 geschah.

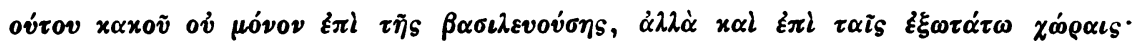

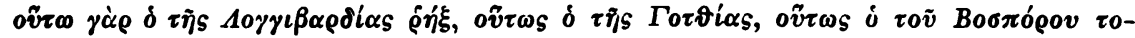

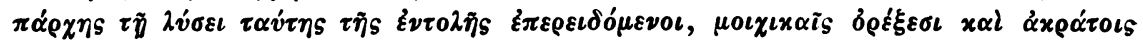

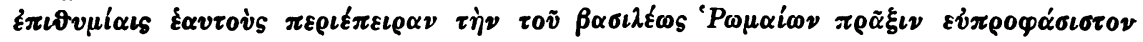

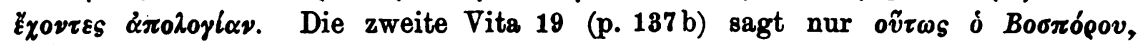

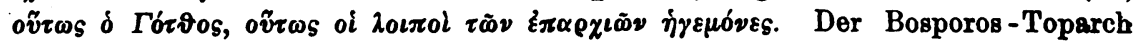
ist offenbar jener Taurerfürst, von dem Ignatios spricht. An wen bei dem Langobardenkonig und dem Gothenkonig gedacht ist, labt sich leider nicht bestimmen. Lothar II, dessen Verhalten zu Teutberga und Walrada die bekannte Intervention Nikola0s' I 863 hervorrief, kommt zeitlich nicht in Betracht, hat auch mit der Lombardei nichts zu tun. Karls d. Gr. VerstoBung der Tochter des Langobardenkőnigs Desiderius and Heirat mit Hildegard 771 liegt vor Konstantins Ehehandel. Das spanische Westgothenreich hat 711 aufgehört; von den kleinen Fürstentümern, die übrig blieben, hatten die Byzantiner kaum Kenntnis: sie verstanden unter Gotthia ein Gebiet am schwarzen Meer (s. u. S. 73 A. 2 die Vita des Gothenbischofs).

1) Kedrenos II 69,17.

2) Vgl. auch Tarasios 422,16-31. Dagegen gilt Leons Erhebung gegen den frommen Michael Rhangabe natürlich als gemeiner Aufruhr, Nic. 163. - Ähnlich wird Irene, in einer unserem Empfinden unverständlichen Weise, verherrlicht als

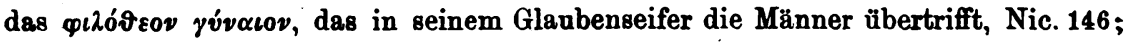
von ibren Schandtaten schweigt der fromme Redner. 
Von den freundlichen Beziehungen zu Theodor und den Studiten in dieser letzten Zeit ist so wenig die Rede wie vorher von den feindlichen. Die Musterrede eines Ungenannten bei den Verhandlungen vor Leon (187) könnte man auf Theodor zu beziehen geneigt sein, der nach dem Zeugnis nicht nur seines Bingraphen, sondern auch der Historiker dabei eine hervorragende Rolle spielte. ${ }^{1}$ ) Aber ebenso lassen die Biographen anderer Heiligen ihre Helden neben dem Patriarchen auftreten, so daB man dem Ungenannten besser die Anonymität des Repräsentanten all der Glaubensstreiter beläBt, die ihm der Verfasser zugewiesen hat.

Die Heiligenlegende liebt es, ihren Helden möglichst allein strahlen zu lassen; sie kennt wohl Eltern und Erzieher, darunter auch ältere Mönche und Heilige, wiederum Schüler und Verehrer, daneben die Feinde des Heiligen, aber keine Konkurrenten. So steht hier Nikephoros, der wahrhafte Siegesträger, als einsamer Stern in seinem vollen Glanze da: nur das Licht seines Vorgängers Tarasios vereinigt seine Strahlen mit den seinen. Das verdient Beachtung. ${ }^{2}$ )

LieB sich im Leben des Nikephoros der Konflikt mit der zelotischen Mönchspartei umgehen, so war diese Aufgabe schwieriger in dem Leben des Tarasios ( $†$ 25. Febr. 806). Es ist geradezu raffiniert, wie der Verfasser sie hier zu lösen versucht hat. Nach den üblichen Lobsprüchen auf die Eltern des Heiligen berichtet er von der Resignation des Patriarchen Paulos, der in tödlicher Krankheit der Kaiserin Irene und ihrem Sohn den Protasekretis ${ }^{3}$ ) Tarasios als den zur Ausrottung der Häresie geeigneten Mann empfiehlt: so wird dieser in göttlichster Übereinstimmung aller ${ }^{4}$ ) gewählt: nur die Anhänger der Häresie widerstreben. Tarasios, vorgefordert und zur Rettung der Kirche aufgefordert, erklärt vor Kaiserin und Kaiser in wohlgesetzter Rede: eine Heilung der Schäden sei nur möglich, wenn sie den alten Kirchenglauben, dio Verehrung der Bilder wiederherstellten; dann werde Eintracht unter allen Gläubigen herrschen. Wohl widerstrebt das den Bildem feindliche Heer, aber Tarasios, wie er selber bezeugt, von den gläubigen Kaisern gezwungen den Dienst zu übernehmen, weiß das Volk für die Herstellung der Orthodoxie zu gewinnen. So vertauscht er unter Einwirkung des heiligen Geistes mit Zustimmung des kaiser-

1) Vita 33, 280c; Ps. Symeon p. 608; Georg. mon. 779,18 de Boor.

2) Ebenso steht es in der Synaxarnotiz (p. 723 Delehaye) zum 2. Juni, die eine sich eng an Ignatios anschlieBende, verhältnismäBig stoffreiche Regeste bietet.

3) In der künstlich klassizistischen Sprache heißt das: $\tau \dot{\partial} \nu$ \&̇i $\tau \tilde{\omega} \nu \mu v \sigma \tau \eta-$

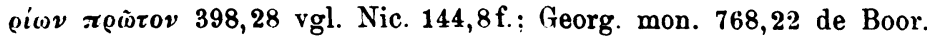

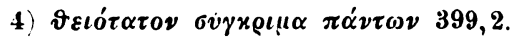


lichen Willens ${ }^{1}$ ) seinen weltlichen Stand mit dem geistlichen, wird zum Mönch geschoren und zum Patriarchen geweiht.

Ist so die eine Anklage der Mönchspartei auf unkanonische Wahl ${ }^{2}$ ) entkräftet, so steht dem Verfasser die schwerere Aufgabe bevor, Tarasios von dem Vorwurf zu reinigen, die unkanonische EheschlieBung des Kaisers Konstantin, den berüchtigten Ehebruch, wie die Studiten es nannten, begünstigt zu haben. Hier zeigt sich die Gewandtheit des Verfassers auf ihrer Höhe. Nachdem an Tarasios alle christlichen Tugenden reichlich aufgewiesen sind (401-3), nachdem sein Sieg zugunsten der Orthodoxie durch die Synode zu Nikaia glänzend dargestellt (403) und sein Auftreten zugunsten der kirchlichen Ordnung, besonders gegen Simonie, geschildert ist (406), zuletzt mit besonderer Emphase die Wahrung des kirchlichen Asylrechts gegen Übergriffe der Staatsgewalt (407), wirft der Verfasser die Frage auf: „Und der so für Aufrechterhaltung der kirchlichen Ordnung gesorgt hat, sollte die kirchlichen Kanones außer Acht gelassen haben"s)? Nun kann dem wohlvorbereiteten Leser ruhig erzählt werden, mit welcher Intrigue sich Konstantin seiner ersten Gattin zu entledigen suchte, wie der Patriarch die Lüge durchschaut, wie er dem Kaiser die schärfsten Vorhaltungen macht (409) - der in solchen Reden besonders starke Verfasser weib es glänzend zu schildern, mit welcher Kraft Tarasios den Wünschen des Kaisers entgegentritt (411), ein zweiter Johannes der Täufer.4) Freilich läBt der Kaiser von seinem Vorhaben nicht ab, er verstöBt die rechtmäBige Gattin, aber vergebens versucht er den Patriarchen zu bewegen, die neue Ehe zu trauen. Dann sucht er überall nach einem Priester herum, der ihm den Kranz winde ${ }^{5}$ ) - nun kommt es, denkt der Leser; da springt der Yerfasser mit dem Satz: "soviel von dem Wunsch des Kaisers, das Gebot außer Acht zu setzen und dem mutigen

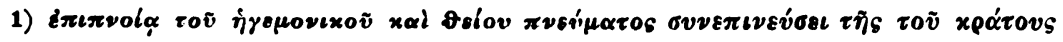

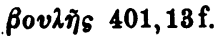

2) Bedenken dieser Art hatte übrigens auch Papst Hadrian geänBert. Auch hier aber betătigte die Patriarchalkanzlei ihr Geschick im Verschweigen: die betreffenden Stellen der päpstlichen Schreiben kamen nicht in die Synodalakten. Hergenröthen, Photius I 249; Gelzer, Kleine Schriften 149.

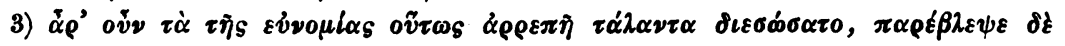

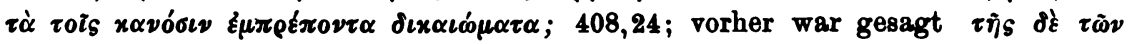

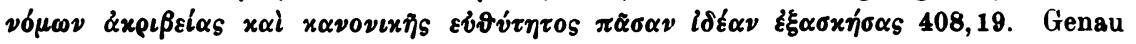
übersetzen lassen sich diese verkïnstelten Stilblüten nicht.

4) Gerade dieser Vergleich ist wohl berechnet: das war der Ehrentitel, den die Studiten ihrem gefeierten Vorkămpfer Theodor gaben (vgl. vita 17, 256 b); war doch der Prodromos der Patron ihres Klosters (265 b).

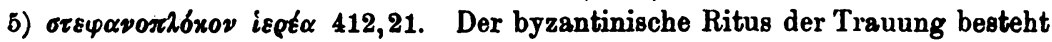
in einer Bekränzung, bezw. Krönung des Brautpaares. 
Eintreten des göttlichen Vaters; es wäre nicht recht, das, was darüber hinausgeht, dem Gedächtnis zu überliefern, da es den Hörern keinen Nutzen bringt" ${ }^{\text {) }}$, von der verfänglichen Sache ab. Die ganze sog. Ökonomie, daß nämlich ein hoher Funktionär des Patriarchates, der Oikonomos Joseph, mit Zulassung des Patriarchen die Trauung vollzog, ist unterschlagen! Dafür wird Tarasios als Gegenstand des kaiserlichen Zorns dargestellt (412) und in schwungvollster Rhetorik allen Märtyrern sowie allen Heiligen des Neuen wie des Alten Bundes ${ }^{2}$ ) verglichen, und der Verfasser ergeht sich in einer wortreichen Apologie des Bilderkults (414), die an dieser Stelle im Leben des Tarasios recht unbegründet ist, um schlieBlich seines Sterbens (419) und seiner Wunder (421) zu gedenken, bei denen auch auf den Sturz des Bilderfeindes Leon $\mathrm{V}$ im voraus hingewiesen wird (422). ${ }^{3}$ )

So ist das Ganze unter den einen großen Gesichtspunkt der Wiederherstellung der Orthodoxie gerückt und dem ahnungslosen Leser sorgfältig verborgen, daB es noch andere Kämpfe unter diesem Patriarchen gab, bei denen eifrige Bilderfreunde als Verfechter der Unantastbarkeit kirchlicher Kanones Kerker und Exil zu leiden hatten. Eintracht aller Rechtgläubigen nach Restitution des Bilderkults (400,21), das war das Programm des Patriarchen Methodios. Es scheint mir fast sicher, daB dieser der ungenannte Auftraggeber ist, an den sich Ignatios am SchluB wendet. Die feierliche Translation der Gebeine des Nikephoros aus dem Theodorkloster in die Haupt- und Residenzstadt, die Methodios am 13. März 847 veranstaltete, mag den AnlaB dazu geboten haben.") Tarasios und Nikephoros, nebeneinander in der Apostelkirche bei den Kaisergräbern beigesetzt, waren fortan die eigentlichen Patrone des Bilderkults, vor deren Sarkophagen auch die Kaiser ihre rechtgläubige Devotion betätigten. ${ }^{5}$ )

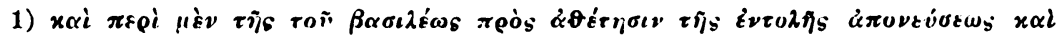

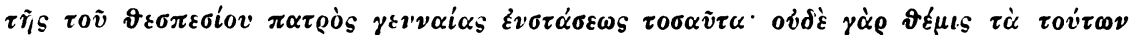

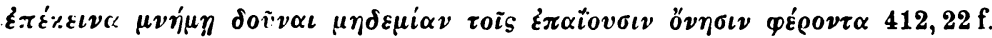

2) Das gehört zum Schema des Bíos; vgl. vita Niceph. 210 ff.; vita 8. Nicolai MSG 105, $917 \mathrm{ff}$; s. Josephi hymnogr. ibd. 948; s. Joannicii AS Nov. II 1. 435; schon Theodors Rede auf seine Mutter MSG 99, $889 \mathrm{f}$.

3) Das Synaxar zum 25. Febr. (p. 487 Delehaye), rhetorisch und stoffarm, bebt nur die Herstellung des Bilderdienstes und eine Klostergründung hervor. Hier scheint einmal die Rezension $\mathrm{Da}$ noch kürzer als $\mathrm{S}$.

4) Die Rede des Presbyters Theophanes über die Translation (ed. Theoph.

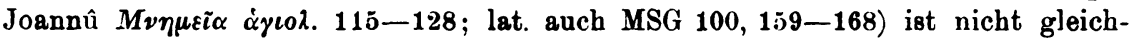
zeitig, sondern ein farbloses späteres Produkt der Rhetorik. Hiernach Synax. (p. 533 Delehaye) zum 13. März, ausführlicher in $D$ als in $S$.

5) Konstantinos Porphyr. de caerimon. 110 p. 77 : Nikephoros unà Méuhudios. Tarasios und Nikephoros, das ist die Formel zur Zeit des Methodios und darïber 


\section{III.}

Wenden wir uns nun von diesen Darstellungen der Patriarchenleben aus der Feder eines Geistlichen des Patriarchats zu den Schriften aus dem Lager der Studiten. Wir haben da zunächst neben Theodors Briefen $\left.{ }^{1}\right)$ seine Grabreden auf seine Mutter Theoktiste und auf seinen Oheim Platon ", sodann zwei Biographien Theodors ( $\dagger$ 11. Nov. 826), die eine von dem Studiten Michael (nach 855), die andere anonym, vielleicht von Theodoros Daphnopates (um 950) ${ }^{3}$ ); endlich die Vita des Studiten Nikolaos, Theodors zweiten Nachfolgers ( $\dagger$ 868). ${ }^{4}$ )

In Theodors Rede am Grabe seiner Mutter - Theoktiste starb noch unter Irene, wohl zwischen 797 und $802^{5}$ ) - kommt noch die ganze Erbitterung des eben erst überstandenen moichianischen Streites zum Ausdruck; ebenso wie in den Briefen aus der Zeit dieses Streites redet er von dem berüchtigten Ehebruch des Selbstherrschers (893a); von wem und durch wen die Mutter aus ihrem Kloster vertrieben worden sei, scheue er sich zu sagen, aus Schonung der Zuhörer: das scheint auf Tarasios oder Leute seiner Partei zu gehen. Theodor schildert, wie Theoktiste Bruder und Söhne im Gefängnis pflegt, dann selbst ins Gefängnis kommt und 30 Tage lang dort grausam gehalten

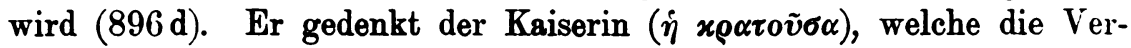
bannten zurückrief (897a); kein Wort von dem Patriarchen und seinem Einlenken.

Noch schärfer ist der Ton in dem Epitaphios auf Platon, der wohl am 7. April 814 starb. $^{6}$ ) Der Wiederausbruch des Streites unter Nike-

hinaus. Nur vereinzelt tritt daneben die triadische Germanos, Tarasios und Nikephoros auf, z. B. AS Nov. II $1,382$.

1) MSG 99, 903-1670 (zwei Bücher zitiert als ep.I und ep.II) und Mai, Patr. Nova Biblioth. VIII 1, 1-244 (zitiert als ep. M.).

2) MSG 09, 888-902 und 808-850.

3) MSG 99, 233-328 und 113-232.

4) MSG 105, 863-926.

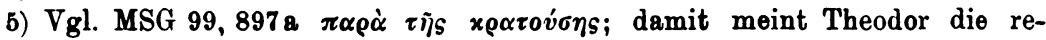
gierende Kaiserin.

6) Das Datum war bisher ganz unsicher: D. Papebroek kam der Wahrheit am nächsten mit dem 19. März 813 (AS Apr. I 364. 376), während Sirmond mit 19. März 812 (MSG 99, 83), dem ich leider $R E^{8}$ XIX 606 gefolgt bin, sicher im Unrecht ist. Die Menäen setzen die Kommemoration auf 4. Apr. (übrigens nach Delehaye 585 nur D und Mc), hiernach die Bollandisten von einst und jetzt (AS Apr. I 364; BHG 112). Die einzige Quelle, Theodors Epitaphios gibt zwei Anhaltspunkte: $845 \mathrm{a}$ am SchluB der Berechnung der Lebensjahre nach den 4 Jahren Ver-

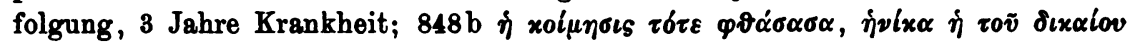

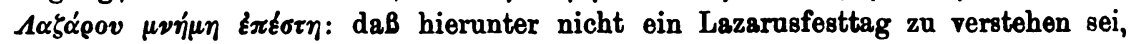
hat Papebroek gegen Sirlet mit Recht gezeigt: so fallen nicht nur der abendlän- 
phoros, das zweite Exil auf der Prinzeninsel 809-811 hatte die alten Leidenschaften wieder angefacht. Freilich wird alle Schuld zunächst auf Kaiser Konstantin geschoben; die Namen der feindlichen Kleriker will Theodor auch hier nicht nennen ${ }^{1}$ ); einmal scheint er auf Tarasios hinzudeuten (832c, 824c), dafür tritt der Oikonomos Joseph, um den es sich ja bei dem zweiten Streit handelte, als der Grund alles Frevels

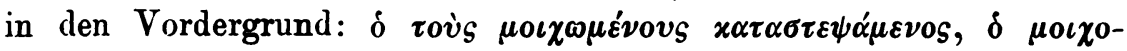

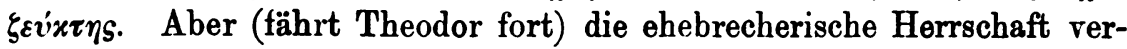
geht, die Verfolger verschwinden, Irene, ihres Namens wert, kommt wieder zur Herrschaft; auch der Patriarch ehrt den Heiligen sich entschuldigend (833c) und der $\sigma \tau \varepsilon \varphi \alpha \nu \omega \sigma \sigma \alpha$ wird ausgestoßen. Bei der Wahl eines neuen Patriarchen wirkt Platon kräftig mit: er vQtiert für jemand, den Theodor nicht nennen will (offenbar ist er es selbst oder sein Bruder Joseph, der Erzbischof von Thessalonich) ${ }^{2}$ ), aber der Kaiser weiB die Wahl auf Nikephoros zu lenken. Platon opponiert und wan-

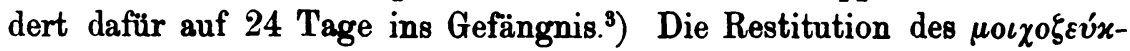
$\tau r_{\text {, }}$ gibt AnlaB zu schwererem Streit (840a); die Studiten trifft das Exil; der Kaiser ist grausam, aber er geht zugrunde. Der Patriarch entschuldigt sich, das Skandalon wird wieder entfernt, d. h. Joseph entsetzt $844 \mathrm{~b}$. Im Frieden seines Klosters entschläft der greise Kämpfer,

dische (Surius), sondern auch die spätbyzantinischen Lazarusfeste (17. März oder 4. Mai, Delehaye 544, 24; 658, 37) fort. Es ist vielmehr der nach der Lektion

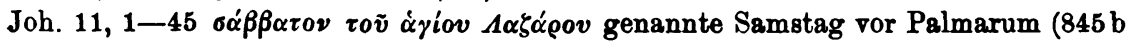
erwähnt die hl. Fastenzeit). Dieser traf 811 auf den 5. April, 812 27. März, 813 19. März, 814 8. April. Platons Tod also auf den Abend vorher! 4. April 811, woran das Synaxar denken läBt, ist ausgeschlossen, da die erst unter Michael Rhangabe (seit 2. Okt. 811) erfolgte Versöhnung mit dem Patriarchen vorangeht. Rechnet man die 3 Jahre Krankheit von der Rückkehr aus dem Exil Okt. 811, so fällt auch 26. März 812, m. E. aber auch 18. März 813 fort und wir kommen auf 7. April 814: hierfür spricht, daB Theodors Fpitaphios in Vat. gr. 1660 (a. 016) auf den 6. April gesetzt ist, und auch der 4. April des Synaxars orklärt sich von hier aus am leichtesten. Dann sind die Lebensperioden Platons zu berechnen.

$$
\begin{array}{ll}
2 \times 12 \text { vor dem Mönchsstand } & =736-747.748-759 ; \\
4 \times 12 \text { als Mönch } & =760-771.772-783.784-795.797-808 ; \\
4 \text { Jahre Verfolgung } & =796.809-811 ; \\
3 \text { Jahre Krankheit } & =812-814 .
\end{array}
$$

Dem widerstreitet nicht, daB die jüngere Theodorvita c. 55 p. 165 Platons Tod noch unter Michael Rhangabe za setzen scheint: Leon der Armenier, wenn schon seit 12. Juli 813 Kaiser, tritt erst seit März 815 als Bilderfeind hervor.

1) Dieselbe Wendung $\alpha i \delta o i \tau \iota \nu \omega \nu \pi \rho o \sigma o ́ \pi \omega \nu$ auch ep. II 218 p. 1660 a.

2) $837 \mathrm{~b}$; vgl. damit $825 \mathrm{c}$ und Theodors eigentümlich gewundenes Votum in ep. I 16 p. 960 an den Kaiser.

3) Theodor spricht garnicht von dem Unkanonischen der Wabl, sっ daB ss fast aussieht, als verfechte Platon nur seinen abweichenden Vorschlag. 
nachdem ihn noch auf seinem Sterbebett der Patriarch begrüBt und um seine Fürbitte gebeten hat 845 b. $^{1}$ )

Man sieht hieran, daB sich die Kämpfe dieser Zeit in den Augen eines der daran Beteiligten sehr anders ansahen, als wir es eben in den offiziösen Patriarchenviten fanden: von dem Kampf um die Bilder ist kaum die Rede: Theodors Gedanken sind noch ganz beherrscht von dem inneren Streit der beiden kirchlichen Parteien, den er jenem an Bedeutung gleichsetzt. ${ }^{3}$ ) Dabei liegt ihm gewiB daran, mit dem $\mathrm{Pa}$ triarchen in Frieden und Eintracht zu leben ${ }^{3}$ ), aber er sieht das Unrecht ganz auf der anderen Seite und redet beidemal davon, dab der Patriarch sich zu entschuldigen hatte.

Das wird freilich schon etwas anders, als der Bilderstreit unter Leon von neuem losbricht. Zum Belege greife ich die beiden Briefe Theodors an den exilierten Patriarchen Nikephoros heraus: der erste ein Trostschreiben, worin Theodor der Mönch voller Unterwürfigkeit den Patriarchen als den Besieger der Gottlosigkeit, die große Sonne der Orthodoxie feiert.") Man hat das Gefühl, daB Theodor anknüpfen will. Der Brief gehört offenbar nicht in die erste Zeit: da schreibt Theodor, der Mönch, als wäre er der Vertreter der orthodoxen Kirche, an die vier auswärtigen Patriarchen. ${ }^{5}$ ) Offenbar beurteilte der kampfesfreudige Studit die halbfreiwillige Abdankung des Patriarchen, der sich in sein Kloster zurückzog, als ein feiges Ausweichen vor dem feindlichen Angriff. Dann aber, da Nikephoros in seiner Zurückgezogenheit literarisch mannhaft für die heiligen Bilder eintrat, vielleicht auch allerlei Drangsal dafür duldete, änderte sich die Stimmung und Theodor erkannte ihn als Mitkämpfer, und entsprechend der auch seinem eignen

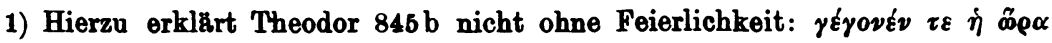

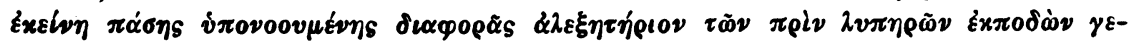

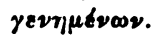

2) Vgl. ep. I 53, 1108 a.

3) Theodor empfindet den Vorwurf des Schismas schwer: vgl. ep. I 25, 988; I 53, $1101 \mathrm{ff}$. Tarasios gegenüber war er gebunden, da er von ihm die Priesterweihe empfangen hatte (vita 10, 248b): daher er auch den Vorwurf der Simonie von jenem fernhält. Aber eine von Nikephoros nach der Moichosynodos vollzogene Bischofsweihe ist ihm bedenklich, umso mehr als sie einem Studiten Gregoras galt: mit ihm sollen seine Mönche nicht kommunizieren. Dabei erhălt der P\&-

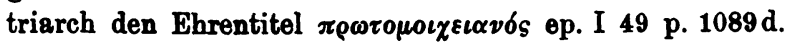

4) Ep. II 18, 1173.

5) Ep. II 12. 13. 14.15 (vgl. vita 38 p. $289 \mathrm{c}=192 \mathrm{~d}$ ) wohl bald nach Ausbruch des Streites, doch nicht vor 817 (Paschalis); die Vita setzt sie allerdings nach Bonita, also erst 819. Ep. II 18 kann nicht schon, wie Baronius will, 814 geschrieben sein. Als Theodor für Nikephoros' Antwort dankt, ist bereits Michael zur Regierung gekommen (Weihnachten 820). 
jüngeren Bruder Joseph, dem Erzbischof von Thessalonich gegenüber stets bezeugten mönchischen Demut vor dem hohen Klerus als Vorkämpfer an. Das zeigt sich dann deutlich in dem zweiten Brief, einem Dankschreiben für die Antwort des Patriarchen. Thendor dankt ganz überschwänglich dafür, daB der Patriarch ihn überhaupt einer Antwort gewürdigt hat und preist Gott, daB er seiner Kirche einen solchen Vorkämpfer und Steuermann geschenkt habe. ${ }^{1}$ ) Vergessen sind die alten Zwistigkeiten noch nicht. In einer ganzen Reihe ron Briefen aus der späteren Zeit kehren Erinnerungen an den mojchianischen Streit wieder (vgl. bes. II 218). Theodor gedenkt in einem Briefe an seinen Bruder dessen, wie zwei Brüder im moichianischen Streit abfielen: der eine hat das jetzt durch das Martyrium für die heiligen Bilder wieder gut gemacht; der andere, Leontios, steht jetzt wieder auf seiten der Feinde und ist dafür Abt von Studion geworden; gleichzeitig aber rühmt Theodor, was er von der Standhaftigkeit und dem Bekennermut des Patriarchen gehört hat. Von dem Anteil eben dieses Patriarchen an jenem Streit ist nicht mehr die Rede. ${ }^{2}$ ) Theodor hat doch gelernt, daB der Bilderstreit, wenn akut, etwas mehr zu bedeuten hat. Der gemeinsame Feind hat die alten Gegner geeint. Theodor ist jetzt noch mehr als früher beflissen, den Vorwurf eines Schismas von sich fern zu halten. Sein Auftreten auch noch unter Michael II., seine Äußerungen müssen doch den Eindruck gemacht haben, als widerstrebe er der Gemeinschaft mit dem Patriarchen, als gehe er in der Behandlung derer, die sich zur Kommunion mit den Häretikern hatten verleiten lassen, seine eignen Wege. Er selbst betont den gegenüber seine volle Gemeinschaft mit dem Patriarchen und hebt den Besuch hervor, den er diesem auf dem Wege zur Hauptstadt gemacht hat; ja er nimmt seine früheren Äußerungen über Tarasios und die zweite Nikänische Synode direkt zurück. ${ }^{3}$ )

Von den eignen Äußerungen Theodors kommen wir zu seinen Biographen: der Studit Michael, der Verfasser der ältesten erhaltenen Biographie war kein persönlicher Schüler des Heiligen mehr ${ }^{4}$ ); er hat erst geraume Zeit nach dessen Tod geschrieben. Für die beiden kleinen Wundersammlungen, die er bietet, nennt er für c. 48-52 den Hypatos

1) Ep. II 79, 1317 wohl 821.

2) Ep. II 31, 1204 vielleicht schon 816 .

3) Ep. II 127 p. 1412 an Petros von Nikaia; II 152 p. 1472 f. an den Mönch Theodor.

4) $\mathrm{DaB}$ er selbst seine persönlichen Beziehungen z.u Theodor nirgends betont, was sonst fast immer geschieht, daB er ibn $\pi \rho \alpha_{\alpha} \tau \omega \rho$ nennt $(236 \mathrm{~b})$, daB er sich

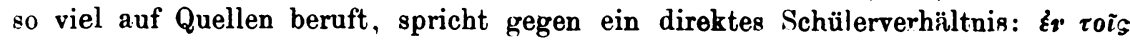

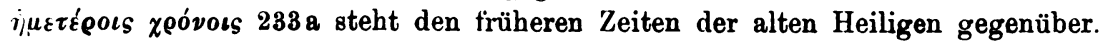


Leon (als Mönch Theodor) und für c. 53-57 den Vater Sophronios als Quelle: es ist klar, daB er den Tod des letzteren, der am 3. Nov. 855 als Abt von Studion und dritter Nachfolger Theodors starb, voraussetzt. ${ }^{1}$ ) In seiner Einleitung erklärt Michael ausdrücklich, daB schon ältere Darstellungen des Lebens Theodors vorlägen: Versuche in Versen aus dem Kreise der Mönche unmittelbar nach dem Tode des Meisters und Schriften in Form von Enkomien aus der Feder hoher kirchlicher Würdenträger $\left.{ }^{2}\right)$; er wolle, auf Wunsch der Väter für den gröBeren Kreis der Mönche und des Volkes in schlichter Sprache das Leben dieses "göttlichen Vorvaters und allweisen Lehrers der Welt" erzählen. ${ }^{3}$ ) Dabei kennt und benutzt er auBer Theodors Briefen insbesondere seine beiden Grabreden auf die Mutter und auf den Oheim Platon, deren Geist und Ton wir schon kennen lernten. ${ }^{4}$ ) Aber Michael hat nicht im Sinne diesen Geist weiter zu pflegen, im Gegenteil: seine Parole ist volle Einheit, Friede, Harmonie, so weit das mit der Ehre des gefeierten Heiligen in Einklang zu bringen ist.

Es versteht sich von selbst, daB Theodors Gestalt hier in den Mittelpunkt tritt; aber dabei ist eine Bezugnahme auf die gleichzeitigen Patriarchen in diesem Mönchsleben viel weniger zu umgehen als umgekehrt in den Patriarchenleben die Beziehungen zu dem Abt, zumal Theodor wirklich mit der Politik der Patriarchen zu schaffen hatte, und sein Biograph sich bemüht das Lebensbild seines Heiligen nicht ohne den Hintergrund der Zeitgeschichte zu zeichnen. Man gewinnt gleich in der Einleitung den Eindruck, daB Theodor in Konkurrenz zu den Patriarchen treten soll, wenn er, der Abt, mit Emphase der Poimenarch genannt wird. ${ }^{5}$ ) In die Jugendgeschichte (c. 1-4) ist eine kurze Dar-

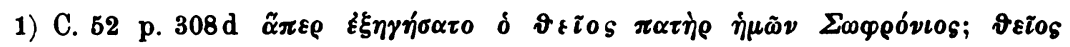
wird von einem Abt bei dessen Lebzeiten nicht gebraucht; deutlicher noch: c. 54

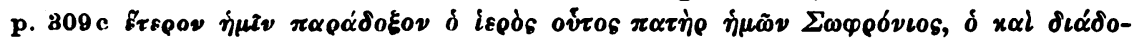

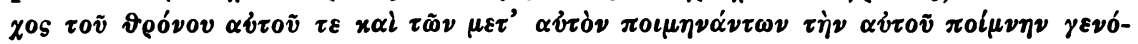

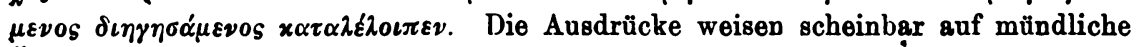
thberlieferung; trotzdem ist mir wahrscheinlich, daB die Sammlung Michsel bereits

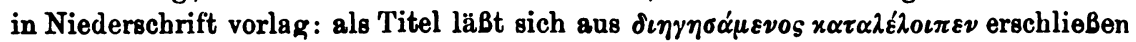

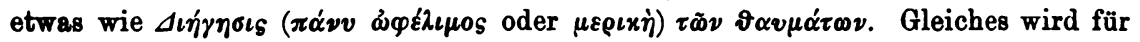
die Leon Sammlung gelten.

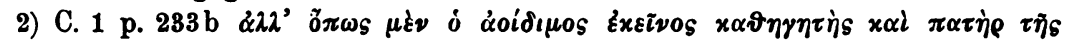

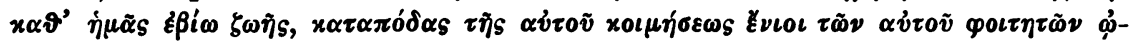

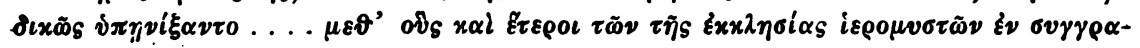

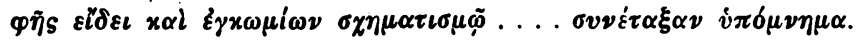
Paulus.

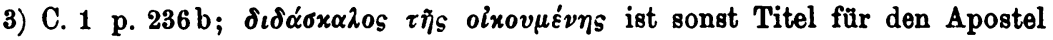

4) C. 2 p. 237 a und c. 4 p. 240 c.

5) C. 1 p. 233 a: ebenso Platon c. 10 p. 248 a; auch Michael Synk., vita $253,4$. 
stellung des ersten Bilderstreits verwoben, auslaufend in die Schilderung der Synode von Nikaia, bei der Platons Anteil und seine innige Gemeinschaft mit dem hochgefeierten Patriarchen Tarasios besonders hervortritt. ${ }^{1}$ ) Man muB das mit Theodors Rede auf Platon (828ab) vergleichen, um zu sehen, daB zwar die Tatsachen stimmen, wie sehr aber der Ton verschieden ist. Während der ersten Jahre des Klosterlebens (c. 5-13) wird Theodors Priesterweihe durch Tarasios, den $\vartheta \varepsilon \delta \lambda \eta \pi \tau o s$ $\pi \alpha \tau \rho i \alpha ́ \varrho \chi \eta s ~(248 a)$ erwähnt. Der moichianische Streit (c. 14-19) bringt dann an die Sache selbst heran: sehr kurz, aber deutlich wird hier die Verweigerung der Trauung durch Tarasios erzählt. Der Oikonomos Joseph handelt durchaus eigenmächtig. ${ }^{2}$ ) Bei der Aufhebung der Kommunion seitens der Studiten, denen sich dann andere Äbte anschließen, ist immer nur von dem kaiserlichen Hof, nie von dem Patriarchen die

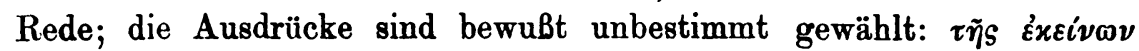

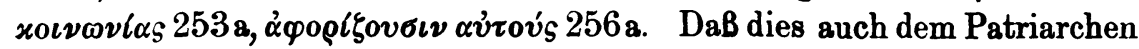
galt, verrät der Verfasser erst, als nach dem mit Wohlgefallen be-

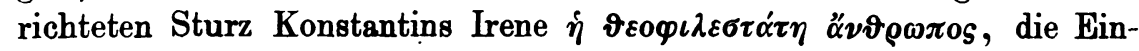

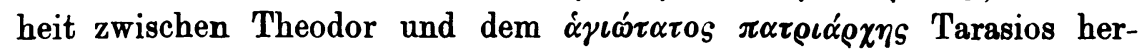
stellt durch Ausstoßung jenes Joseph aus dem Priesterstand (256d); der Verfasser läBt die Kaiserin hierbei erklären, beide hätten recht gehandelt, Theodor, indem er bis aufs Blut für die evangelischen Satzungen kämpfte, Tarasios, indem er ökonomisch verfuhr und den argen Sinn des Kaisiers, der mit Erneuerung des Bilderstreits drohte, zügelte. ${ }^{3}$ ) Dies habıe der Patriarch selbst bestätigt, wofür der Verfasser auf den oben schon erwähnten Brief Theodors über die Gemeinschaft mit Tarasios (ep. I 53 p. 1101) verweist. So fordert er von den Lesern, d. h. in erster Linie den Studiten, Anerkennung dieser Gemeinschaft. Was

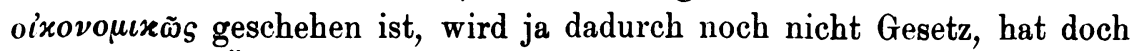
auch Paulus Ökonomie geübt, indem er Timotheuș beschnitt!

Beherrscht von dem Bild der Gemeinschaft mit Tarasios folgt dann die Schilderung des Klosterlebens von Sakkudion und Studion (c. 19 -22), wobei die liebevolle Aufnahme der vor einem Arabereinfall in

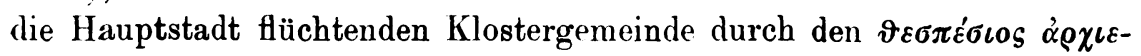
$\varepsilon v_{S}$ Tarasios und die höchstfromme Kaiserin besonders gerühmt wird (260) a). Hier zählt der Verfasser Theodors Schriften auf (c. 23. 24). Dann folgt die zweite Phase des moichianischen Streites unter Nike-

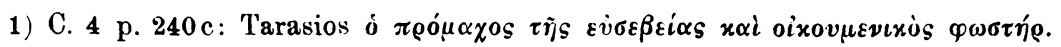

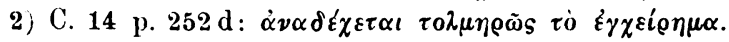

3) Wie Theodor selbst von diesem Begriff der oirovouía dachte, zeigt $u$. a. ep. I 4s p. $1073 \mathrm{c}$, doch wendet auch Theodor selbst unter Imstïnden oi:s0:'ouiciv an ep. I 49 p. 1089 a. 
phoros, selbstredend eingeführt als ein Werk des auf die Tugenden und Erfolge des Heiligen neidischen Teufels: der Kaiser, vom Satan inspiriert, weiß den heiliggesinnten durchaus widerstrebenden Patriarchen Nikephoros zu zwingen, dab er jenen Joseph, den Urheber des ganzen Unheils, restituiert (265d). Die Opposition der Studiten erscheint hier

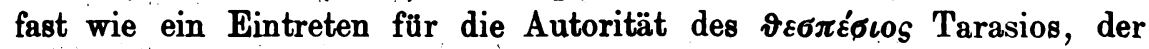
den Bann über Joseph gesprochen hatte (268a). Immerhin ist der Eindruck dieser neuen Spaltung dem Biographen des Heiligen so fatal, daB er auf das Zerwürfnis zwischen den Aposteln Paulus und Barnabas. (AG 15, 39) hinweisen zu müssen glaubt und an das Urteil des Chrysostomos erinnert: wer von ihnen den besseren Rat befolgte, zu entscheiden, ist nicht unseres Amts (268b). Michael aber weiB in unserem Fall es besser; er erklärt feierlich: beide handelten recht; es war auch bei dem seligen Nikephoros wie bei Tarasios Ökonomie, um schlimmeres

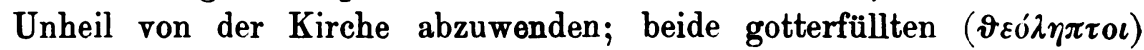
Patriarchen haben ja anerkannt, daB Theodor sachlich recht hatte, indem sie sofort nach des Kaisers Tode den Schuldigen, Joseph, bannten (268. 269). Nur in einer Rede des Kaisers bei dem Versuch die Mönche von Studion ihrem Leiter abspenstig zu machen, kommt es so heraus, daB wer dem Kaiser gehorcht auch in Gemeinschaft mit dem Patriarchen und der katholischen Kirche steht (269c), sonst wird bei dem ganzen Streit wieder nur der Kaiser, nicht der Patriarch erwähnt. Erst nachträglich kommt es auch hier zur Sprache, daß der äußerst christliche Michael mit Unterstützung des römischen Papstes Leo III

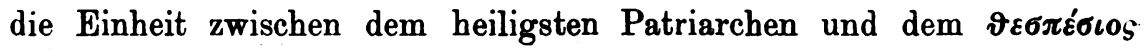

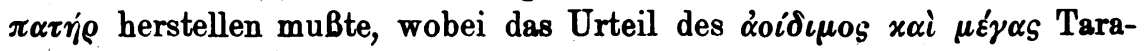
sios über Joseph, der die $\mu \circ \chi \chi 0 \xi \varepsilon v \xi \xi^{\prime} \alpha$ gewagt, erneuert wird (273a). In köstlicher Eintracht mit dem Patriarchen erblüht nun Studion (c. 29); da erneuert der Armenier Leon den Bilderstreit. $\left.{ }^{1}\right)$ Hier kann der Bioyraph nun seinen Heiligon auf der Höhe zeigen; er ist vor dem Kaiser der Wortführer der Rechtgläubigen (280c), in glänzender Rede verficht er den Bilderkult, vor allem aber die These, daB der Kaiser in kirchlichen Angelegenheiten nichts zu sagen habe, und verweist so den Kaiser auf den Patriarchen, dem or als seinem geistlichen Vater folgen müsse $(284 \mathrm{~b})$. Als $\pi \rho 0 \alpha \gamma \omega \nu i \sigma \tau \eta \mathfrak{s}$ von allen Vätern gefeiert, ist Theodor die Seele im Rate des heiligsten Patriarchen; nichts geschjeht von seiten des $\vartheta \varepsilon \sigma \pi \varepsilon \sigma i o s$ Nikephoros, was nicht von jenem eingegeben

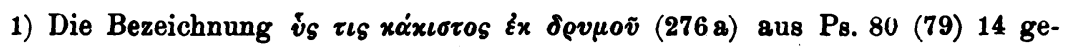
schøpft findet sich ebenso in der Vita Tarasii des Ignatios p. 398, 22 Heikel mit bezug auf die ikonoklastische Häresie im allgemeinen. Sie ist bekanntlich auch auf Luther angewandt in Leos X Bulle Exsurge domine v. 15. Juni 1520. 
und gutgeheißen wäre $(284 \mathrm{~cd})$. Kein Wort von feiger Flucht oder auch nur freiwilligem Rückzug des Patriarchen: was am 20. März (815) geschah, ist gewaltsame Entfernung, Exil (285a). Auch nachher ist Theodor, der am Palmsonntag die herausfordernde Bilderprozession veranstaltet, der spiritus regens in dem verwaisten Patriarchat (285c): sein im Namen aller Äbte an die Ikonoklastensynode gerichtetes Schreiben (ep. II 1 p. 1116) wird wiedergegeben bis zu der Stelle, wo er auf den heiligsten Patriarchen Nikephoros als den allein rechtmäBigen Inhaber der geistlichen Gewalt verweist (285d). Es folgt die ausführliche Erzählung des Exils mit all seinen Leiden (c. 37-47), dann anläBlich des Ortswechsels bei dem Regierungsantritt Michaels 820 jene zwei Reihen von Wundergeschichten (c. 48-52, 53-57). Die neu erlangte Bewegungsfreiheit führt die Verteidiger der Orthodoxie von allen Seiten zusammen: am wichtigsten aber ist dem Verfasser die Begegnung

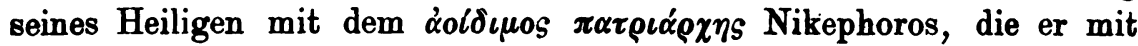
den üblichen Tränengüssen sehr rührend darstellt, ohne irgend etwas Sachliches darüber beizubringen (316 c). Zu einer zweiten Begegnung führt die Internierung aller.bislang aus der Hauptstadt Verbannten in derselben während des Thomasaufstandes 822/4: von dieser kann Michael mit hoher Genugtuung berichten, wie der heiligste Patriarch Nike-

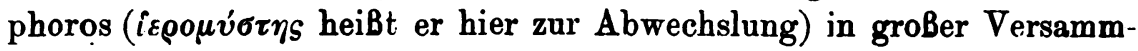
lung von Metropoliten den Abt Theodor als den verdientesten Märtyrer gepriesen und ihm den Platz an seiner Seite angewiesen habe (320bc). Hiermit ist offenbar für den Zweck des Verfassers der Höhepunkt erreicht, und er setzt mit einer kräftigen Philippica gegen alle anders Urteilenden ein: „Weg mit dem Neid, der sich gegen den gerechten Theodor erhebt; schämen müssen sich, die den gottgleichen Führer und Lehrer der Mönche schmähen, die Hand sollten sie legen auf ihre eignen Lippen, wie die Schrift sagt (Sap. 8, 12), wenn sie sehen, wie diese ehrwürdigen und ansehnlichen Personen für einander eintreten: denn weder hüitte der Hirt unserer Herde öfter den heiligsten Nikephoros aufgesucht, wenn er ihn nicht als durchaus würdigen Hohepriester Christi gekannt und voll anerkannt hätte: noch wiederum hätte der große Oberpriester über Metropoliten und Bischöfe den göttlichen Theodor geehrt, wenn er ihn nicht in göttlich-weisem Urteil an Tugendruhm und äußerstem Christusbekenntnis für allen anderen überlegen und dadurch sichergestellt gehalten hätte“. Zum Beweise auf die Briefe Theodors verweisend, warnt der Verfasser jedermann, nicht durch hartnäckiges Festhalten übler Vorurteile zu einem Kämpfer wider Gott zu werden. Es folgt die Schilderung der allerletzten Lebenszeit und des Lebensendes Theodors (63-67): der sterbende entbietet dem Patriarchen 
seinen ehrerbietigen GruB. ${ }^{1}$ ) Zuletzt wird noch die Überführung seiner Leiche nach dem Kloster Studion unter Methodios „dem heiligsten Patriarchen und Vernichter der Häresie der Halbchristen" erwähnt (328).

Dieser Überblick zeigt zur Genüge, von welchem Geiste diese Biographie erfüllt ist: das sind nicht mehr die Ideen Theodors und seine unbeugsam harten Urteile. Aber es ist auch nicht einfach die Irenik des Methodios, so sehr die Betonung der Harmonie seinen Wünschen entspricht. Hier wird doch gekämpft, und zwar gekämpft für die rechte Anerkennung des großen Studitenabtes. Ich wenigstens habe den Eindruck, daß diese Vita weniger ein Abrücken von den die Patriarchen schmähenden Mönchseiferern als ein Wiedergeltendmachen der Studitenauffassung gegenüber einseitiger Verherrlichung der Patriarchen seitens der offiziösen Hagiographie des Klerus der Hagia-Sophia, solcher Schriften wie der Patriarchenviten des Diakon Ignatios ist. Ich möchte vermuten, daB es auBer diesen auch eine Vita oder ein Enkomion Theodors gegeben hat, das von Methodios inspiriert, die Einheit so weit ausdehnte, dab der streithafte Studitenabt schlieblich nur als gehorsamer Gefolgsmann der Patriarchen erschien. Ja man scheint, ehe unter Ignatios die volle Aussöhnung zustande kam, wie ron seiten der Studiten die Patriarchen, so seitens der Anhänger des Nikephoros den Führer der Mönche als Urheber des Schismas geschmäht zu haben. All das ist uns verloren. Eine kleine Probe bietet nur jenes oben S. 51 erwähnte Bruchstück einer Vita, das uns der Mönch Methodios im 13. Jahrhundert aufbewahrt hat: da wird Theodor gradezu der Streit- und Zanksucht bezichtigt. Leider kann man aus dem Zitat nicht mit Sicherheit erschließen, ob den Verfasser im 13. Jahrh. noch diese Vita ganz vorlag. Er kann auch aus zweiter Hand davon Kenntnis gehabt haben. Das Wahrscheinlichere ist, daB diese Streitliteratur uns unwiederbringlich verloren ist.

Von ganz besonderem Interesse wäre es, wenn sich eine Theodorvita aus der Feder desselben Ignatios nachweisen lieBe, dem wir die Patriarchenviten verdanken. Goar bezeichnet jenes oben erwähnte Stück eines Historikers über Tarasios und Nikephoros, das er durch Combefis' Vermittlung aus den Papieren des Allatios erhalten hatte als Ignatius in narratione de Theodoro instituta. Leider ist die Quelle dieser Angabe für uns unkontrollierbar. Und so gut der den Studiten offenbar feindliche, den Patriarchen unbedingt ergebene Geist dieses Stückes zu der Stellung passen würde, die Ignatios in dem Streit unter Metho-

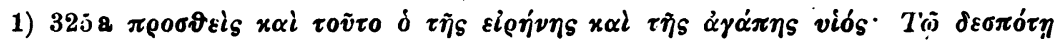

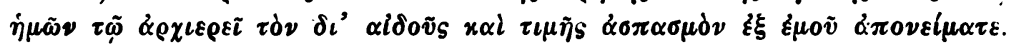


dios einnahm, so wenig entspricht der schmucklose Historikerstil des Bruchstücks den schwungvollen, panegyrisch gehaltenen Bioı des Skeuophylax der Hagia-Sophia.

Die zweite erhaltene Vita, nach der Überlieferung von Theodoros Daphnopates, entstammt einer Zeit, wo dieser Streit längst verstummt war: sie ist wirklich nur eine stilistisch erbauliche Bearbeitung der Vita Michaels. ${ }^{1}$ ) Von dem, was dessen Sinn bewegte, spürt der Bearbeiter

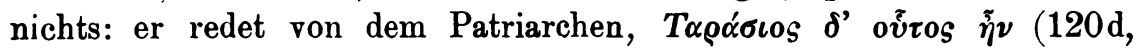
$129 \mathrm{c}$ ), als gälte es nur eine gelehrte historische Notiz: welche Verwicklungen sich gerade an diesen Namen knüpfen, davon hat er keine Idee. Es gehörte sich, daB ein Heiliger wie Theodor von dem Patriarchen selbst die Priesterweihe empfing (129d). Inbezug auf Tarasios' Ablehnung der Trauung und Josephs eigenmächtiges Handeln (137a) und Nikephoros' erzwungene Restitution des Ausgestoßenen (156c) gibt er nur wieder, was er bei Michael fand. Auch die drei Kraftstellen des letzteren über Theodors Verhältnis zu den Patriarchen (257a, 268b, $320 \mathrm{~d}$ ) hat er getreulich paraphrasiert (141d, 157c, 224b), aber wie dünn und wäBrig ist diese Paraphrase; es sind Gemeinplätze über christliche Eintracht daraus geworden. Recht erbaulich weiB Theodoros Daphnopates den Schmerz seines Heiligen über die unvermeidliche Lossage von dem Patriarchen darzustellen (157b). Die erste Begegnung mit Nikephoros gilt dem Kampfgenossen und Freund (220a). Es klingt, als sei nur eine räumliche Trennung, keine Lostrennung vorangegangen. ${ }^{2}$ ) Aus der zweiten Begegnung wird ein häufiger Verkehr $(221 \mathrm{~d})$. So mußten Heilige gelebt und zueinander gehalten haben!

Aus Michaels Vita scheint auch der Synaxartext zum 11. November geschöpft zu sein. ${ }^{3}$ ) Hier ist nach einer Verherrlichung des Tara-

1) Theod. Daphn. braucht das gleiche Bild von der emsigen Biene $117 \mathrm{~d}=$ 237 c; dasselbe Zitat aus Prov. 13, 17 und 4, 19 an der gleichen Stelle $141 \mathrm{a}=256 \mathrm{c}$; er befolgt durchweg die gleiche Anordnung: insonderheit entsprechen sich die beiden Wundersammlungen $208 \mathrm{c}-217 \mathrm{~d}=305 \mathrm{a}-316 \mathrm{a}$. Der sicherste Beweis liegt in dem Brief Theodors an die Ikonoklastensynode, dessen Anfang von Michael wörtlich zitiert wird $285 \mathrm{c}=1116$; Theod. Daphn. paraphrasiert auch diesen $188 \mathrm{~b}$, so daB

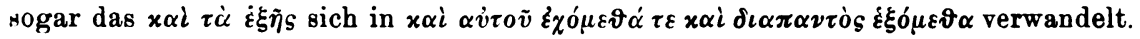

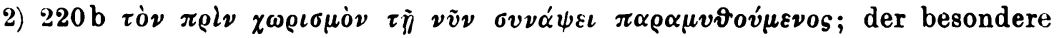
AbschiedsgruB des Sterbenden an den Patriarchen (Michael 325a) ist in seiner Bedeutung nicht mehr verstanden (229a).

3) Delehaye $213 \mathrm{f}$. gibt eine längere Form aus $\mathrm{F}$ und eine kürzere aus $\mathrm{S}$. Sirmond unter den Testimonia (MSG 99, $100 \mathrm{ff}$.) 6 Formen, darunter die nahe verwandten S, B, M (hier wird gar Tarasios von Konstantin abgesetzt!) und eine Nachschrift aus einem Pariser MS der Werke Theodors, die den Abt, Lehrer, Märtyrer feiert, ohne näher auf seine Geschichte einzugehen. Ba stellt Theodor rersebentlich zum 10. Nov. 
sios, von dessen Händen Theodor die Priesterweihe empfängt, noch klarer gesagt, dab der Patriarch und Theodor den Kaiser als Ehebreoher exkommunizierten, wozu dann freilich schlecht stimmt die Wiedervereinigung mit dem Patriarchen Tarasios nach VerstoBung des Joseph. Beim zweiten Exil wird nur der.Kaiser Nikephoros genannt und als Grund, daB Theodor nach Tarasios' Tod jenen Joseph nicht anerkennen wollte. ${ }^{1}$ ) Dann wird Theodors Rückkehr unter Michael I und die neuen Leiden wegen der Bilder unter Leon, die verhältnismäBige Ruhe und der Tod unter Michael II berichtet, ohne daB der Patriarch Nikephoros auch nur erwähnt wäre. In der kürzeren Fassung wird auch Tarasios nur bei der Priesterweihe genannt.

Theodors Bruder Joseph von Thessalonich wird am 14. bezw. 15. Juli kommemoriert ${ }^{2}$ ): aber offenbar ohne Grundlage einer Vita; der Translation beider nach Studion wird am 25. Jan. gedacht ${ }^{3}$ ): dabei ist mit Betonung die Beteiligung des Patriarchen Methodios an dieser Überführung hervorgehoben.

Mehr lernen wir aus der Theodors langjährigem Leidensgefährten Nikolaos gewidmeten Biographie ${ }^{4}$ ): sie ist anonym, und sicher nicht gleich nach Nikolaos' Tod (4. Febr. 868), sondern erst beträchtlich später von einem Schüler des Studitenabtes Anatolios $(882-886)$ geschrieben, wohl erst 40 Jahre nach Nikolaos' zweitem Nachfolger Hilarion (105, 924a). Sie hat für uns ein doppeltes Interesse: in ihrem ersten Teil läuft sie den Theodorviten ein Stäck parallel; in ihrem zweiten läbt sie uns Blicke tun in den Lauf der Dinge in Studion nach Theodors Tod. Auch hier finden wir die Auffassung, daB der Batriarch Nikephoros ebenso wie Theodor und sein Schüler Nikolaos

1) $\alpha \pi \omega \sigma \vartheta \varepsilon \dot{v} \tau \alpha \tau \eta_{5} \pi \alpha \tau \rho\llcorner\alpha \rho \chi \varepsilon i \alpha s$ klingt, als sei Joseph selbst Patriarch gewesen!

2) Delehaye $819 \mathrm{ff}$.: 14. Juli alle (auch die Translationsnotiz 8. u.) auBer'HPSSa Mv, die es zum 15. Juli baben: S gibt keinen Text; Del. hat den aus D beigeffigt, der aber sich nur in Allgemeinheiten bewegt, obendrein die Verbannung der beiden Brüder unter Theophilos setzt.

B) Delehaye 421 aus Db ohne Text; diesen gibt Sirmond (MSG 99, 104), aus Ambr. 014 d (wohl Druckfehler für O 142 = B 133 sup. = 142 Martini-Bassi, das ist $\mathrm{D} \mathrm{b}$ ).

4) Eine Vita des Naukratios ist unbekannt; er scheint keinen Biographen gefunden zu haben, wie er denn auch nicht ins Synaxar gekommen ist. Als Todestag nennt die Vita Nicolai (904c) den 18. April. Hierzu hat das Synaxar in keiner seiner Rezensionen einen Naukrstioseintrag, zum 8. Juni nennt nur Mc (789, 21 Delehaye) drei sonst unbekannte Heilige, Melaneia, den ö́6ıs Atre und

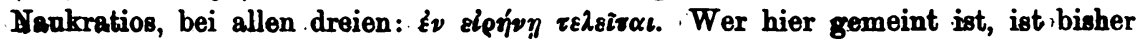
nioht fostge stellt; an den Studitenabt ist kanm gedacht. AS Juni II 136 sind nur Natisen aus Theodors Briefen und aus der Nikolsosvita zusammengestellt. Letztere steht nach Combefis auct. II $889 \mathrm{ff}$. bei Migne 105, 863-926. 
verbannt worden sei (881a); die Begegnung mit Nikephoros in Chalkedon unter Michael wird zusammengezogen mit der in Konstantinopel zu einem lang andauernden Verkehr (889c); hier findet sogar Michaels Philippika gegen die Verleumder der Heiligen einen unvermuteten Nachhall. ${ }^{1}$ ) Dann wird das Zusammensein in Konstantinopel doch noch eigens erwähnt unter Betonung, daB Theodor und Nikolaos mit der ganzen Umgebung des Patriarchen Gemeinschaft hielten (900a). Anläblich der Beisetzung Theodors auf der Prinzeninsel verweist der Verfasser auf die Aufzeichnungen kirchlicher Würdenträger. ${ }^{y}$ ) SchlieBlich erwähnt er Theodors Translation nach Studion unter dem großen Hohepriester, dem Vorkämpfer der Frömmigkeit, Methodios (904b). 'In dem nun folgenden zweiten Teil bilden den Hintergrund die photianischen Wirren: die Absetzung des Patriarchen Ignatios und sein Nachfolger Photios werden sehr ungünstig beurteilt $(908 \mathrm{ab})$. Nikolaos und sein Schüler halten entschieden zu' Ignatios, wie sich auch in der Absetzung nach Ignatios' Sturz und 'der gleichzeitigen Restitution mit diesem Patriarchen im. Jahre 868 zeigt. Wichtiger als diese spätere Patriarchengeschichte ist hier fŭr uns, dab der Verfasser, obwohl er es verschleiert, uns doch in die Parteiungen unter den Studiten selbst einblicken läßt. DaB nach Theodors Tod Naukratios die Leitung uberkam, war selbstverständlich: hatte er sie doch schon in Theodors Auftrag während dessen Exil lange' Jahre geführt: er erlieB das Rundschreiben, das allen Brüdern den Tod des gefeierten Heiligen kundtat. ${ }^{3}$ ) Aber es scheint, als hätte ein Teil der Brüder Nikolaos als dem langjährigen Kerkergenossen des Heiligen ein höheres Anrecht zugespröchen: Nikolaos zieht sich zurück; sein Biograph motiviert das mit der Liebe zu der ihm vom Gefängnis her gewohnten Einsamkeit (904a): diese hat ihn doch

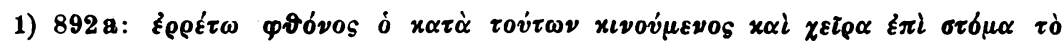

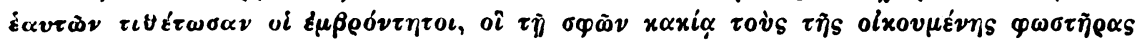

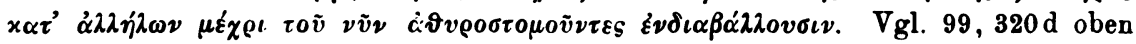
S. 67 .

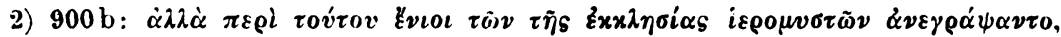

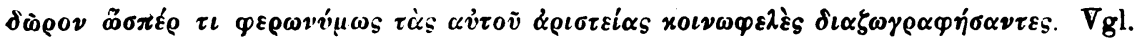
94,233 c oben S. 64 A. 2.

3) S. Theodors viele Briefe an Naukratios: I 40. [45. 47.] 49. 50. 51; II 10. 11. 34. 36. 40. 61. 63. 65. 67. 71. 73; M 32-39. 44-50. 61-66. 74. 75. 78-81. 104. 130. 146. 198-201. 208. 259. Naukratios Encyclica MSG 99, 1825-1849. In Theodors Testament findet sich sein Name nicht, der Abt wird angeredet

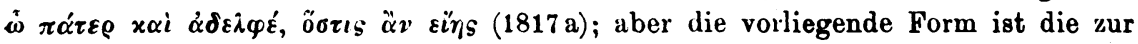
Vorlesung bei der Vorfeier des Theodortages bestimmte $(1813 \mathrm{a}$; s. auch den SchluB $1824 \mathrm{~d}$ ). Naukratios fragt den Sterbenden nach seinen letzten Verfügungen, Michaelsvita $32 \check{c} a=225 a$, er war dumals Oikonomos $324 \mathrm{c}=225 \mathrm{~d}$, nächst dem Al,t der höchste im Kloster. 
nicht verhindert, zu dreienmalen die Leitung der tausendköpfigen Mönchsgemeinde zu übernehmen; zunächst nach Naukratios' Tod 18. Apr. 848 (904c). Nach drei Jahren treibt ihn, wenn wir dem Biographen Glauben schenken wollen, wieder die Liebe zur Einsamkeit zur Resignation: er selbst hatte Sophronios an seiner Stelle zum Abt vorgeschlagen (904d). Als dieser nach vier Jahren, am 3. Nov. [855?], stirbt, übernimmt Nikolaos abermals die Leitung (905a). Nach Ignatios' Sturz hebt Nikolaos die Gemeinschaft mit dem neuen Patriarchen Photios und dessen Gönner Bardas auf und zieht sich in ein Hospiz seines Klosters in Prainetos zurück (908c). Der Kaiser ernennt dann einen anderen Abt für Studion, Achillas (909b), der dann nach fünf Jahren Erzbischof von Nakolia wird: die Verwaltung der vier folgenden Äbte Theodosios (ein Jahr), Eugenios (vier Monate), Theodoros Santabarinos (ein Jahr) und des Photios-Schülers Sabas von Kallistratos wird ganz kurz abgetan: unter dem letzteren wird Nikolaos, nach sieben Jahren des Exils, zwei Jahre lang im Kloster Studion selbst in harter Haft gehalten. Als aber unter Basilios Makedon Photios abgesetzt und Ignatios restituiert ist [23. Nov. 867], gelingt es den vereinten Bitten von Kaiser und Patriarch, den heiligen Nikolaos zur erneuten Übernahme der Klosterleitung zu bewegen (913b). Aber nicht lange darauf stirbt er, Klemens zu seinem Nachfolger designierend (921d), am 4. Febr. 868 und wird neben Naukratios beigesetzt. Der Verfasser verfolgt die Schicksale des Klosters noch durch die Zeiten zweier weiterer Äbte: des Klemens und Hilarion. Aber wir lernen daraus nichts mehr für unseren Zweck. Daß die Darstellung der Wirren in Studion unter Photios einseitig im Interesse des Abtes Nikolaos ist, ist klar; ebenso daB ein Zusammenhang dieser Wirren mit den älteren Parteiungen unter Methodios bestanden haben wird. ${ }^{1}$ ) Leider aber vermögen wir diesen nicht mehr zu durchschauen; nur das verdient Beachtung, daB die Absetzung des Ignatios mit einer Sache zusammenhängt, die einigermaßen an den moichianischen Streit erinnert: des Kaisers Oheim, der allmächtige Staatslenker Bardas, ward wegen blutschänderischen Umgangs mit seiner eignen Schwiegertochter von dem Patriarchen von der h. Kommunion ausgeschlossen. Das geben alle kirchlichen Quellen als den Hauptgrund der Beseitigung des Ignatios an, während doch offenbar noch tiefere Machtfragen dieselbe herbeiführten.

1) Patriarch Ignatios war der Sohn jenes bigotten Kaisers Michael I Rhangabe, unter dem Theodor von Studion die Politik des Reiches bestimmte, sehr zum Cnheil; nach des Vaters Entthronung durch Leon den Armenier war der Prinz Niketas entmannt und zum Mönch geschoren worden unter dem Namen Ignatios (Niketas Paphl. vita 8. Ignatii MSG 105, 492 b, Theophanes cont. I 10, p. 20). 
IV.

Wenden wir uns nun den übrigen Heiligen dieser Zeit zu, so machen wir zunächst eine für die Periode des Bilderstreites charakteristische Beobachtung: liebt es die Hagiographie sonst, ihren Heiligen in möglichst einsamem Glanz erstrahlen zu lassen, so dab die andächtige Gemeinde der Zuhörer den Eindruck empfängt, daB kein anderer sei, der so Großes vollbracht habe und so helfen könne als er, so treten hier der besonderen Zeitlage entsprechend die Heiligen immer gleich scharenweise auf: in geschlossener Phalanx rücken sie gegen den gemeinsamen Feind, die gottlose Häresie der Ikonoklasten. So kommt es, $\mathrm{daB}$ in den meisten Viten auch von den anderen Bekennern die Rede ist, und gerade das macht sie historisch so wertvoll.

Mit den Patriarchenviten des Ignatios gehören die Leben der Metropoliten Michael von Synada ( $† 23$. Mai 826$)$ und Theophylakt von Nikomedien ( $\uparrow 8$. März 835̃) auf das genaueste zusammen. Das läBt sich sogar aus den Synaxarauszügen erkennen, während die Viten selbst noch auf dem Athos verborgen liegen. ${ }^{1}$ ) Beide waren wie jener Ignatios Schüler des Tarasios, noch zu der Zeit, als er Laie und Asecretis war; beide traten nach seiner Erhebung auf den Patriarchenstuhl in ein Kloster am Schwarzen Meer und wurden von ihrem einstigen Lehrer zu Metropoliten von Synada und Nikomedien geweiht. Beide traten dann unter Leon dem Armenier kraftvoll für die Bilderverehrung ein und muBten wie der Patriarch Nikephoros in die Verbannung wandern, Michael nach Eudokias, Theophylakt auf die Insel Strobilos, wo sie im Exil starben. Theophylakts Leichnam wird unter Methodios nach Nikomedien überführt.

Dabei wird uns in dem längeren Theophylakttext die Abdankung von Tarasios' Vorgänger Paul IV. ganz wie bei Ignatios erzählt. ${ }^{\text {) }}$

1) Eine Vita Michaels in Pantokr. 149; eine Theophylakts in Dionys. 143; eine Akoluthie über Michael ed. Ven. 1769 ist mir auch unzugänglich, ebenso die Aufsätze von Pargoire über Michael in Échos d'Orient IV (1901) 347-350 und von Loparev über Theophylakt in Viz. Vrem. IV 354--jō). - Delehaye Synax. CP. 519 gibt für Theophylakt neben der S-Form eine bessere, ausführlichere aus Mc; 703 zu Michael (Bb. setzt diesen irrig zum 24. Mai). Wenn das Synaxar Theophylakt 30 Jahre im Exil leben läBt, so würde das von 815 auf 845 als 'Todesjahr führen; das ist aber unmöglich, da seit 842 Frieden herrscht; 845 könnte die Translation fallen; vielleicht ist $\gamma^{\prime}$ statt $\lambda^{\prime}$ zu lesen.

2) Vgl. S. 57. Ebenso in der Vita des Gotenbischofs Johannes (AS Juni V 190-194), der von den Orthodoxen gegen einen Ikonoklasten aufgestellt, in Iberien geweiht wird, sich daun aber in Jernsalem und in Konstantinopel die Bestäíigung holt und dabei Tarasios' Wahl erlebt. 
Tarasios heiBt da der groBe Leuchter der Orthodoxie. An Theophylakt als Metropolit ron Nikomedien wird eine ähnliche Armen- und Krankenpflege gerühmt, wie Ignatios sie von Nikephoros vor dessen Erhebung auf den Patriarchenstuhl berichtet. Besonders merkwürdig ist, wie die Regierungszeit des Kaisers Nikephoros mit dem zweiten moichianischen Streit übergangen wird: auf Tarasios' 'Tod folgt gleich' Leons des Armeniers Regierung und damit der' Bilderstreit. Auch das verdient Beachtung, daB 'bei dem Disput vor dem Kaiser nieben dem großen Nikephoros nur die Scharen der Hohenpriester, d. h. de facto sechs Metropoliten, genannt werden, unter ihnen auch Joseph von Thessalonich, der Bruder Theodors, aber der große Studitenabt, der doch nach der Studitenüberlieferung der Wortführer gewesen sein soll, nicht. ${ }^{1}$ ) Hier ist es vielmehr Theophylakt von Nikomedien, der am SchluB langer Verhandlungen, nachdem alle anderen schweigen, allein noch dem Kaiser, weil sein Sinn sich nicht zum bessern wenden will, das göttliche Strafgericht androht.

Theophylakt hatte, wie aus Theodors ep. I 48 hervorgeht, im moichianischen Streit auf Seiten des Patriarchen gestanden - natürlich als Schüler des Tarasios - und unter Nikephoros sich an der Verfolgung der Studiten und ihrer Gesinnungsgenossen beteiligt. ${ }^{2}$ ) Aber im Bilderstreit hatte Theodor vom Exil aus, wie mit dem Patriarchen Nikephoros, so mit ihm brieflich angeknüpft, wie zwei im'Ton höchster Anerkennung gehaltene Briefe beweisen..$^{3}$ ) Offenbar sind es die Schüler, die dann den alten Zwist wieder' hervorgesucht haben und - wie so oft - eine Rivalität der Meister in Szene setzen: darum schweigt die Vita Theophylakts von Theodor.

Die an geschichtlichem Stoff arme Kommemoration Michaels zeigt in ihren - von dem Synaxarstil auffallend. abstechenden - schwung-

1) Das tritt noch schärfer hervor, wenn man Theosterikts Vita des Niketas von Medikion (s. u. S. 81) vergleicht, wo dieselben Metropoliten um Nikephoros genannt werden, unter ihnen sber statt Josephs von Thessalonich Theodor von Studion (AS Apr. I p. XXIX).

2) Theodor ep. I 48 an den zu den. Gegnern übergegangenen Studiten Athanasios, dem Theodor aufzahlt, was die Seinen alles zu leiden hatten (99, 1072 d):

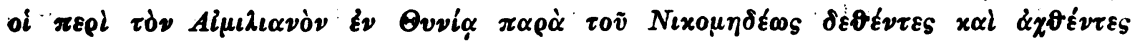

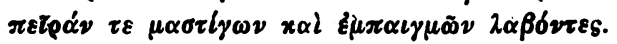

3) Ep. II 4 und 26 MSG 99, 1121. 1192: Baronius setzt beide 816, was nicht angeht; im ersten sagt Theodor, 2wei' Jahre lang sinne er darauf, Theophylakt zu schreiben; im zweiten, langst habe or zu schreiben begehrt, aber'keinen Boten gefunden. Sollten beide zugleich abgegangen sein? Beachtung verdient, "wie Theodor in ep. II 4 Theophylakts Verhaltnis zu Tarasios heraưsstreicht. 
vollen Wendungen noch deutlich die Herkunft aus einen rhetorisch gehaltenen Bios nach Art der Patriarchenviten des Ignatios. ${ }^{1}$ )

Mit den beiden Tarasiosschülern und dem Studiten Joseph werden noch drei Metropoliten zusammen genannt als solche, die sich im Bilderstreit ausgezeichnet haben und daher den Homologetentitel führen: Aimilian von Kyzikos, Euthymios von Sardes und Eudoxios von Amorion. ${ }^{2}$ ) Leider wissen wir von diesen dreien nur wenig. Eudoxios wird im Synaxar nur hier erwähnt; Amorion kommt in Theodors Briefen (ep. I 48 p. 1072 c) vor unter den Plätzen, wo Gresinnungsgenossen in Kerkerhaft saßen, die also offenbar mit Gegnern besetzt waren; wir wissen aber nicht, ob Eudoxios damals schon den erzbischöflichen Stuhl von Amorion inne hatte. Aimilian von Kyzikos wird am 8. Aug. an erster Stelle gefeiert. ${ }^{3}$ ) Das Synaxar spricht nur ganz allgemein von Leiden und Exil um der Bilder willen. Wichtiger erscheint Euthymios von Sardes s. $^{4}$, den wir noch in Theosterikts Leben des Niketas von Medikion (s. u. S. 82) und daraus bei Georgios monachos $^{5}$ ) als Hauptrerteidiger der Bilder vor Kaiser Leon neben dem Studiten Theodor genannt finden werden. Das Synaxar, das ihn am 26. Dez. gleich hinter der Gottesmutter feiert, erwähnt seine Teilnahme an dem zweiten Nicaenum, dann eine Verbannung unter Nikephoros, um der Einkleidung einer Jungfrau zur Nonne willen (ein etwas rätselhafter 'Zug, der an die moichianischen Streitigkeiten erinnert, und jeden-

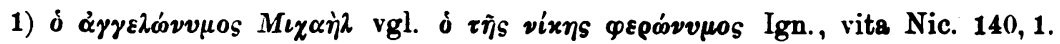

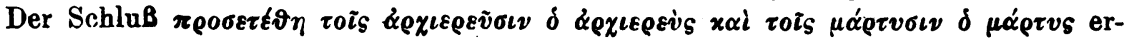
innert an Michaels Theodorvita $67(99,320 \mathrm{c})$; die gemeinsame Quelle ist aber wohl in einem Brief Theodors über den Tod Michaels von Synada an Petros von Nikaia (ep. II 200 p. $1613=$ M. 295 p. 243) zu suchen. - Ein Brief Theodors an Michael von Synada M. 264 p. 214 feiert diesen als Bekenner; erwähnt als Leidensgenossen den Abt (Johannes) von Kathara.

2) Synaxar p. 519 Delehaye; ebenso Theosterikts Vita des Niketas von Medikion AS Apr. I p. XXIX.

3) Synaxar p. 875 Delehaye (an zweiter Stelle nur C*Bc; in HP fehlt er); ein ausfiibrlicherer Text in $\mathrm{Cg}$ beruht auf einer Verwechslung. - Es verdient Beachtung für die Komposition des Synaxars, daB diese Bilderstreit-Homologeten durchweg vor die altkirchlichen Märtyrer eingesetzt sind.

4) Delehaye 345; der Text in $\mathrm{S}$ ist auch hier kürzer und schlechter als die

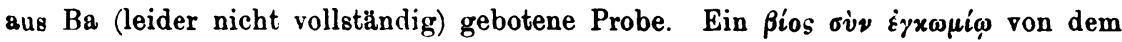
Mönch Metrophanes steht nach Delehaye in Oxon. Laud. 69. J. Pargoire, Saint Futhyme et Jean de Sardes, Fichos d'Orient V 157-161 ist mir leider nicht zagïnglich, ebensowenig die 1852 in Athen erschienene Akoluthie.

5) AS Apr. I p. XXIX, XXX; Gearg. mon. p. 779, 8 de Boor, Theodosios p. 144 Tafel: dabei hat der Bischof von Sardes natürlicherweise den Vortritt vor dem Abt von Studion: aber in Theodors Rede gipfelt gleichsam der Disput. 
falls zeigt, daB es noch andere Fragen als die des Bilderkults in jener Zeit gab), endlich unter Leon die Verbannung nach Assos ${ }^{1}$ ), unter dessen Nachfolger die nach Akrita (wo auch Theodor zeitweilig war): hier stirbt Eathymios an den Folgen einer grausamen Auspeitschung. Da sonst Michaels Regierung nicht darauf ausging, Märtyrer zu machen, wäre man geneigt, im Synaxar eine Verwechslung mit Michaels Sohn Theophilos anzunehmen, wie sie bei der verkürzenden Methode leicht entstehen kann; aber Genesios 1. II p. 50,14ff., Zonaras XV 22, $18 \mathrm{f}$. (III 338f.), Kedrenos (II 73,10) bezeugen ausdrücklich, daB Methodios' harte Kerkerhaft und Euthymios' Auspeitschung von Kaiser Michael ausgingen, bei letzterer allerdings Michaels Sohn Theophilos persönlich beteiligt war. ${ }^{2}$ ) Euthymios von Sardes ist also in dieser Art eng mit dem nachmaligen Patriarchen Methodios verbunden, aber schon etwa 826 (ungefähr gleichzeitig mit Theodor) gestorben.

Derselbe Ignatios, dem wir die Patriarchenviten verdanken, hat auch den als Confessor gefeierten Gregorios Dekapolites ( $† 20$. Nor. 81i) verherrlicht. Dieser, aus Isaurien stammend, lebte meist in Thessalonich, kam aber auch nach Sizilien und Rom, offenbar in kirchlich-diplomatischen Aufträgen. Zeitweilig übte er seine Askese auch auf dem Olymp, dem Zufluchtsort so vieler Einsiedler, die wir noch kennen lernen werden. Bei einer Reise, die er von Thessalonich aus unternahm, um seinen geistlichen Vater Symeon ${ }^{3}$ ) im Gefängnis in Konstantinopel aufzusuchen, orlag er in der Hauptstadt einer Krankheit. Wenn er nicht zufällig gerade im Westen weilte, muB Gregorios in Thessalonich gewesen sein, als Theodor dort als Verbannter weilte (25. März 796 bis nach dem 15. Aug. 797). Damals sab dort (vor dem Studiten Joseph) ein ganz kaiserlich gesinnter Erzbischof, der Theodors Gesinnungsgenossen hart bedrückte, u. a. einen Abt Theosostos mit seinen Anhängern aus der Stadt vertrieb. ${ }^{4}$ ) Es wäre von dem höchsten Interesse, diese Vorgänge auch von der Gegenseite dargestellt zu sehen. Freilich bei dem Patriarchalbiographen Ignatios darf man davon kaum etwas erwarten. So wird kein neues Licht auf diese Verhältnisse fallen, wenn einmal die noch

1) Hierher gehören wohl Theodors Briefe ep. M 3 p. 3 f., 41 p. 33.

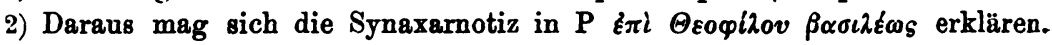
Auch die Vita der h. David, Symeon und Georg von Lesbos (s. u. S. 92) setzt die Geißelung des Euthymios unter Theophilos.

3) Dieser Symeon, Gregors Oheim, war erst Archimandrit eines Klosters in der isaurischen Dekapolis (p. 133), in dem Gregor 14 Jahre nach seiner Flucht aus dem Ikonoklasten-Kloster (?) verbrachte, dann noch einige Zeit nachher als. Klausner.

4) Theodor ep. I 43 p. 1068 b; I 48 p. 1072 c. 
in Pariser Handschriften verborgene Vita an die Öffentlichkeit kommt. ${ }^{1}$ ) Immerhin wird sie mehr bieten als der Text, den wir jetzt haben ${ }^{2}$ ), und der zu der dürftigsten Klasse asketischer Mönchsbiographien gehört, ohne jedes Verständnis für die großen Zeitfragen: Gregors viele Reisen erscheinen hier durchweg als Flucht vor der Berühmtheit, ein Verbergenwollen seiner Wunderkräfte. ${ }^{3}$ ) Nur vom Bilderstreit ist die Rede, wobei man sich des Eindrucks nicht erwehren kann, daB der Heilige etwas gewaltsam in die Rolle eines Märtyrers der h. Bilder gezwängt wird: schon in seiner Jugend soll er in einem Kloster seiner Heimat viel wegen seiner Bilderverehrung zu leiden gehabt haben, in Thessalonich dann einem ikonoklastischen Bischof in die Hände gefallen sein. $\left.{ }^{4}\right)$ Sein mutiges Eintreten bei dem Wiederausbruch des Bilderstreits unter Leon dem Armenier wird mit vielen schönen Wendungen beschrieben, ohne daß wir auch nur das geringste konkrete Detail erführen. ${ }^{5}$ ) Gregor der Asket, der kirchenpolitisch eine Rolle spielte, ist offenbar nachträglich zum Homologeten avanciert. Ist dies das Werk jenes Ignatios?

Zur Ergänzung des Wenigen, was wir über Gregor aus seiner Vita erfahren, kann die seines Schülers, des Hymnographen Joseph († 3. Apr. [nach] 878), dienen, der, aus Sizilien gebürtig, mit ihm in Thessalonich lebte, ihn auch auf seinen Reisen begleitete, und jedenfalls bei seiner Beisetzung auch in Konstantinopel anwesend war. Auch hier ist die ältere Form, von einem Presbyter und Mönch Theophanes, noch unbekannt, oder gar verloren. Was wir haben, ist eine sehr späte Redaktion photianischen Gepräges, aus den Kreisen des hauptstädtischen Klerus, von einem Rhetor nnd Diakon der großen (d. h. der Sophien-) Kirche Joannes. ${ }^{6}$ ) Hier wird uns u. a. erzählt, daB Gregor seinen

1) Par. gr. 501, 1525, 1549. Vgl. Ehrhard bei Krumbacher 73.

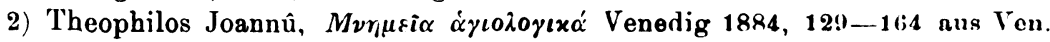
Marc. 363. Das Synaxar (p. 239 Delehaye) scheint hieraus geschöpft.

3) Vgl. bes. S. 141, 142.

4) Ebd. 133, 144. Nach manchen Analogien könnte man vermuten, daB der ikonoklastische Bischof hier an die Stelle eines studitischen oder antistuditischen getreten sei.

5) Ebd. 157, 160.

6) Aus AS Apr. I, XXXIV-XLI bei Nigne 105, 931-976; über Theophanes' rita ebd. 941c, Verhältnis zu Gregor. Dekapol. 952c; Theophanes ist offenbar identisch mit dem Schüler, den Joseph dem Patriarchen Photios als seinen Nachfolger empfiehlt, 97:2 a. - Vgl. Ehrhard bei Krumbacher ${ }^{2} 197$; Krumbacher selbst $676 \mathrm{ft}$. Das Synaxar (p. 582 Delehaye) widmet ihm eine sehr ausführliche Kommemoration (zwei Formen aus $S$ und $D$ ), die aber nichts Neues lehrt und auf dem bekannten Text zu ruhen scheint. Bb rerschiebt irrig Niketas und Josepb rom 3. anf den 4. April, Mr nur letzteren. 
Schüler Joseph nach Rom entsendet, um den Papst gegen Leon derr Armenier zur Hilfe aufzurufen - also analog dem Auftreten des Studitenabtes; Joseph aber kommt nicht nach Rom, sondern wird von Piraten gefangen nach Kreta gebracht, wo ibm im Gefängnis die Gabe des Gesanges zuteil wird. Zum Begräbnis seines verehrten Meisters Gregor kommt er gerade zurecht nach Konstantinopel, wird dann aber wieder verbannt, bis Theodora ihn zurückruft. Patriarch Ignatios macht ihn zum Skeuophylax und als diesem, der in hohem Alter und von vielfachen Mühen gedrückt starb, Photios folgte (so!), da erwies auch er dem h. Joseph hohe Ehren.

Eine besondere Stellung ninmt dann Theophanes Confessor $(†$ 12. März 817) ein. Dieser gelehrte Heilige ist uns zunächst schon darum interessant, weil wir in seiner Chronographie ein authentisches Zeugnis seiner Auffassuug der moichianischen Streitigkeiten besitzen. Der Chronist teilt nicht ganz die unbedingte Verehrung der Hagiographen für Irene: Konstantin VI erscheint ihm nicht so schlecht; er weiB, wie sehr die ehrgeizige, herrschsüchtige Mutter die Hände im Spiel hatte, die ihm erst die erhoffte Heirat mit der fränkischen PrinzeB, einer Tochter des großen Karl, verdarb ${ }^{1}$ ) und ihn zur Ehe mit der Armenierin Maria zwang, dann deren Auflösung und die neue Ehe mit Theodote betrieb, um den Sohn in Verruf zu bringen $(463,21 ; 469,23) .^{2}$ ) Wohl beurteilt auch Theophanes diese zweite Ehe als ungesetzlich (falls $\pi \alpha \rho \alpha-$ $\nu \boldsymbol{o}_{\mu \omega s}$ 470,3 nicht spätere Zutat ist), aber von der Erregung der Studiten über die $\mu \circ \iota \chi \varepsilon l \alpha$ findet sich keine Spur. Im Gegenteil, wie Tarasios' Verdienst um Herstellung der Orthodoxie glänzend (genau so wie bei dem späteren Biographen Ignatios) gewürdigt worden ist (457-463), so wird Platons Schisma recht ungünstig beurteilt (470) und die Protektion, die Irene den Verbannten angedeihen lieB, gewertet als das was sie war: Politik zum Sturz ihres Sohns. ${ }^{3}$ ) Davon, daB Tarasios den Abt Joseph von Katharon (wie er hier 470,27 genannt wird) exkommuniziert und sich bei den Studiten entschuldigt habe, ist nicht die Rede. Bei Nikephoros' Wahl wird der Protest der Studiten gegen den sofortigen Aufstieg eines Laien zum Bistum erwähnt, aber durch den Hinweis auf zahllose Präzedenzfälle abgetan (481). Von einem

1) Utber diese Sache gehen die Urteile auch der heutigen Forscher sebr anseinander, s. Brandi, Arch. f. Urkundenforschung I 53 A 2.

2) Kedrenos II 23, 19. 26, 7; Leo gramm. 193, 16. 198, 20 wiederholen das. In der verkürzenden Wiedergabe des Georgios monachos (770 de Boor) dagegen fehlen alle diese Züge.

3) Hiernach Kedrenos II 26, Leo gramm. 198f., Theodosios p. 137 Tafel, Zonaras XV 13, 2 (III 297). 
Einschreiten gegen jene wird dem Kaiser abgeraten; dazu kommt es erst drei Jahre später, als sie wegen des Oikonomos Joseph offen mit dem Patriarchen Nikephoros brechen (484). So wenig Theophanes den Kaiser Nikephoros leiden kann, den er als Ausbund von Geiz, Habgier und Grausamkeit zeichnet und gegen den er weit schwerere Vorwürfe erhebt als die Studiten gegen Konstantin VI (483), so sehr ist ihm der Patriarch Nikephoros im Recht. $\left.{ }^{1}\right)$ Bei der Wiedervereinigung der Studiten mit diesem, die er dem hochgefeierten Kaiser Michael als Verdienst anrechnet, versteht er sich núr zu einem: „alle, die sich von der heiligen Kirche fern hielten aus irgendwelchem sei es guten oder nicht guten Grunde" $\left.(494,14)^{2}\right)$. SchlieBlich wird Theodor, der Studitenabt, für den schlimmen Ausgang des Bulgarenkriegs und Michaels Sturz verantwortlich gemacht, weil er gegen den Rat des Patriarchen und der Metropoliten den Kaiser bestimmte, den Frieden nicht anzunehmen $(498,20)$ : die kriegsunkundigen Ratgeber $(500,24)$ verderben schlieblich alles und sind so indirekt schuld an dem Wiederaufleben des Ikonoklasmus. ${ }^{3}$ )

Soweit der Heilige von Sigriane. Wir wundern uns nicht, bei dem Studitenabt eine kräftige Antwort darauf zu finden: er hat 7war auf die Nachricht von Theophanes' Exil diesem wiederholt in den Tönen höchster Bewunderung geschrieben, ihn als den Bekenner feiernd ${ }^{4}$ ); er hat seinen Tod als Martyrium verherrlicht ${ }^{5}$ ); aber er hat auch dann noch mit Anklagen gegen ihn wegen Begünstigung der Moichianer nicht zurückgehalten. Auf die Beschwerde, die darob ein Abt (wohl der.von Sigriane) erhob, antwortet Theodor dem Hypatos Demetrios: „Der Wahrheit die Ehre; auch der große Apostel Petrus konnte die Verleugnung, David den Ehebruch, Cyprian die Magie nicht ableugnen.

1) Kedrenos II 34, 36 wiederholt das; ebenso Zonaras XV 14, 14 f. (III 305),

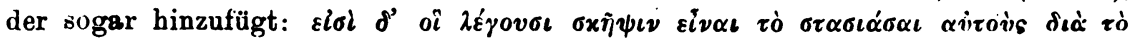

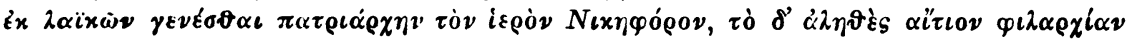

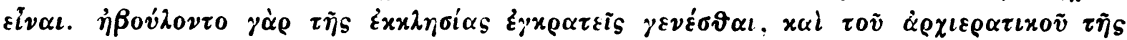

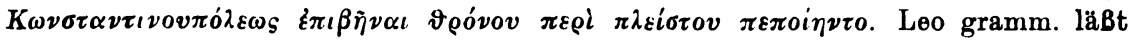
hier den Patriarchen Nikephoros ganz fort. In der kurzen Fassung bei Georg. mon. 770, 774 erscheinen die Studiten als Märtyrer. Für Glykas p. j31 ist Nikephoros' Tod in dem Bulgarenkrieg Strafe für die Verbannung des Studiten Theodor.

2) Anders Zonaras XV 16,8 (III 313).

3) Dies fehlt bei Kedrenos, während Leo gramm 206,15 ff. von den schlechten Ratgebern spricht, aber ohne den Studiten zu nennen. Nach Theophanes: Zonaras XV 17, 21 (III 316).

4) Ep. M 140, 205, p. 124, 176. Auch in ep. M 16r p. 160 zählt er den Abt ron Agrû unter die wenigen Glaubenstreuen.

5) Ep. M 224 p. 191 an Niketas von Medikion; daher Theodor auch ep. If 21\%

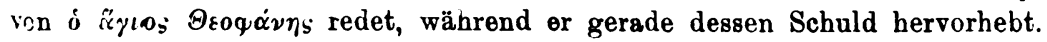


Die Kirche gedenkt seiner als eines Orthodoxen; das besagt aber nicht, daB er sich nicht gröblich verfehlt hat" (ep. II 218, 1660a b).

Bei dieser Sachlage ist es von gröBter Bedeutung, daB keïn geringerer als Patriarch Methodios selbst es unternommen hat, die Biographie des Theophanes zu schreiben, und es ist eine schmerzliche Lücke unseres Wissens, daB wir diese Vita, obwohl sie in zwei Handschriften aufgewiesen ist, noch nicht kennen. Wir würden hierin wohl ein Meisterstück der Kunst, Unbequemes nicht zu sagen, zu bewundern haben. Einstweilen müssen wir uns mit den sekundären Formen begnügen, die Krumbacher als Auszüge aus jener Methodiosvita nachgewiesen hat. $\left.{ }^{1}\right)$ Da zeigt sich, dab Theophanes lediglich als der heilige Asket aufgefabt ist, der nach enthaltsamer Ehe sich von seinem Weibe trennt, ein Kloster nach dem andern gründet, selbst die Abtswürde immer ablehnt, an der Bildersynode unter Irene teilnimmt, unter dem Armenier Leon für die Bilder Kerkerhaft erleidet und im Exil stirbt. Außer Theophanes werden noch lokale Mönchsgrößen wie Gregorios und Christophoros von Sigriane erwähnt: die großen umstrittenen Namen Tarasios und Nikephoros sowie Theodor von Studion kommen in dem Moskauer Auszug aus Methodios nicht vor. Die jüngere rhetorische Bearbeitung (vita A bei de Boor II 1-12), die sich ausdrücklich auf Methodios bezieht $(8,33)$, schildert Tarasios' Erhebung zum Patriarchen als ganz korrekt und sein großes Verdienst um die Orthodoxie; zählt bei der Synode von Nikaia nicht sowohl die Vertreter der Patriarchate als die großen Klosterhäupter: Platon von Sakkudion, Niketas und Nikephoros von Medikion, Christophoros von Mikrû Agrû (9, 30ff.) und vor allem den seligen Theophanes auf, gleich als sei ihm vornehmlich der Erfolg des Konzils zu danken (10,7ff.). Dann aber springt sie sofort auf den Wiederausbruch des Bilderstreits unter Leon, wobei außer einem Schreiben des Theophanes an den Kaiser zweimal der Leiden des Studitenabtes Theodor gedacht wird $(10,29 ; 11,33)$. Von dem ganzen moichianischen Streit wieder kein Wort. Haben diese anerkennenden Bemerkungen über Theodor bei Methodios gestanden, der damit ausgleichen und die Studiten gewinnen wollte? Oder haben wir darin die Hand eines späteren Studiten zu erkennen?

Der Skeuophylax Nikephoros endlich, der zwar noch andere Quellen benutzt, in der Hauptsache aber doch wohl auf Methodios fuBt (vita B bei de Boor II 13-30), gibt gar eine begeisterte Schilderung des Friedens, dessen sich die Kirche unter Irene und Konstantin zu erfreuen

1) Krumbacher, Ein Dithyrambus anf Theophanes Confessor, SB München 1896, 583-625, and besonders Eine neue Vita des Theophanes Confessor, SB München 1897, 371-399. 
hatte $(22,20 \mathrm{ff}$ ), bis plötzlich Leon als Satans Organ diesen störte. Irgendwelche Beziehungen auf Einzelheiten der Zeitgeschichte suchen wir bei diesem Enkomiasten vergebens.

Wie Theodor im Kreise der Studiten das gefeierte Haupt ist, so erscheint Theophanes als der Heros eines anderen Kreises: der gleich zu erwähnende Eremit Joannikios pilgert zu Theophanes' Grab ${ }^{1}$ ); Patriarch Ignatios rühmt sich, daB dieser Heilige ihm als Knaben segnend die Hand aufs Haupt gelegt habe. ${ }^{2}$ ) Als Patriarch Nikephoros in die Verbannung fuhr, soll Theophanes ihm von seinem Kloster aus - ungesehen - mit Weihrauch und Kerzen feierliches Geleit gegeben und der Patriarch, der dies in geistigem Rapport erkannte, seine Heiligkeit und sein Bekennertum vorausverkündet haben. ${ }^{3}$ )

SchlieBlich hat Kaiser Konstantin VII Porphyrogennetos, der sich der Abstammung von dem Confessor rühmte, für dessen Ruhm gesorgt, indem er die Fortsetzung von dessen Geschichtswerk anregte.")

Neben den Abt von Sigriane (oder Agrû) tritt als ein etwas anderer Typus Abt Niketas von Medikion ( $†$ 3. April c. 820). Er gehört zu Theodors Korrespondenten, und die von seinem Schüler Theosterikt abgefaßte Vita hat für uns doppeltes Interesse, weil sie uns in einer Handschrift aus Studion erhalten ist. ${ }^{5}$ ) Dies ist um so bedeutsamer, als Niketas kein unbedingter Anhänger Theodors war und Theodors Urteile über ihn keineswegs nur günstig lauten. Ihm galt auch der Medikiotes, wie er Niketas nennt, als ein Freund der Moichianer, den erst der Bilderstreit auf die rechte Seite gebracht habe (ep. II 31 p. 1204b); und als er im Bilderstreit sich momentan beirren lieb, durch falsche Zusagen bestimmt, mit dem ikonoklastischen Patriarchen Gemeinschaft zu halten, was er bald genug bereute und durch Bekennerleiden wieder sühnte, da hielt ihm Theodor in fast unzarter Weise brieflich vor, wie er sich damals schon durch schlechten Rat habe bestimmen lassen, die Übertretung evangelischer Satzungen als Ökonomie hinzunehmen (ep. M. 195 p. 169); allerdings war es derselbe Oikonomos .Joseph, um den es sich

1) AS Nov. II $1,405=360$.

2) MSG $105,500 \mathrm{~b}$.

3) Georg. Kedrenos II 57 ed. Bonn. Genesios p. $15 \mathrm{f}$.

4) Theophanes contin. prooem., 1. 5 Bonn.

5) Act. Sanct. Apr. I p. XXII-XXXII aus Vat. gr. 1660 (nicht 1190 wie 1. XXII irrig angegeben ist): vgl. Catalogus codicum hagiogr. bibl. Vatic. 153:

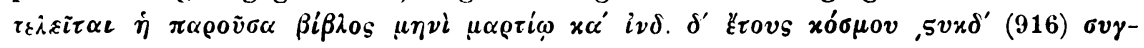

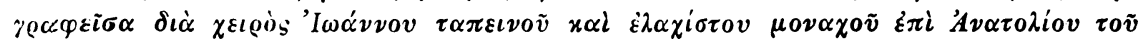

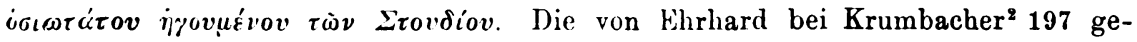
naruten anderen Viten des Niketas waren mir nicht zugünglich. Der Synaxartext (p. 581 Delehaye) ist ganz farblos.

Iiv zant. Zeitschrift XVIII 1 u. 2. 
damals gehandelt hatte, der jetzt in kaiserlichen Diensten die Äbte verschiedener Klöster zur Kommunion mit dem Patriarchen eingefangen hatte. Die Reue des Medikioten und seine Leiden für die heiligen Bilder wertete Theodor dann freilich so hoch, daB er ihn einem anderen Abt Theophilos als Vorbild hinstellt (ep. II 89 p. 1337a). Aber die nach Theodors eignem Zeugnis ${ }^{1}$ ) rege Korrespondenz aus der späteren Zeit ergibt doch recht verschiedene Beurteilung der Sachlage. Der Abt von Studion will auch jetzt nichts von irgendwelcher Ökonomie wissen; wer sich von der Häresie zu den Bilderfreunden zurückwendet, soll den früheren Irrtum rund eingestehen und abschwören, aber nicht durch Wendungen wie „Ich habe teilgenommen, aber nicht Gemeinschaft gehabt" sein bisheriges Verhalten beschönigen. Der Medikiotes, der selbst in jener Lage gewesen war, dachte offenbar entgegenkommender.

In der Vita fällt zunächst eine, wohl in den Umständen gegebene, große Ähnlichkeit mit dem Leben Theodors auf: auch Niketas empfängt die Priesterweihe von Tarasios, die Abtsweihe von Nikephoros: beide Patriarchen werden als Hüter der Orthodoxie und Heilige gefeiert (XXVIII F, XXIX C). Dabei ist eine förmliche Reichs- und Kirchengeschichte von Leon dem Isaurier an bis auf Leon den Armenier eingelegt (XXVIIC-XXXD), welche mit dem Leben des Heiligen garnichts zu tun hat, aber von Chronisten wie Georgios Monachos mit Wonne benutzt wurde. ${ }^{9}$ ) $\mathrm{DaB}$ in dieser kurzen Übersicht der Geschichte eines Jahrhunderts von den inneren Zwistigkeiten des moichianischen Streites nicht die Rede ist, versteht sich von selbst. Es will eine Geschichte des Ikonoklasmus sein. Sie gipfelt in der Darstellung der kühnen Glaubensbekenntnisse der um den Patriarchen Nikephoros gescharten Bilderverteidiger vor Kaiser Leon: da treten die uns schon bekannten Metropoliten Aimilian von Kyzikos, Michael von Synada, Theophylakt von Nikomedien, Petros von Nikaia, Euthymios von Sardes und schlieBlich als der kraftvollste Zeuge der Abt Theodor von Studion mit seinem berühmten Hinweis auf I. Kor. 12, 28, wo nichts von den Kaisern stehe, auf ${ }^{3}$ ) - von Niketas ist erst wieder die Rede bei der Einkerkerung und Verbannung der glaubenstreuen Äbte (XXXD). Hier kommt nun der kritische Punkt: es ist dem ikonoklastischen Gegenpatriarchen Theodot Kassiteras gelungen, durch falsche Vorspiegelungen etliche dieser Äbte zu bewegen, daB sie mit ihm Kommunion hielten, darunter auch Niketas. Der Biograph verschweigt das nicht, sucht es aber nach Kräften zu entschuldigen: Niketas tut es

1) Brief an die Kaiserin Theodosia, ep. II 204 p. 1620 c

2) S. de Boors Apparat von S. 769 an.

3) XXIXE bis XXXB; vgl. Georg. mon. 774, 5-9; 778-780. 
wider Willen, nicht aus Leidensscheu, sondern den Vorstellungen der anderen Äbte folgend. Es reut ihn sofort, er will sein Kloster verlassen, wird aber vom Kaiser vorgefordert und gefangen gesetzt (XXXIBC). Sechs Jahre duldete er so für den rechten Glauben; unter Michael freigelassen, starb er dann bald. Bei seiner Leichenfeier waren die Erzbischöfe Theophilos von Ephesos und Joseph von Thessalonich (das ist der Bruder Theodors!) zugegen (XXXIIC).

Die Vita will von Theosterikt, einem Schüler des Heiligen, verfaBt sein, und gehört also wohl nach Medikion. Man wäre versucht, ihren Ursprung in Studion zu suchen, so sehr ist die Person Theodors auf Kosten des Hauptheiligen hervorgehoben und die Beurteilung des letzteren durch studitische Mabstäbe bestimmt. Vielleicht haben wir auch in dem einzigen uns vorliegenden Text eine studitische Bearbeitung des Originaltextes.

Unter Theodors Korrespondenten findet sich auch der Abt Makarios von Pelekete: er gehört zu den wenigen glaubenstreuen (ep. M 188 p. 160); Theodor schreibt ihm wiederholt sehr anerkennend (ep. II 20 p. $1177 ;$ M. 87 p. $76 ; 151$ p. $132 ; 262$ p. $213 ; 271$ p. 218 ). Die von Hipp. Delehaye neuerdings veröffentlichte Vita aus der Feder seines Schülers Sabas ${ }^{1}$ ) gehört leider zu jenen hagiographischen Produkten, die über dem speziellen Heiligen und seinen Wundern alles andere vergessen: wir erfahren nur, daB er in Konstantinopel geboren, früh verwaist, beim Eintritt in das Kloster seinen Namen Christophoros mit Makarios vertauschte, von Tarasios die Priesterweihe empfing, unter Leon ins Exil muBte, wo er den vertriebenen Patriarchen Nikephoros traf, später mit Kaiser Theophilos disputierte und ins Exil nach Aphusia kam (kein Wort davon, daB hier eine ganze Anzahl Confessoren sich traf!) und an einem 18. Panemos (=17. August) im Beisein seiner Schüler starb (jedenfalls wohl vor 842). Die einzige Episode von zeitgeschichtlicher Bedeutung in dieser Vita ist das Wunder, das sich bei der von einem Priester des Klosters zelebrierten Messe ereignet: der betreffende war abgefallen, aber reuig zurückgekehrt; Makarios hatte ihn aufgenommen, ihm aber alle priesterlichen Funktionen untersagt; als er dennoch die Eucharistie feierte, bemächtigte sich der

1) Anal. Boll. XVI 1897, 140-163 aus Par. 548 (saec. XI). Die von Ehrhard bci Krumbacher ${ }^{2} 198$ vor Bekanntwerden des Textes vermutete Identität des Verfassers Sabas mit dem der Joannikiosvita bestätigt sich nicht; es weht hier ein gan\% anderer Geist, und dieser Sabas ist Mönch von Pelekete $(162,4,163,17)$, jener von Agaurôn. Die von Delehaye notierten sprachlichen Anklänge gehören der Zeit an; ebensoviel Unterschiede heben die Beweiskraft auf. Das Synaxar erwähnt ihs zaw 19. Aug. RuN (p. 910) und 1. Apr. Mcr (p. 577). 
Teufel der Kommunikanten. Das ist das göttliche Siegel auf die Theorie Theodors, daB wiederaufgenommene Priester bis zur Wiederherstellung der Orthodoxie keine priesterlichen Funktionen ausüben dürfen, wie er sie des öfteren, und auch in einem Brief an Makarios von Pelekete, darlegt (ep. II 20 p. 1177).

\section{V.}

Lag das Interesse der bisher besprochenen Viten in ihrer Stellung zu dem moichianischen Streit, so führen uns die folgenden in etwas spätere Zeit: wir haben es da mit Männern zu tun, die gleich jenem Gregorios Dekapolites von auswärts nach Byzanz kamen, erst zu einer Zeit, da jener Streit bereits durch den Bilderkampf abgelöst worden war, die dann aber, Theodor überlebend, eine Rolle bei der Restitution der Orthodoxie und den Vorgängen unter Methodios spielten.

Da sind zunächst drei Palästinenser, die gewöhnlich als eine Gruppe betrachtet werden, der Synkelle Michael und die Brüder Theodor und Theophanes, die sog. Graptoi. ${ }^{1}$ ) Von letzteren wissen wir mit Sicherheit, dab sie früher in der Laura des Mar Saba waren (sie selbst nennen das: aus Moab) und vor der Regierung des Armeniers Leon nach Konstantinopel kamen. Der Chronograph Theophanes berichtet von Verwüstungen der Lauren durch die Araber unter der Regierung des Kalifen Muhammed al Amin in den Jahren 809 bis 813; im letzteren Jahre seien viele Mönche nach Kypern und von da teilweise weiter nach Konstantinopel geflohen; Kaiser Michael Khangabe, der damals ganz unter dem Einfluß des Studitenabtes stand, nahm sie freundlich auf und schenkte ihnen ein bedeutendes Kloster. ${ }^{2}$ ) Die Kombination hat viel Wahrscheinlichkeit, daB hiermit das Chorakloster gemeint ist und unter den Flüchtlingen auch jene beiden Brüder waren. Sie treten bei den Chronisten erst hervor unter Theophilos, der sie (aus dom Exil in Aphusia) ${ }^{3}$ ) vor sich bringen und nach einem mit Auspeitschung verbundenen Verhör mit jenen zwölf (wie er selbst sagt) schlechten Jamben, die ein gewisser Christodulos verfaßt hat, an der Stirn brandmarken läßt - daher ihr Ehrenbeiname der Graptoi. ${ }^{4}$ ) Hierauf werden sie aufs neue verbannt. Theodor stirbt

1) Vgl. den Art. Theodor und Theophanes die Graptoi in $\mathrm{RE}^{3} \mathrm{XIX}, 596$, wo ich leider Vailhé und den Auszügen der Michaelsvita gefolgt bin, deren Unzuverlässigkeit sich mir jetzt erst ergeben hat.

2) Theophanes Chron. 484 ad a. $6301(=808 / 9) ; 499$ ad a. $6305(=812 / 3)$ :

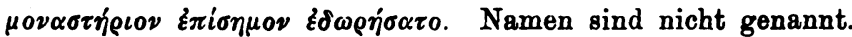

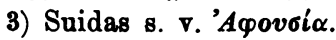

4) AuBer dem Brief der Brüder an Bischof Johannes von Kyzikos (s. unten S. 83 A.4) haben wir zwei Relationen dieses Auftritts bei den Chronographen : a) Theophanes 
noch im Exil ${ }^{1}$ ); Theophanes, der berühmte Hymnendichter erlebt die Restitution und wird von Methodios zum Erzbischof von Nikaia geweiht, nicht ohne daB dieser Akt Widerspruch erfahren hätte: er sei ein Syrer, man könne nicht wissen, ob er orthodox sei, Bedenken, die der Patriarch durch den Hinweis auf die Stigmen niederschlägt. ${ }^{2}$ ) Nach achtjähriger Verwaltung des Erzbistums starb er am 11. Oktober $\left.851(?) \cdot{ }^{3}\right)$

Die Brüder waren, wie ihr aus dem Exil an Bischof Johannes von Kyzikos geschriebener Brief ${ }^{4}$ ) - unsere Hauptquelle - zeigt, von einem nicht èben erfreulichen Confessorenhochmut beseelt; Theophanes hat diesem in einer für alle Anwesenden höchst peinlichen Art noch bei einem Festmahl, das die fromme Kaiserin den rechtgläubigen Bischöfen gab, Ausdruck verliehen, indem er ihr ins Gesicht sagte: um dieser Stigmen willen werde er ihren verstorbenen Gemahl vor Gottes Gericht fordern. ${ }^{5}$ )

Von Michael wissen wir sicher nur, daB er erst Synkelle des Patriarchen Thomas von Jerusalem war $^{6}$ ); die Motive seines Kommens

cont. p. $104 \mathrm{f}$; Kedrenos II $114 \mathrm{f}$; Zonaras XV 27, $11 \mathrm{f}$. (III 365); Manasses $4779 \mathrm{ff}$; b) Ps. Symeon 641, Georg. mon. cont. 806 f., Leo gramm. 226, Theodosios p. 156 Tafel. Dazu kommen die Viten der drei Lesbier (s. unten S. 92) und des Studiten Nikolaos p. 901 (s. oben S. 70). Die Predigt über Bilderwunder (von Dobschütz, Christusbilder $256^{* *}$ ) erwähnt die iambische Korrespondenz mit Methodios, die auch Ps. Symeon 643, Kedrenos II 117, Glykas 538, Manasses $4902 \mathrm{ff}$. bieten.

1) So ausdrücklich die unter $b$ genannten. Hiergegen kann die Darstellung bei Theoph. cont. und Kedr. (8. unten Anm. 5) nicht aufkommen, die an dem Festessen unter Theodora beide Brïder teilnehmen läBt, umsoweniger als Theodor dabei eine stumme Nebenfigur bleibt, die gut wegbleiben kann, wie die Darstellung derselben Szene bei Ps. Symeon zeigt.

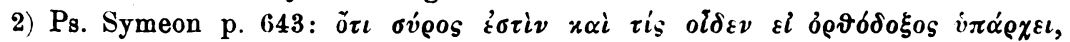

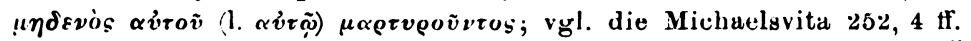

3) Raoulaina (s. u. S. 87 Anm. 1) p. 223, offenbar nach alter Utberlieferung; die Michaelsvita nennt vier Jahre; nach ihrer Indiktionsangabe müBte man den Tod auf 11 . Oktober 845 berechnen. 845 war der 11 . Okt. ein Sonntag wie 851.

4) Aufgenommen in die Vita des Metaphrasten c. 23--31 MSG 116, 67:2 lis 680 .

5) Theoph. cont. 160 f., Kedr. II 149 f.; Ps. Symeon 653; Glykas 539.

6) Leider liegt die Chronologie der Patriarchen von Jerusalem für diese Zeit noch sehr im argen, obwohl seit Papebroeks Arbeit in AS Mai III (1680) und Le Quiens Oriens Christianus III (1740) viel neues Material, besonders durch Papadopoulos-Kerameus, Analecta I 231-307 (1891) aus Dositheos und III (1897) 1-86 aus Maximos Symaios und 123-333 aus Prokop von Nazianz hinzugekommen ist. Thomas wird als Topoteretes des Patriarchen Elias auf der Synode von 787 erwähnt bei Georgios mor. p. 7£9, 16 de Boo: (nack 'Theophanes 461, 4 war Thomas der Vertreter Alexandriens und wurde Erzbischof von Thessalonich; Jerusalem 
nach Byzanz werden verschieden angegeben. Genesios p. 74 und der Fortsetzer des Theophanes III 15 (p. 106 Bonn) erwähnen neben der Stigmatisation der Graptoi auch die Verbannung Michaels. Theodor von Studion beglückwünscht ihn in einem wohl erst unter Michael (also 821 oder später) geschriebenen Brief zu seinen Leiden (ep. II 213 p. 1640). Dann dürfen wir wohl der Vita glauben, daB er bei der Restitution 843 die Leitung des Choraklosters (wieder, fügen wir hinzu) übernahm, und wenige Jahre später, am 20. Dez. 845, 85 Jahre alt starb.

Wir besitzen nun außer den bisher ausschlieBlich verwendeten Chronistennachrichten reichliches hagiographisches Material über diese drei Männer, das aber, wie sich gleich zeigen wird, nur mit großer Vorsicht aufzunehmen ist: es sind zwei erst neuerdings durch Th. Schmitts prächtige Publikation über das Chorakloster ganz bekannt gewordene Michaelsviten $^{1}$ ), ein Leben Theodors von dem Metaphrasten ${ }^{2}$ ), eine

wäre gar nicht vertreten gewesen); ob or mit dem Arzt in der Sabaslaura (mart. der 20 Sabasmonche v. J. 796 AS März III 20) identisch ist, mag dahingestellt bleiben, Arzt war er und Kleriker in Jerusalem (Leontios vita s. Stephani Sab. 136, AS Juli III 588): er war Patriarch 807, wie aus seiner Gesandtschaft an Karl d. Gr. (Annales regni Franc. ed. Pertz-Kurze 1895 p. 123) hervorgeht; 809 korrespondiert er mit Papst Leo in Sachen des fränkischen Symbolstreites, der durch lateinische Mornche auf dem Ölberg auch in Jerusalem zu Unfrieden führte; den Kampf eroffnet ein Sabasmönch Johannes; s. das Schreiben der Ölbergmönche an Papst Leo und dessen Brief an Karl d. Gr. MG epist. V 64-66. 66-67, speziell 67, 4. 817 (oder 819) und 821 korrespondiert Theodor von Studion mit ihm (ep. II 15 und 121, vgl. M 194). Die ihm in allen Jerusalemer Listen gegebenen 10 Jahre sind also zu wenig. Nach der einen Jerusalemer Liste folgte er direkt anf Elias (Prokop III 128); die andern fügen einen Georg ein, was durch die vita 8. Stephani Sab. 49 (Juli III 561. 529) und Alkuins ep. 210 p. 350 bestätigt wird: dieser Georg muß unter dem Patriarchen von Jerusalem gemeint sein, dessen Fésandtschaft die Annales reg. Franc. p. 108 z. J. 799 erwähnen (der ungenannte Mönch hieß wohl Leo, s. epist. V 66); er ward Anfang 800 zurückgesandt mit dem Priester der capella Palatina Zacharias; dieser traf am 23. Dez. 800 wieder bei Karl in Rom ein, begleitet von zwei Mönchen aus Jerusalem, die Karl im April 801 zurücksandte.

1) Bulletin de l'institut archéologique russe à Constantinople XI 1906; KahriéDjami I. Histoire du monastère Khora. Architecture de la mosquée. Mosaiques des narthex. p. 227-259 vita $A$ aus Athous Pantokr. 13 und Genuens. 33; p. 260 -279 vita B aus Vatic. gr. 1085 und Monac. gr. 10. Auszüge aus A gab schon

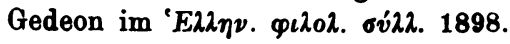

2) MSG 116, 653-684 nach Combefis. Zock (bei Wetzer und Welte KL ${ }^{2}$

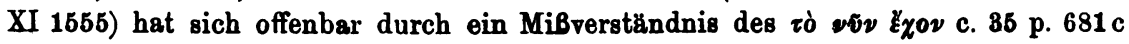
(in dieser Zeitlichkeit) verleiten lassen, diesen Tert, der sicher metaphrastisch ist (Fhrhard, Festschrift 60), noch zu Lebzeiten des Theophanes entstanden sein zu lassen. Das gilt nicht einmal von dem vormetaphrastischen Text sicher. 
Lobrede auf Theophanes von Theodora Raoulaina Kantakuzene Paläologina $^{1}$ ) und etliche Synaxarnotizen. ${ }^{2}$ )

Von jenen beiden Michaelsviten ist die jüngere lediglich eine aus AnlaB eines Neubaues der Chorakirche durch Theodoros Metochites von seinem Freund Nikephoros Gregoras verfaBte Neubearbeitung der älteren, ohne jeden selbständigen historischen Wert. Fast aus derselben Zeit stammt die Theophanesvita der Raoulina, die außer dem Theodortext (wohl dem metaphrastischen) sicher auch eine Michaelsvita kennt.

Auf der älteren Michaelsvita beruht so ausschlieBlich die Verbindung jener drei Männer zu einer geistlichen Familie derart, daß die beiden Graptoi schon als junge Männer von 25 bezw. 22 Jahren im Sabaskloster Schüler Michaels geworden seien und ihn dann zeitlebens begleitet hätten. Davon wissen weder ihr Brief, noch der Metaphrast, noch die aus dem vormetaphrastischen Leben der Graptoi schöpfenden Synaxartexte, noch endlich die Chronisten etwas: Genesios und der Fortsetzer des Theophanes erwähnten unmittelbar nach der Exekution der Graptoi das Exil Michaels, aber ohne jede Andeutung eines Zusammenhangs. Auch nach der Michaelsvita laufen die Martyrien des von einem Sabasmönch Job begleiteten Michael und der beiden Graptoi zwar parallel, aber Gefängnisse und Verbannungsorte sind fast immer verschieden; unter Leon dem Armenier sitzt Michael im Phialagefängnis in Konstantinopel, die Brüder sind im Pontos exiliert, selbst als die Regierung Michaels ibnen den Aufenthalt in Klöstern nahe der Hauptstadt erlaubt, vereinigen sie sich nicht, sondern Michael geht ins Plusiadoskloster am Olymp, die Brüder ins Sosthenion am Bosporus. Unter Theophilos sitzt Michael wieder im Praetoriumgefängnis zu Konstantinopel, während jene ins Exil nach Aphusia gehen. Nar einmal berühren sie sich, als die Brüder nach ihrer Exekution auf kurze 'Zeit in dasselbe Gefängnis kommen, ohne jedoch Michael zu sehen; er schreibt ibnen (p. 246). Die Theodorüberlieferung weiß zwar von einem ungenannten Lehrer der zwei, aber sie hebt vielmehr ihren auch ins Sabaskloster eingetretenen Vater Jonas hervor: in der Michaelsvita verschwinden diese Gestalten alle hinter dem einen Michael.

1) Papadopoulos-Kerameus, Analecta Hierosolym. Biblioth. IV (1897) 185-223, lazu V 397-399. Raoulaina ( $†$ 1301) spielt 187, 20. 197, 22 auf die vorübergehende Enion mit Rom unter Michael Paläologos und Bekkos 1277-1283 an.

2) Synaxarium eccl. Const. ed. Delehaye p. 130 (Oct. $11^{3}$ Theophanes), 35: (Dez. $28^{2}$ 'Theodor; auBer $\mathrm{S}^{*} \mathrm{~B}^{*} \mathrm{Db}$ alle zum 27. Dez.), dazu p. 65 (Sept. 21 ${ }^{2}$ ) Jonas uder Joanas, der Vater der Graptoi (vgl. Papadopoulos-Kerameus IlI 4 Anm. 2). DaB die Brüder erst unter Theophiles nach Byzanz kommen, von Patiiach Elids geechickt, muß auf falscher Verkürzung beruhen. 
Wichtiger aber ist: die alte Theodorvita lieb, wie wir aus dem Synaxar und dem Metaphrasten erschließen können, in Übereinstimmung mit der einen Gruppe der Chronisten Theodor im Exil sterben und von Theophanes in einem hölzernen Sarg beigesetzt werden, bis ihn nach langer Zeit ein Frommer von Apamea nach Chalkedon überführen läBt. Theophanes scheint in Nikaia, seinem Bischofssitz, gestorben und beigesetzt worden zu sein. Die Michaelsvita dagegen läBt. (wie jene eine Gruppe der Chronisten) beide Brüder die Restitution erleben und erst Theodor, dann auch den Erzbischof von Nikaia Theophanes in den Armen ihres greisen Lehrers im Chorakloster sterben und dort beigesetzt werden. $\mathrm{DaB}$ dies sekundär ist, liegt auf der Hand. Ist es einfach die gemeinsame Herkunft aus Palästina, die den Verfasser der Michaelsvita bewogen hat, durch die Verbindung seines Heiligen mit den berühmten Graptoi seinem nicht eben reichen Stoff einige interessante Züge zu geben (die ganze Episode des Verhörs vor Theophilos und der Brandmarkung, aus dem Brief der Graptoi geschöpft, erweist sich als der eigentlichen Michaelsüberlieferung fremde Einlage), oder besaB zu seiner Zeit das Chorakloster wirklich die Leiber derGraptoi neben den Sarkophagen des Patriarchen Germanos und des Synkellen Michael?

Wie dem auch sei, die Michaelsvita ist in ihrer Glaubwürdigkeit stark diskreditiert; sie muB beträchtliche Zeit nach Michaels Tod $\left.(845)^{1}\right)$, immerhin aber noch im 9. Jahrh. verfaßt sein, da das Synaxar sie bereits benutzt. ${ }^{2}$ ) Der Verfasser gesteht selbst, daB er ganz auf Berichte anderer angewiesen war (p. 258, $30 \mathrm{ff}$.) und vielfach aus Briefen schöpfte $(227,11.232,9)$. Die verführerisch exakten Daten sind trügerisch. ${ }^{3}$ ) Für uns aber ist sie aus dem Grunde höchst interessant, weil

1) In bezug auf diesen bietet sie arge Widersprüche: Michael soll ihn zehn T'age zuvor durch Offenbarung erfahren haben $(255,12)$; er benutzt diese zu Abschiedsbesuchen beim Patriarchen und im Kaiserpalast! Bei jenem bleibt er fünf Tage $(257,10)$; ins Kloster zurïckgekehrt, hält er am Sonnabend den 19. Dez. (was nur auf 845 paBt), in der Kapelle des Ignatius die Vigil auf dessen Fest $(258,3)$; am anderen Morgen verabschiedet er sich in seiner Zelle von den Mönchen und stirbt - am 4. Januar. Auf den 4. Jan. ist der Text auch in beiden Hss der Vita A gesetzt. Das Synaxar hat die Sache richtiger verstanden, wenn es seiner besten Form nach als Todestag den 20. Dez. nennt (s. die folg. Anm.)

2) P. 324 Dez. $18^{8}$ nach $S^{*} D^{*} B^{*}{ }^{*}$ (so auch Raoulina 219,18 und die Überschrift der Vita B, also Zougen des 13./14. Jahrh.); HPF*C* zum 20. Dez.; Bb zum 19. Der aus $\mathrm{Fb}$ mitgeteilte Text ist viel ausführlicher und besser als der aus $S$.

3) Schon das macht einen guten Eindruck, daB der Verf. gesteht, die Namen der Eltern nicht zu kennen 227, 15; er weiB aber, daB Michael dreijährig dem Patriarchen zugeführt und zum Anagnost(!) geweiht wurde 228, 14; fünfund- 
sie nicht nur Michaels notorische Beziehungen zu Methodios deutlich hervorhebt, sondern auch eine Verbindung mit Theodor von Studion herstellt.

Sie weiß allerlei Motive für Michaels Kommen nach Jerusalem: zunächst erwähnt sie Michaels Sehnsucht die Apostelgräber in Rom zu besuchen, dann die Bitte des römischen Papstes an den Patriarchen Thomas von Jerusalem, ihm in dem durch die Franken angeregten Symbolstreit weise und orthodoxe Männer zu Hilfe zu senden ${ }^{1}$ ), zu-

zwanzigjährig tritt er in das Sabaskloster 229, 27; achtzehn Jahre übt er sich im Fasten 229, 35, zwölf Jahr bekleidet er Klosterämter 230, 8 (vgl. die Vita des Sabaiten Stephanos c. 184 AS Juli III 610), nach zwei Jahren priesterlicher Funktion 230, 20 zieht er sich als Hesychast zurück. Theodor und Theophanes kommen fünfundzwanzig- und zweiundzwanzigjährig zu ihm 230, 30. Mit fünfzig Jahren wird er Synkelle 231,15: die Bestimmtheit dieser Daten der Jugendgeschichto steht in einem merkwürdigen MiBverhältnis zu den ungenauen Angaben der Folgezeit: genau gegeben ist 234,8 das Datum der Ankunft in Konstantinopel Mai Ind. VII = 814 (also unter Leon, aber vor Ausbruch des Bilderstreits); das stimmt zu sechs Jahre bis Leons Tod (237, 31); die Regierungszeit Michaels ist nicht genannt. Unter Theophilos lange in verschiedenen Kerkern - hier wird nur zweijährige Krankheit erwähnt 238,20. Ganz genau sind dann auch wieder die Angaben über das Martyrium der Graptoi 8. Juli Ind. XIV $=836$ treffen sie in der Hauptstadt ein, 241, 15, tags darauf Verhör vor dem Kaiser, vier Tage später vor dem Präfekt, 18. Juli das Einbrennen 246, 27; eine Woche bleiben sie dann noch im Gefängnis 248, 2. Theodors Tod wird nach Theophanes' Weihe auf den 27. Dez. gesetzt, 70jährig 252, 21; Theophanes' Tod nach vierjährigem Bistum auf 11 . Okt. ind. IX $=845,67$ jährig 252,32. 253, $14 \mathrm{ff}$. Michaels Tod - etwa 85jührig 255,3 auf 20. Dez. 845 (s. S. 88 A. 1). Die Daten widersprechen sich: wenn Theophanes drei Jahre jünger sein soll als Theodor, so müBte ihr Tod bei 70 und 67 Jahren gleichzeitig sein! Man sieht die Berechnung. Bis 11. Okt. 84ら kommen nie vier Jahre Bistum, geschweige acht (wie Raoulaina sagt) heraus. Auch die genauen Daten aus Michaels Jugend fügen sich nicht zu den ø0 Jahren; die einzigen Daten, denen man trauen darf, sind: Mai 814 Ankunft in Konstantinopel (für Michael allein), 836 Martyrium der Graptoi, 845 Tod Michucls.

1) Tatsächlich verhielt sich die Sache recht anders: der Streit war von Jerusalem aus angeregt, wo fränkische Mönche auf dem (j)lberg mit ihrem filioque im Symbol AnstoB gegeben hatten: Führer der Gegner war ein Sabasmönch Johannes. Die Sache kam 808 an Papst Leo, der sie weitergab an Kaiser Karl; dieser lieB x09 auf einer Synode von Aachen zugunsten der Franken entscheiden; der Papst erkannte zwar die Lehre als korrekt an, wollte aber von einer Einfügung ins Symbol nichts wissen und protestierte feierlich durch Aufstellung der silbernen 'Tafeln mit dem reinen Symboltext (vgl. Hefele, Konziliengesch. " III 749 ff., Kattenbusch, Konfessionskunde I 324, Loofs Symbolik I $48 \mathrm{f}$, bes. Hauck, Kirchengesch. Deutschlands II 333-337). Die Darstellung der Michaelsvita mit dem im Orient Hilfo suchenden Papst ist charakteristisch byzantinisch: die Betonung, daB der Papst Leo der Ketzerei der großmäuligen Franken sich widersetzt habe, erinnert an Photios, De spir. s. myst. 87; can. 1?, ep. I 13, 8. 24, 5, MSG 102, s76 f. 396. 725. 800 . 
gleich aber das Begehren des Patriarchen, daß der Papst ihm finanzielle Hilfe und Deckung der von den Arabern der Grabeskirche auferlegten schweren Kontribution gewähren solle. ${ }^{1}$ ) Diesen Doppelzweck soll eine Gesandtschaftsreise Michaels nach Rom erfüllen; dabei aber soll er über Konstantinopel gehen und hier Kaiser Leon und seinem . Patriarchen oder vielmehr Parteiführer ${ }^{2}$ ) Theodot ein Synodalschreiben der Jerusalemer überbringen und sie von ihrer Häresie zu bekehren suchen. „Denn der heilige Bekenner Theodor, der Abt von Studion (so fährt die Vita fort), hatte, unter Kaiser Nikephoros in den Orient verbannt, dem vorhergenannten Patriarchen von Jerusalem einen Brief gesandt, er möge doch helfen und mit ihm vereint für die Kirche Gottes zu Konstantinopel kämpfen, der von seiten der gottlosen bilderfeindlichen Häretiker Gefahr drohe." ${ }^{\text {) }}$ ) Hier sind zunächst zwei Daten aus dem Leben Theodors verwechselt: seine Verbannung auf die Prinzeninsel 809-11 unter Kaiser $\mathrm{N}_{\mathrm{i}}$ kephoros wegen des zweiten moichianischen Streites und sein Exil im Thema Anatolikon in Bonita unter Leon dem Armenier wegen des Bilderstreits (819). Das erste Datum paßt etwa zu den andern beiden Motiven der Reise: die Korrespondenz mit Leo von Rom fällt 808/9; der Arabereinfall 809. Aber der Bilderstreit beginnt erst 815 und Theodors Briefe an den Patriarchen von Jerusalem und die Äbte der Lauren (ep. II 15. 16.17 p. 1160 ff.) sind erst 817 oder gar 819 geschrieben ${ }^{4}$ ), wir besitzen noch Theodors Dank für die Antwort des Patriarchen Thomas (ep. II 121 p. 1396). Hier ist von einem Boten die Rede, der aber wieder zurückgeht: kein Wort von der Entsendung Michaels oder der Graptoi. Man wird - wie immer über die andern Motive der Reise Michaels zu denken sein mag - den

1) Sehr charakteristisch für diese Orientalen! Sie bieten Orthodoxie und verlangen Geld!

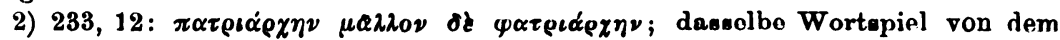
Ikonoklasten Konstantin $764-766$ bei Stephanos in der vita Stephani iun. MSG $100,1112$.

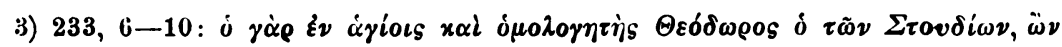

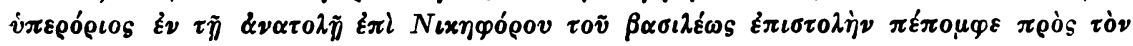

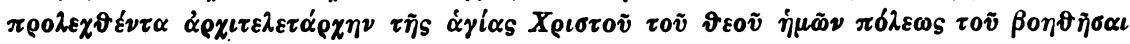

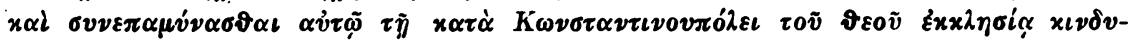

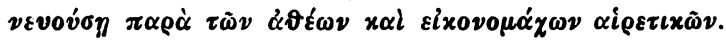

4) Baronius setzt die vier offenbar gleichzeitig gesandten Briefe an die Patriarchen von Rom, Alexandrien, Antiochien und Jerusalem 817, das erste Jahr des Papstes Paschalis, dessen Namen der erste trägt. Die Vita setzt diese Schreiben nach Bonita, Theodors zweitem Exilsort, im Thema Anatolikon (vgl. ep. M. 10 p. 10), wohin er wohl erst nach Jahresfrist, vielleicht erst 819 von Metopa aus überführt wurde. Das paBt auch besser dazu, daB der Dank an Thomas von Jerusalem erst nach dem Regierungswechsel 821 geschrieben ist. 
Auftrag an den bilderfeindlichen Kaiser als legendär, vor allem aber die Hineinziehung des Studiten Theodor als tendenziös zu beurteilen haben: er sollte verherrlicht werden. Das ist um so auffallender, als gleichzeitig nicht nur Methodios, sondern auch jener Einsiedler Ioannikios recht auffällig hervorgehoben werden, in dem wir noch einen heftigen Feind der Studiten kennen lernen werden: die Vita erzählt p. 249, daB sich bei der Restitution der Orthodoxie alle Blicke auf Michael als den für den Patriarchenstuhl geeigneten richteten - natürlich! -, Michael aber weist das aus Bescheidenheit zurück und veranlaßt die Kaiserin und die Synode bei dem Einsiedler Joannikios ${ }^{1}$ ) anzufragen, wer der von Gott zum Hirten seiner Herde bestimmte Mann sei; der sendet auf Grund göttlicher Offenbarung einen Stab an Methodios! Auch diese Episode war in der Michaelsvita nicht nötig, muB also dem Verf. sonst von Bedeutung gewesen sein. Theodor und Joannikios, die Repräsentanten zweier feindlichen Richtungen unter den Orthodoxen durch Michael um Methodios friedlich geeint: das ist die Tendenz! Als Patriarch tritt Methodios dann gegen Ende der Michaelsvita stark in den Vordergrund: er macht Michael zu seinem Synkellen und lebt in innigster Gemeinschaft mit ihm - Gleiches lesen wir in anderen Viten von anderen Heiligen!

Die Verbindung Michaels mit Methodios und Joannikios hat mehr historischen Sinn als die mit Theodor. Denn wenn auch diese Palästinenser Beziehungen zum Westen hatten ähnlich wie Theodor, aber mehr noch Gregorios Dekapolites, so waren sie doch Vertreter eines ganz sndern Mönchsideales als der Abt von Studion: in den Lauren hielt sich das System der nur zum Gottesdienst vereinigten Einsiedler bezw. Einsiedlerfamilien, während Studion unter Theodor das Prototyp des streng koinobitisch organisierten Klosters im Sinne des h. Basilios geworden war. ${ }^{2}$ )

Die Michaelsvita muB im ('horakloster oder doch im Interesse desselben entstanden $\operatorname{sein}^{3}$ ); vielleicht kann man dann folgern, daB damals intime Beziehungen zwischen Chora und Studion bestanden, wenn man

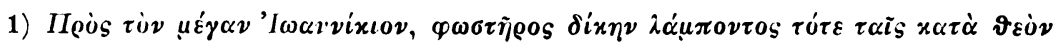

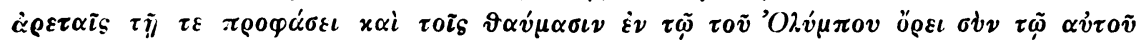

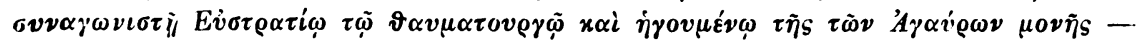
dies ist offenbar nach dem Tode beider, also beträchtlich nach 846 geschrieben.

2) Holl, Enthusiasmus und BuBgewalt beim griechischen Mönchtum 1898, $171 \mathrm{ff} .193 \mathrm{ff}$.

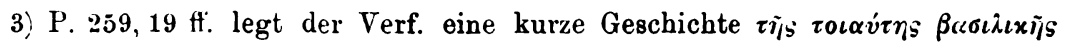

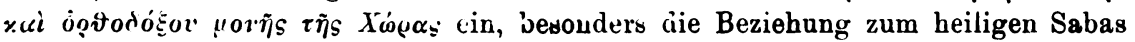
betonend. 
nicht den Absatz über Theodor einer studitischen Überarbeitung zuschreiben will.

Im 14. Jahrh. hat man für alle diese Beziehungen natürlich kein Verständnis mehr: Nikephoros Gregoras läBt sie fort (p. 269. 275), ebenso Raoulaina, die Symbolstreit in Rom und Bilderstreit in Byzanz ganz auf gleiche Stufe stellt, wenigstens die erste: die Hereinziehung Theodors (p. 199). In ihrer Lobrede auf Theophanes muB sie natürlich behaupten, daB die Kaiserin Theodora nächst Michael an Theophanes als geeignet für den Patriarchenstuhl gedacht habe, praktische Folgen hat das nicht, da Theophanes natürlich ablehnt. Dann lenken Michael und Ioannikios gemeinsan die Aufmerksamkeit auf Methodios: von der kirchenpolitischen Bedeutung ist dabei nichts mehr zu spüren.

In naher Beziehung zu Niketas von Medikion und den Graptoi steht der Heilige Symeon von Lesbos ( $\dagger 1$. Febr. 843?), der nach dem Tode des ältesten Bruders David als Stylit in seiner Heimat lebt, von dort durch' den bilderfeindlichen Bischof nach Lagoussai bei Troas verbannt, zur Zeit des Thomasaufstandes (822/4) und der Maureneinfälle nach Byzanz kommt. Der Biograph ${ }^{1}$ ) erwähnt ausdrücklich den intimen Verkehr mit Niketas von Medikion $(233,22)$, Besuche in Sigriane und Kyzikos. Dann erzählt er nach allerlei Wundern die Einkerkerung des damaligen Archidiakons Methodios als einziges Martyrium unter Michael, dem sich dann unter Theophilos die vieler Bischöfe und Äbte, darunter Symeons, anschlieBen: Bischof Euthymios von Sardes wird zu Tode gegeiBelt. Nur der Fürsprache der Kaiserin Theodora verdanken die gefangenen Bilderfreunde, daB sie nicht ins Meer versenkt werden (238); aber vor den Kaiser geführt, werden Symeon gepeitscht, Theodor und Theophanes gebrandmarkt, alle zusammen nach Aphusia verbannt, wo Symeon (nach Auffassung seines Biographen) das Haupt der Schar ist. Nach Theophilos' Tod wird er von der frommen Kaiserin samt allen Exilierten in die Hauptstadt zurückberufen, wohin er auch seinen Bruder Georg von Lesbos kommen läBt. Die Kaiserin ehrt ganz besonders diese beiden Brüder und Methodios. Symeon aber will ihr nicht den Gefallen tun, in die Absolution des verstorbenen Kaisers zu willigen: so verlassen alle die erzürnte Kaiserin, und bereits triumphieren die Ikonoklasten. Da wird Symeon durch die vereinten Bitten der andern bewogen, nachzugeben ${ }^{2}$ ), und während Methodios in öffentlicher Dispu-

1) Acta graeca 8s. Davidis, Symeonis et Georgii Mitylenae in insula Lesbo, ed. H. Delehaye, Anal. Bolland. XVIII 1899, 209-259. Die Biographie ist jedenfalls nach 855 geschrieben (s. p. 252, no. 2.)

2) Die Akten wissen nichts von dem in der Legende zum Fest der Orthodoxie berichteten Wunder göttlicher Absolution darch Auslöschen des Namens. 
tation die Ikonoklasten aus dem Felde schlägt, besiegt der ungebildete Symeon in einer Privataudienz vor der Kaiserin den ruhmredigen Patriarchen Joannes, worauf auf Symeons Vorschlag (!) Methodios zum Patriarchen erwählt wird. Symeon wird sein Synkelle, zugleich Abt von Sergios und Bakchos, sein Bruder Georgios Bischof von Mitylene, wo schlieBlich alle drei Brüder beisammen ruhen. - So viele Namen gerade in dieser üußerst wertrollen, an konkreten Zügen reichen Biographie genannt werden: Studion und sein großer Abt fehlen ganz. Theodor starb allerdings bald, nachdem Symeon nach Byzanz gekommen war. Es scheint, daB sein Nachfolger Naukratios bei den Vorgängen des Jahres 843 keine hervorragende Rolle gespielt hat. Aber es kann auch sein, daB dies Ignorieren den Unversöhnlichen gilt, gegen die Methodios gerade damals anzukämpfen hatte. Symeon und noch mehr sein Bruder Georg waren, wie die Geschichte von des Kaisers Absolution zeigt, zugänglicher.

Wir beschließen diese Reihe mit dem Einsiedler Joannikios vom Berge Olymp († 4. Nov. 846). Es ist ein ganz anderer Typus des Heiligen als Theodor der Abt von Studion oder der gelehrte Mönch Theophanes von Sigriane: erst 18 Jahre Soldat, dann Einsiedler, der sich in der Nähe verschiedener bithynischer Klöster herumtreibt, glänzt er nicht durch Bildung (er weiB nur 30 Psalmen auswendig) ${ }^{1}$ ), umsomehr aber durch seine prophetische Gabe: Wunder und wunderbare Vorhersagungen, das ist der Inhalt seiner Viten, von denen wir zwei unter den Namen zweier Schüler Petrus und Sabas und die auf der letzteren ruhende Paraphrase des Metaphrasten besitzen. ${ }^{2}$ ) Dennoch sind diese für uns von höchstem Interesse: denn nirgends schauen wir so in die verschiedenen Strömungen innerhalb der Kirche, in den heftigen Wider-

Dafür ist hier ein ganz analoges Wunder betreffs eines kleinasiatischen Beamten Hesychios, der Georg um Absolution bittet, mitgeteilt (242).

1) Sabasvita 9 p. 340.

2) Die beiden Viten herausgegeben von van den Gheyn in AS Nor. II 1 . (1894), 384-435, 332-384; der Metaphrastentext MSG 116, 35-92. DaB dieser zum Metaphrastencorpus gehört, hat gegen van den Gheyns innere Kritik $313 \mathrm{f}$. Ehrhard Festschrift 55 aus der Überlieferung bewiesen; daB er auf der Sabasvita ruht, hat van den Gheyn gezeigt. Aus dem Sabastext ist auch die Synaxarlektion geflossen; deren ursprüngliche F-Form van den Gheyn 311 mitteilt (leider mit S-Lesarten durchmischt), während die von Delehaye abgedruckte S-Forn eine recht verständnislose Verkürzung darstellt. Fine Vita des Joannikios (leider können wir nicht erkennen, welche Form) nennt auch der Mönch Methodios im 13. Jahrhundert MSG 140, 792, was van den Gheyn entgangen zu sein scheint. Joannikios' Anteil an Methodios' Wahl wird auch von Niketas Paphlagon in der Vita des Patriarchen Ignatios erwähnt und zu einem entscheidenden Anteil auch an der Wah! des Ignatios verdoppelt MSG 105, $500 \mathrm{f}$. 
streit zwischen den Studiten und den Anhängern des Methodios. Theodor von Studion hatte Beziehungen zu diesem Joannikios gehabt: es wird uns erzählt, wie er und andere Äbte den berühmten Einsiedler. besuchen $\left.(825)^{1}\right)$; hierauf scheint ein Brief Theodors an einen Ein-

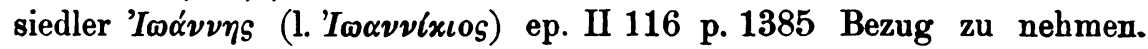
Theodor erwähnt Joannikios auch in seinen Katechesen als Vertreter einer anderen Form von Askese, die er aber seinen Mönchen als nicht höher und begehrenswerter hinstellt: das klösterlich organisierte Mönchtum steht über dem vagierenden Eremitentum; es kämpft für die Heiligtümer der Kirche, während dies nur der Ruhe $(\dot{\eta} \sigma v \chi \ell \alpha)$ nachgeht. Wenn Theodor dabei die scharfen Worte gebraucht: ,jener wird nicht verfolgt, kommt nicht ins Gefängnis, wird nicht gegeißelt" "2), so darf man diese offenbar in der Zeit des heftigen Bilderstreits gesprochenen Worte nicht abschwächen durch Vergleich der überschwänglichen Lobsprüche auf den Moses gleich strahlenden Eremiten in dem nach dem Besuche 825 geschriebenen Brief: sie werden bestätigt durch den Bericht der Biographen, daB Joannikios sich bei Beginn der Verfolgung ouf einen entlegeneren Berg zurückzog, weswegen jene sich verpflichtet fühlen, den Verdacht der Feigheit und Martyriumsflucht von ihm fern zu halten. ${ }^{3}$ ) In die gleiche Richtung weist auch, was jene von Joannikios' Bekehrung, von der Häresie der Ikonomachen, der er in seiner Jugend als Soldat gehuldigt hat, und seinen späteren Bemühungen erzählen, einen Verwandten, der den alten häretischen Irrtum noch festhielt, für den Heiligen- und Bilderkult zu gewinnen. ${ }^{4}$ ) Es sind apologetische Züge, die die Rechtgläubigkeit dieses etwas sonderbaren Heiligen ins volle Licht setzen sollen. Der Biograph Petrus glaubt sogar seinen ja wenig gebildeten Heiligen vor dem Vorwurf mangelhafter Orthodoxie schützen zu müssen, indem er ihm ein langes theologisches Glaubensbekenntnis, das er einer Schrift des Patriarchen Nikephoros entnimmt, in den Mund legt.") Beachtenswert ist auch, daB Joannikios

1) Petrusvita 36 p. 404 c, Sabasvita 28 p. 357 b, Metaphr. 32 p. 68 ab.

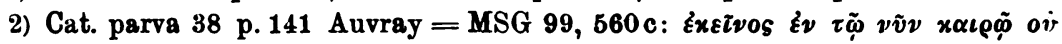

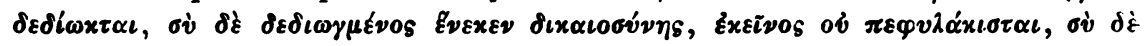

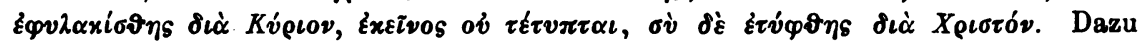
van den Gheyn 328; der Joannikios in ep. I, 41 p. 1060 a ist natürlich ein anderer, ein Stadit.

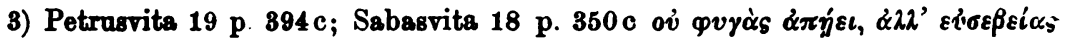

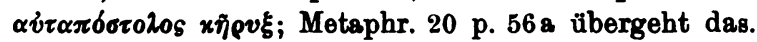

4) Die Bekehrung nur bei Sabas 5 p. 337 a = Metaphr. 4 p. 40, der c. 28 p. 61 lange Reflexionen über eine solche Bekehrung anstellt; Petrus schweigt davon; der Bekehrungsversuch an dem Verwandten bei Petrus 35 p. 408 , Sabas 27 p. 356 f.

5) Petrusvita 65 p. 417-421 = Niceph. apol. I 18-23 MSG 100, 580 d-589d. 
eine besondere Verehrung für Theophanes von Sigriane nachgesagt wird, an dessen Grab er pilgert. ${ }^{1}$ ) Von entscheidender Bedeutung aber ist Joannikios' Stellung zu Methodios, dem er seine Erhebung auf den Patriarchenstuhl vorhersagt, den er in den Wirren seines Patriarchates tröstet und stärkt, den er noch kurz vor ihrem beiderseitigen Ende zu sich kommen läßt, um vor großer Versammlung alle seine Feinde zu anathematisieren, ihn aber mit den drei großen Kirchenfürsten Basilios, Gregor und Chrysostomos gleichzustellen. ${ }^{2}$ ) Von hier aus versteht sich die geradezu leidenschaftliche Erbitterung gegen die Studiten, die wir bei diesem Heiligen und seinem Kreise finden.

Zum Glück hat der Abt Eustratios von Agauron, Joannikios' nächster Vertrauter, mit der Aufzeichnung seiner Erinnerungen an den großen Einsiedler einen Mann betraut, der zwar literarische Bildung genug besaB, um die Vita nach allen Regeln der Kunst auszugestalten, aber weder von der rhetorischen Mode, Namen, besonders miBliebige, nicht zu nennen, angekränkelt, noch durch die klug politischen Erwägungen der Patriarchatskanzlei beeinfluBt war. Der Hesychast Petrus, der selbst vielfach bei Joannikios verkehrte, macht aus seines Heiligen und seiner eignen feindseligen Gesinnung gegen die Studiten durchaus kein Hehl. An drei Stellen macht sich dieser Zorn Luft: das erstemal bei dem Besuch, den Theodor mit andern ${ }^{3}$ ) dem h. Joannikios macht: als dieser dem einen der Gäste, dem Ökonom Joseph, sein baldiges Emde ankündigt, schmähen ihn darob die Studiten, die (wie der Verfasser sagt) immerfort Ärgernisse zu nehmen pflegen und sich über alle andern erhaben dünken, in Gedanken: den Tod eines Menschen wisse nur Gott voraus. Der Heilige, so erzählt Petrus, durchschaut ihren Sinn, schweigt fürs erste, nimmt sie dann aber beiseite, offenbart ihnen ihre Gedanken, straft and demütigt sie; und der Ausgang gibt ihm recht. $)$ Offenbar absichtlich ist hier von den Studiten, nicht von ihrem Haupt, Theodor, die Rede und jeder öffentliche Auftritt vermieden. Jener soll nicht getroffen werden, sondern seine Nachfolger, „die um Athanasios und Naukratios", wie es an den andern beiden Stellen heißt. Da handelt es sich zunächst um eine ganz ähnliche Voraussage, die Joannikios durch zwei Vertraute, Eustratios und Do-

1) Petrusvita 37 p. 405 ; Sabas 31 p. 360; Metaphr. 35 p. 69.

2) Petrusvita 69-71 p. $431 \mathrm{ff}$; Sabas 53 p. 382.

3) Genannt werden die Metropoliten Johannes von Chalkedon und Petros von Nikaia, beide auch in Theodors Korrespondenz vertreten, Theodors Sekretär Clemens (vgl. ep. II 90 p. 1342), der Oikonomos Joseph und sein Bruder: - selbst-

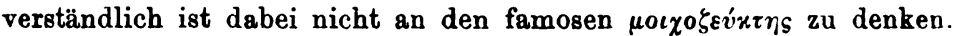

i) Petrusvita 36 p. 405. 
sitheos, einem Isaakis, Kurator eines Nonnenklosters in Konstantinopel, zukommen läßt: er soll schleunigst das Mönchskleid nehmen, denn er wird sterben. Da treten die Studiten dazwischen und hätten ihn durch Anzweiflung der Vorhersagung fast um sein Heil gebracht: dabei läBt sich Petrus zu folgender Invektive hinreißen: „Siehe da kamen auch die Studiten dazu, die um Athanasios und Naukratios, und wie es ihre Art ist, Unruhe zu stiften und zu erschüttern nicht nur die Kirche Gottes, sondern auch die, welche sich Gott hingeben, und ihre giftige Zunge zur Anklage gegen die Heiligen zu bewegen und sich allein zu empfehlen und ihr eignes Gek]äff als inspiriert anzupreisen, so betrojgèñ diese Betrüger auch jenes Weib (die Vorsteherin des Klosters), ja sie verdrehten und machten verächtlich die Worte des Heiligen, sie, die allen verächtlich und verhaBt sind, der Welt sozusagen eine Last, die undankbaren Geschöpfe, Gebilde des Bösen, sie hinderten, wie sie selbst meinten, die Errettung dessen, der zu Gott kommen sollte, und fast wäre er dem Tode unbuBfertig hingegeben worden, wenn nicht das Gebet des Heiligen, zu den Ohren des Herrn dringend, ihm noch eine ganz kurze Lebensfrist gewährt hätte“.1.) Auch hier also treten die Studiten der in den Einsiedlerkreisen gepflegten Wahrsagerei entgegen: der Kurator soll dem Kloster weiter dienen, während jene sagen, er soll für sein Seelenheil sorgen, da göttliche Prophetie ihm das nahe Ende ankündigt. Das sind allerdings total verschiedene Auffassungen von der Art der Religion und den Aufgaben des Menschen. Wir werden den Studiten nicht Unrecht geben können: sie vertreten in diesem Falle in mönchischer Form paulinisches Christentum, Joannikios eine unterchristliche Mantik; und die Verehrung, die sein Kreis diesem Heiligen zollt, grenzt an Vergötterung, wie denn zahllose mythologische Motive sich unter den von ihm erzählten Wundern finden, während die Studiten nur ihren großen Abt, den mutigen Bekenner feiern.

$\mathrm{DaB}$ freilich auch weltliche, egoistische Motive bei den Studiten mitwirkten, zeigt deutlich das dritte Beispiel: als noch die Ikonoklasten am Ruder waren, da kündete eines Tags Joannikios seinem vertrauten Eustratios die Wiederherstellung der Orthodoxie an. Es kam die Rede darauf, wer diese herbeiführen und die Kirche recht leiten könne: die einen rühnten die Studiten Athanasios und Naukratios und den Bischof von Nikomedien Johannes Katasambas ${ }^{2}$ ), die andern Methodios, andere

1) Petrusvita 57 p. 422.

2) van den Gheyn 433 sieht in diesem Johannes, von dem er einen ungenannten Bischof von Nikomedien unterscheidet, den ikonoklastischen Patriarchen Johannes VII Morocharzanios (21. April 834[837?]-12. Febr. 843), früher Abt von St. Sergios und Bakchos, dann Theophilos' Erzieher, auch Johannes Grammatikos, 
wieder andere. Joannikios aber entschied: Methodios sei der gottgewollte Mann. Und so kam es. Petrus erzählt: „Als durch Gottes Gnade die Häresie erstickt war und durch Gottes und der Engel and der Menschen Wahl, gemäB der von Gott eingegebenen Voraussage unseres Vaters, der höchstheilige Methodios auf den hohepriesterlichen Stuhl erhöht war, da stellte er die alte Schöne der Ökonomie Christi und den herrlichen Schmuck in den Kirchen Gottes wieder her. Und es war tiefer Friede in der ganzen Welt durch Christi Gnade und die Fürsorge des großen Patriarchen Methodios und die kostbaren Gebete unseres wundertätigen Vaters Joannikios. Diesen den Kirchen Gottes geschenkten friedlichen Zustand mochte der Feind alles Guten, der böse Dämon, nicht ertragen: so fuhr er in etliche ehrgeizige, dem Ansehen nach Greise, dem Sinn nach Schwätzer, die genannten miBgünstigen Studiten und ihren Genossen, den Kakosambas, die ihr alle als „Gefäße, bereitet zum Verderben“ (Röm. 9, 22) kennt; da er diese fand und ihre ungerechten und unheiligen Zungen zur Schwätzerei bewegte und einen sehr großen Teil durch sie an sich zog, brachte er über die Kirche Gottes durch sie Unruhen. Ihr kennt ja alle das unverschämte Gesicht der Männer und was sie gegen den großen Leuchter und Zeugen Methodios niedergelegt haben, ganz wie es jenem großen und wunderbaren Athanasios von den Schismatikern und Arianern geschah". $\left.{ }^{1}\right)$ Dies ist des Verfassers Urteil. Er läBt aber auch den Heiligen vor versammeltem Volk der Einsiedler zu Methodios dasselbe sagen: „Einst gebot der große Antonios seinen Jüngern, keine Gemeinschaft zu haben mit den Arianern, auch nicht mit den schismatischen Meletianern noch mit ihrer gegen Christus ankämpfenden Werkstatt.

Lekanomantis, Jannes genannt. Aber das ist eine ganz unmögliche Kombination: er muBte ja gestürzt werden, damit der Bilderkult wieder aufgerichtet werde; die Studiten waren seine schärfsten Gegner; selbat oin blinder Foind konnte diese beiden Widerparten niclt zusammenstellen. van den Gheyns Kombination hängt mit seiner falschen Anschauung von der Stellungnahme der Studiten zusammen, als hätten sie Methodios den Ikonoklasten gegenüber zu scharf gefunden. Johannes Katasambas (so schreibt die Handschrift an erster Stelle, und sicher mit Recht, vgl die Vita ss. Davidis, Symeonis et Georgii 27 Anal. Boll. XVIII 245, auch

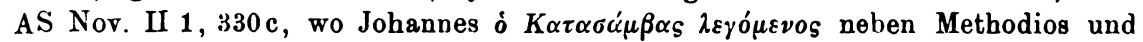
Joannikios als Genosse erscheint; Kakosambas, wie van den Gheyn nach den folgenden Stellen herstellt, ist offenbar eine der den Byzantinern so geläufigen Namensverdrehungen) gehört jedenfalls in den Studitenkreis: unter Theodors Korrespondenten gibt es eine ganze Anzahl Johannes; der Beiname findet sich, soweit ich sehe, nirgends. Er war offenbar schon 843 bei der Neuwahl eines Patriarchen Metropolit vou Nikomedien und wurde von Methodios zugleich mit den Studiten exkommuniziert und abgesetzt.

1) Petrusvita 69 p. 431.

Byzant. Zeitschrift XVIII 1 a. 8. 
So sage jetzt auch ich, der unwürdige, unwerte, nngebildete, von Gott getrieben: haltet euch alle fern von den gottlosen Häretikern und den ganz greulichen Studiten und ihrem Genossen, dem Kakosambas, der von dem Bistum von Nikomedien entsetzt ward, dem Duellanten und Kämpfer wider Gott, und von dem ganz unvernünftigen Eunuchen der Kirche von Kyzikos, die mit viel Geschwätz wider Gott und unsern regierenden Herrn Patriarchen Teden, ohne Furcht und Scheu vor Gott ... haltet euch fern von denen, die wider die Kirche Gottes solches wagen und sich nicht fürchten, den Leibrock des Gott Logos zu zerreißen, sondern ihn in viele Stücke reißen; wie sie sich auch unter den vorangegangenen Vätern und heiligen Patriarchen zu tun nicht gescheut haben, schon damals der Kirche Gottes ein Ärgernis, Söhne des Bösen, ein Unkraut." $\left.{ }^{1}\right)$ Joannikios deutet an, daB man seinen Namen benatzen werde, in Briefen die Eremiten zu verführen, und er protestiert feierlich dagegen - bezw. sein Biograph läBt ihn sich dagegen verwahren.

Hier ist hinlänglich klar als Motiv der Studitenopposition ihr eigner Ehrgeiz gekennzeichnet, und nach dem, was wir über Platon und Theodor bei der Neubesetzung des Patriarchenstuhls unter Nikephoros erfuhren ${ }^{2}$, werden wir es nicht nur für feindliche Unterstellung halten, daB sie für einen der Ihren, Athanasios oder Naukratios, oder für den Metropoliten Johannes von Nikomedien oder den Bischof von Kyzikos $^{3}$ ) den Patriarchenstuhl begehrten, und als dann Methodios obgesiegt hatte, sich durch scharfe Kritik seiner Patriarchatsführung, besonders der Bischofsweihen, rächten. $\mathrm{DaB}$ dabei der Vorwurf auf zu große Härte gegen die ikonoklastischen Priester (wie van den Gheyn annimmt) oder umgekehrt auf $\mathrm{zu}$ leichtfertige Beförderung solcher zu Bischöfen (so Mai) gelautet habe, stimmt nicht $\mathrm{zu}$ dem, was die Methodiosfregmente und die Methodiosvita, recht verstanden aber auch diese Joannikiosvita, uns lehren. Die Opposition ging gegen die einseitige Bevorzugung der Anachoreten, der Hesychasten, der ganzen in Joannikios' Person so trefflich charakterisierten Richtung der Frömmigkeit: Leute, die weltfremd, in dem großen Kampf um die Heiligtiimer der Kirche kaum mitgemacht hatten, den Fragen der Kirchenpolitik fernstanden und wenn man nur ihre stark superstitiöse Wahrsagerei und Wundertaten anerkannte, zum Paktieren gern bereit waren. Gerade die Vita des Joannikios lehrt uns, wie viele aus diesen Kreisen.

1) Petrusvita 70 p. 432.

2) S. oben S. 61 .

3) Dieser, ungenannt, nur als Eunuch bezeichnet. 
unter Methodios zu Bischöfen avanzierten.1) Auch an persönlichen Beschuldigungen gegen Methodios scheint es nicht gefehlt zu haben, darauf weist vielleicht schon der Vergleich mit Athanasios, jedenfalls die Heranziehung der Susannageschichte: nach dem Biographen Petrus hätte Methodios grade aus Joannikios' Schreiben den Anlaß geschöpft, gegen .jene Verleumder mit Bann und Exil vorzugehen. ${ }^{2}$ )

Ist diese Petrusvita offenbar bald nach dem Tode des Heiligen, unter dem Einflub des ihm geistesverwandten Abtes Eustratios von Agaurôn geschrieben ${ }^{3}$ ), so zeigt die sog. Sabasvita ein ganz anderes Gesicht; es sind dieselben Stoffe sogar vielfach in der gleichen Reihenfolge, sodaB an der Benutzung der Petrusvita durch "Sabas" nicht gezweifelt werden kann.") Ich möchte sogar weiter gehen, und "Sabas". trotz mancher selbständigen Züge in Inhalt und Anordnung lediglich als Umarbeitung der Petrusvita ansehen, die den Namen des Joannikiosschülers Sabas sich in absichtlicher Konkurrenz zu jener Petrusvita anmaBt. Sabas wird dort mehrfach genannt neben Petrus ${ }^{5}$ ); die Art, wie das hier wiederkehrt, schlieBt ihn als Verfasser aus. Der Bearbeiter ist ein Gelehrter, der mit seiner (hronologie prunkt ${ }^{6}$ ), sehr viele Namen bietet - ob immer richtige, ist unsicher ${ }^{7}$ ), vor allem ein Dogmatiker

1) Petros jetzt Metropolit von Sylaion; Petrusvita 68 p. 429; Sabasvita 43 p 369. Vgl. Georg von Mitylene, Symeons Bruder (oben S. 93); Theophanes Graptos von Nikaia (oben S. 85, bes. A. 2: die Proteste). In diese Reihe gehort wohl auch Basilios aus Athen, der von Methodios an stelle des Philosophen Leon auf den erzbischoflichen Stubl von Thessalonich erhoben wurde. Er ist der Biograph des rom Olymp zum Athos übersiedelnden Einsiedlers Euthymios des Jüngeren; vgl. AS Febr. I 242; was sich aus der Vita des Euthymios an Lebensdaten

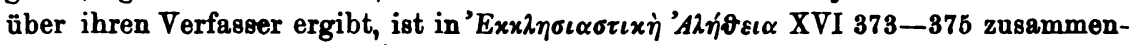
gestellt; vgl. L. Petit, in Échos d'Orient IV 221 (mir beides unzugänglich). Das Synaxar erwähnt Euthymios zum 4. Jan. p. 367 und Basilios zum 1. Feb. p. 439, beide ohne Text. $\quad$ 2) Petrusvitu 70 p. 432 a.

3) Petrusvita 12 p. 390 ; 59 p. 422 f. u. 8 .; auch von einer Äbtissin heiBt es 58 p. 422, daB sie noch lebt. $\quad$ 4) Vgl. van den Gheyn $316 \mathrm{ff}$.

5) Petrusvita 10 p. 389: Petrus und Sabas und Antonios begleiten Joannikios (fehlt bei Sabas); 13 p. 390 : Einer der Brüder, namens Sabas (= Sabas 14 p. 345). - Wenn „Sabas" 44 p. 370 mit „ich" von sich redet, so scheint das Nachahmung von Petrus 68 p. 428. Oder aber der Verfasser Sabas ist von dem Joannikiosschüler zu unterscheiden: er ist Schüler des Petrus von Atroa, dessen Leben er auch beschrieben hat 44 p. $370 \mathrm{f}$.

6) Er datiert alles nach Lebensjahren des Heiligen unter Angabe genauer Synchronismen der Kaiserregierungen, des Bilderstreits usf. Dabei befolgt er eine eigenartige Lebensalter-Einteilung nach 7 jährigen Perioden (z. B.6 p. 337): vgl. Byz. Z. XII $564 \mathrm{ff}$.

7) Die Art, wie er 14 p. 345 Abt Gregorios von Agauron, Eustratios, Sabas und Theophylakt zusammenstellt, macht stark den Eindruck, aus Petrusvita 10. 11. 13 
und Kirchenpolitiker von ganz anderem Schlage als jener Petros.1) Bei ihm spielt die Geschichte des Bilderstreits, die für Petros fast verschwindet, eine entscheidende Rolle. ${ }^{2}$ ) Dafür ist die Polemik gegen die Studiten einfach beseitigt: Theodors Besuch bei dem Heiligen wird erzählt, auch die Kritik, die an Joannikios' Voraussage des Todes geübt wird, aber der Verfasser spricht nur von „etlichen derer die mit zu Tische saßen, die einfältig und neidisch bei sich dachten: was redet dieser". Die biblisch eingekleideten Bedenken werden ausführlich theologisch widerlegt. ${ }^{3}$ ) In dem zweiten Fall sind es wieder nicht die Studiten, sondern nur „böse und verderbliche Männer“, welche die Äbtissin umstimmen, indem sie die Richtigkeit der Voraussage in Zweifel ziehen.") In dem dritten Fall endlich läBt der Verfasser die Aussagen über die Konkurrenten des Methodios einfach weg, und macht aus der nachfolgenden studitischen Opposition ein Eintreten etlicher für Zulassung der Ikonoklasten. ${ }^{5}$ ) In dem breit ausgeführten Schreiben des Joannikios an den als engelgleich verherrlichten Patriarchen Methodios läßt er den Heiligen von den schlechten Erfahrungen reden, die dessen Vorgänger Tarasios mit Zulassung solcher Ikonoklasten gemacht habe. Darum soll Methodios unerbittlich gegen die Ikonomachen ankämpfen. So wird aus dem Anathem über die schismatischen Studiten ein energisches Einschreiten gegen die Ikonomachen. Das Glaubensbekenntnis des Heiligen - eine freie Wiedergabe des bei Petrus aus Nikephoros genommenen - hat hier einen viel stärker anti-ikonomachischen Tenor. Auch bei Methodios' Besuch ist die Glorifikation dieses Patriarchen und die scharfe Verurteilung aller seiner Gegner die gleiche. Aber niemand, der nicht die Petrusvita vorher gelesen hat, würde darauf kommen, daB hier die Studiten gemeint seien: man denkt an die Ikonoklasten und ihre Freunde.

Auch vou Joannikios' eifrigstem Verehrer, dem Abt Eustratios von Agaurôn ist neuerdings eine ausführliche Vita oder richtiger Mirakelsammlung bekannt geworden. ${ }^{6}$ ) Er ist der Heilige des unendlichen Mit-

p. $389 \mathrm{f}$. zusammengelesen zu sein: andererseits kennt der Verfasser offenbar die Klostergeschichten dieser Zeit, die Namen der Äbte und Oikonomoi.

1) Er fühlt sich verpflichtet, das harmlose trinitarische Bekenntnis des Heiligen gegen den Vorwurf des Hăretischen zu schützen 10 p. 341; er gibt eine lange Antichristdarlegung 17 p. 348.

2) Sabasvita 3. 4 p: 334 f.; 17 p. 347 f.; 24 p. 365 ; 36 p. 365.

3) Sabasvita 28 p. 367 f. 4) Sabasvita 33 p. 362.

5) Sabasvita 46 p. 372.

6) Ed. Papadopoulos-Kerameus Analekta IV 867-400 nach Cod. a. 8ab. 242 ; diese anonyme Vita scheint in vielem Kopie nach der Subasvita des Joannikios, wenn man nicht die Erklürung, vorzieht, daB schon die mündliche tberlieferung 
leids: Sünder, die alle andern von sich stoßen, nimmt er noch zur Buße an. Seine Wunder sind fast alle Barmherzigkeitstaten. Von der hohen Kirchenpolitik ist in dem Leben dieses Heiligen nicht die Rede ${ }^{1}$ ), obwohl er mehrfach auch die Hauptstadt aufsucht ${ }^{2}$ ) und einmal auch vom Patriarchen empfangen wird: gerade an dieser, der einzigen historisch bedeutsamen Stelle ist leider das einzige bekannte Manuskript defekt. Man kommt fast auf den Gedanken, daB hier etwas Unliebsames etwa über Photios - gestanden haben könnte, was herausgerissen wurde. Bezeichnend ist, wie wenig der Bilderstreit, obwohl er in dies Leben hineinspielt, hervortritt: die fünf Heiligen von Agaurôn, denen sich der junge Eustratios anschlieBt, werden als eifrige Verehrer der Trinität bezeichnet ${ }^{3}$ ), in andern Kreisen würde man lieber ihre Bilder-

von beiden Heiligen gleiche Züge z. B. das in der Luft Schweben beim Gebet, das Durchschreiten eines reißenden Stroms u. a. m. bot. Dieselben Züge wiederholen sich bei Petros von Atroa, der nach der Sabasvita des Joannikios dessen Zeitgenosse war - die Datierung des Synaxars 13. Sept. p. 42 in die Zeit des Nikephoros und Staurakios und des Patriarchen Tarasios ist offenbar ein aus dem Anfang der Vita genommener Irrtum (Bab nennt statt Petros Andronikos, Bb zum 12. Sept. p. 37, aber das ist weitere Verwechslung). Uber Petros hat van den Gheyn AS Nov. II 1, $325 \mathrm{f}$. gehandelt, die Vita ist noch nicht gedruckt. Es lohnte sich diese Thaumaturgen des Olymp einmal im Zusammenhang zu behandeln. - Vgl. Synaxarium CPtanum 9. Jan. p. 379 f. Delehaye: in beiden von Delehaye abgedruckten Formen wird das sich Zurückziehen wăhrend der Verfolgungszeit auf die Anweisung des Joannikios zurückgeführt.

1) Erwähnt werden Kaiser Michaels Sturz durch Loon Arm. (368, 374); bei der Restitution der Orthodoxie (376) ist kein Name genannt. Die fromme Kaiserin Theodora wird 378 erwähnt; ein Arabereinfall unter dem gottlosen Herrscher Theophilos und ein Manichäeredikt von Theodora und Michael 382.

2) P. 378. 389. $391 \mathrm{ff}$. Eustratios stirbt bei einem Aufenthalt in Byzanz, am 10. Jan. - das Jahr ist leider schlechferdings nicht zu bestimmen. Auch die zahlreichen Wunder post obitum entbehren jeder chronologischen Angabe.

3) Es sind Gregorios (an den sich schon Joannikios wandte), Basilios, Petros,

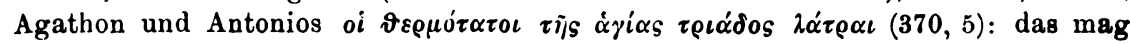
mit dem Kampf gegen den Manichäismus zusammenhüngen, von dem auch die Vita des Joannikios redet (393 c der Ikonoklasmus Leons des Armeniers wird dem Manichäismus gleichgesetzt, vgl. vita Eustr. 374), der neben dem Bilderstreit herging und diesen beeinflußte: Patriarch Nikephoros hatte zu klagen, daB Kaiser Nikephoros die Manichäer (d. h. Paulikianer und Athinganen) schützte (vita Niceph. $158 \mathrm{vgl}$. Theophanes 488, $22 \mathrm{ff}$., dazu Gelzer, Kleine Schriften 128); er schalt dann Leon den Armenier einen Anhänger des Manes (MSG 100, 396, 464, 501 u. ö., vita Niceph. 147, 14). Theodora und Michael erlieBen nach Wiederherstellung der Orthodoxie ein Edikt gegen die Manichäer (vita Eustratii 382). Der Kampf wurde aber besonders von Basilios Makedon geführt (Kedr. II $209 \mathrm{ff}$.). - PapadopoulosKerameus überbietet noch die falschen Identifizierungen ran den Gheyns, indem er in diesem Petrus nicht nur Petrus von Atroa, sondern zugleich den Biographen des Joannikios sehen will. Antonios kann der in der Sabasvita 365 b erwähnte 
verehrung gerühmt haben. Als unter dem neuen Ahab, dem Vorläufer des Antichrist Leon, der Bilderstreit wieder ausbricht (374), da verläBt mit allen frommen Mönchen auch der Abt von Agaurôn das Kloster, um sich in die Bergeseinsamkeit zu Joannikios zurückzuziehen. Als die Orthodoxie wieder hergestellt ist, kehrt or zum Kloster zurück und sammelt die zerstrente Herde (376). Daß einem Heiligen der Kampf zu gunsten der Heiligtümer der Kirche gebühre, davon verrät weder er noch sein Biograph ein Gefühl. Das unterscheidet diese Mönche vom Olymp von den Studiten, trotz ihrer Rechtgläubigkeit. Es sind andere Interessen, wenn auch hier unter den Triumphen des Heiligen nach seinem Tode aufgeführt wird, daB ein von seinem Leichnam ausgehendes Heilwunder einen Häretiker bekehrt: sehr bezeichnend wird dabei die Verachtung des Mönchsgewandes als die Hauptschuld der Ikonomachen aufgefaßt.1)

\section{VI.}

Wir sind mit der Umschau durch die hagiographische Literatur der zweiten Phase des Bilderstreits zu Ende. Wohl gibt es noch eine Anzahl Texte, aber teils liegen sie in Bibliotheken vergraben ${ }^{2}$ ), teils tragen sie nichts für die hier untersuchte Frage aus. ${ }^{3}$ )

Das Resultat ist: die Hagiographie zeigt sich außerordentlich stark beeinflußt von den Strömungen der Kirchenpolitik.

Im Mittelpunkt steht der Patriarch Methodios, der selbst Hand angelegt hat ans Werk und andere dazu angetrieben hat. Die genaue Untersuchung der von ihm veranstalteten Sammlung von Märtyrerakten und Heiligenleben ist eine der dringendsten Aufgaben der Forschung auf diesem Gebiet.)

Abt von Agaurôn sein, dẹr zur Häresie übergegangen war und von Joannikios zurackgowonnen wurde. Dio vita Eustratii nennt zwischen Gregor und Eustratios als Abt nur Eustathios (373), als Nachfolger des Eustratios einen Nikola0s (397).

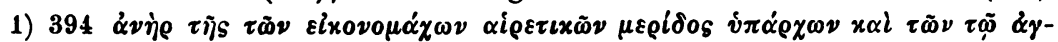

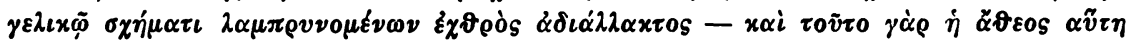

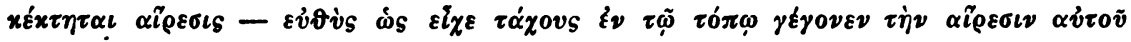

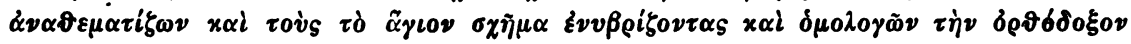

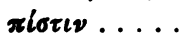

2) Ehrhard bei Krumbacher ${ }^{2} 197$ nennt noch Johannes Psichaites (vgl. unten S. 298); Jakob den Jüngeren (Enkomion von Theophanes Anastasiotes).

3) So die Vita des Gothenbischofs Johannes (Krimgothen) s. ob. S. 73 A. 2.

4) Vgl. Usener Jahrb. f. prot. Theol. XIII (1887) 252; Deubner, Kosmas und Damian (1907) 42 A. 1. - Auf Methodios' t'bersetzertätigkeit fallt neues Licht durch den von v. Soden, Scbriften des NTs I 327, entdeckten, von Chapman, Notes on the early history of the Vulgate Gospels 237, als Utbersetzung aus dem lateinischen erwiesenen Prolog zu Luk. 
Von Methodios angeregt, teilweise in seinem Auftrag schreiben mehrere Geistliche des Patriarchalklerus, allen voran der durch rhetorisches Geschick leuchtende, die Tatsachen aber verdunkelnde Ignatios. ${ }^{1}$ )

All diese direkt oder indirekt von der Patriarchalkanzlei beeinflußten Texte tragen nicht nur ein feierliches rhetorisches Gepräge, sondern auch eine ganz bestimnte Farbe: sie verherrlichen die Kirche in ihren offiziellen höchsten Repräsentanten. ${ }^{2}$ )

Daneben stehen die Mönchsviten, welche ihre Entstehung dem Lokalpatriotismus der einzelnen Klöster verdanken: sie sind nach Stil und Form meist schlichter: sachlich aber teilen sie sich je nach der Stellungnahme des betreffenden Mönchskreises: schroff stehen sich hier das stramm organisierte Mönchtum der hauptstädtischen Klöster und das durch Anachoreten und Styliten der Provinzen, oft mit orientalischem Einschlag, repräsentierte Asketentum gegenüber. ${ }^{3}$ ) Das erstere findet seine typische Ausprägung in Theodor und seinen Studiten.4) Theodors äberragende Persönlichkeit weiß nicht nur die zu Studion gehörigen Klöster wie Sakkudion und Boskytion, sondern auch andere selbständige Klostervorsteher für dies Ideal zu begeistern; aber wie in seinem eignen Orden (so darf man hier sagen) Zelanten und Männer der Vermittlung sich zusammenfinden, so überwiegt in den übrigen Klöstern die andere Partei: ein großer Kreis auch der Klosterleiter schaut voller Bewunderung zu dem Anachoretenideal auf, dessen Ubergeistigkeit jeder Disziplin spottet. Den Studiten steht ein Kreis von nicht minder respektabeln Mönchsheiligen gegenüber. ${ }^{5}$ )

In Studion aber hat sich Theodors strenge Zucht bewährt: auch nachdem ein Ausgleich zustande gekommen war und unter neuen Verhältnissen die Zelanten den Widerstand gegen das Patriarchat aufgegeben hatten, hat Studion an Bedeutung und Kraft alle andern übertroffen. Das zeigt sich $u$. a. darin, daB es die Überlieferung auch nichtstuditischer Heiligenleben beeinfluBt hat. ${ }^{6}$ )

1) Vgl. ob. S. 53. 68, 73. 76.

2) Vgl. Methodios' charakteristischen Ausdruck in der Predigt: oben S. 43.

3) S. ob. S. 84 die Palästinenser Michael und die Graptoi, 92: die lesbischen Styliten, 93: Joannikios vom Olymp aus Isaurien.

4) S. ob. S. 60 f. Theodor und Nikolaos.

5) S. ob. S. 78 Theophanes von Sigriane, S. 81 Niketas von Medikion.

6) S. ob. S. 81 A. 5 Niketas von Medikion: vielleicht. auch Michael S. 91. Auf gewisse Analogien in der Überlieferung besonders der Theodorviten mit der gleichfalls durch die verschiedensten Tendenzen hin und her gezerrten Überlieferung über den heiligen Franciscus sei nur eben hingewiesen. Sachlich gehörte der echte Franciscus ja eher an die Seite eines Ioznnikio3, so viel böher er auch mit seinem Armutsideal steht. 
Jedenfalls wird man künftig nicht mehr mit der äuBerlichen Einteilung der Heiligenleben nach Landschaften auskommen, überhaupt weniger nach den dargestellten Heiligen als nach den Autoren und ihrer Stellung zu den brennenden kirchenpolitischen Fragen zu gruppieren haben. Welchen EinfluB dann die Photianischen Streitigkeiten anf die Hagiographie gehabt·haben, das wäre einer eignen Untersuchung wert.

\section{Exkurs.}

\section{Zum Synaxarium Constantinopolitanum.}

Den in den Gött. gel. Anzeigen von $1905 \mathrm{Nr} 7$ gegebenen Gründen für die Abfassung des Synaxars unter Leon dem Weisen zwischen 901 und 907 (S. 568) kann ich jetzt noch folgende Beobachtung hinzufügen: In fast allen Rezensionen ist einer Sonnenfinsternis vom Jahre 891 Erwähnung getan (in SHD zum 8. Aug., NC 9., Re 10., Rb 5. Aug.), deren als eines eindrucksvollen Ereignisses auch die Chronisten gedenken. ${ }^{1}$ ) Es ist die einzige Sonnenfinsternis, der im Synaxar eine Kommemoration gewidmet ist, und dabei heiBt es nach sehr genauen

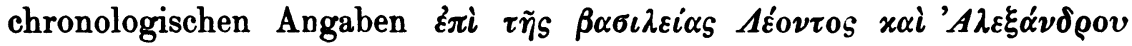

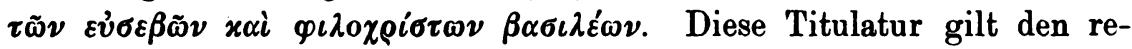
gierenden Kaisern. Sie fehlt sonst im Synaxar, auch bei Kaisern, die um ihrer Orthodoxie willen gefeiert sind, wie Michael und Theodora. Ähnlich heißt es bei der Translation der Lazarusreliquien von $901^{2}$ )

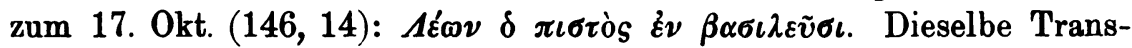
lation wird zum 4. (5.) Mai nochmals kommemoriert (658, 37): das ist offenbar ein Nachtrag aus der Zeit Konstantins VII, denn hier steht

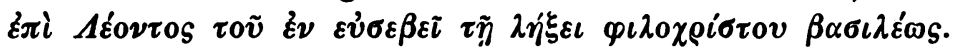

Das Synaxar ist also als Quelle aus der Zeit 900-910 etwa zu bewerten, womit die oben gemachten Beobachtungen über Aufnahme und Nichtaufnahme von Heiligen durchaus übereinstimmen. ${ }^{3}$ )

Die oben durchgeführte Vergleichung der Synaxartexte hat für viele derselben zu genauerer Quellenfeststellung geführt, für alle aber

1) Theophanes cont. VI 6 p. 356,20, Kedrenos II 253,8 , Georg. mon. cont. 852,12 , Leo gramm. 266, 7 setzen sie ein Jahr vor den Tod des Patriarchen Stephanos (17. Mai 893); Ps. Symeon 701, 13 in Leos zweites Jahr (887/8): aber seine Datierungen stimmen nicht; Glykas 553, 19 stellt eine Verbindung mit Photios' Sturz Dez. 886 her.

2) Theoph. cont. VI 18 p. 364 nach der Weihe des Nikolaos Mystikos; ebenso Kedr. II 260, 4, Georg. mon. cont. 860, Leo gramm. 274.12; Zonaras XVI 13: darauf folgt in dieser Utberlieferung die Einnahme von Tauromenion und Lemnos und die ins 10. Jahr vor Leons Tod gesetzte Pfingstprozession nach dem heiligen Mokios (11. Mai 902). Ps. Symeon 704 nennt Leons 13. Jahr = 899; G]ykas 554, 2 stellt es zu jener Bonnenfinsternis von 891. Zahns Anmerkung in Forschungen zur Geschichte des NTl Kanons VI $61 \mathrm{f}$. geht auf dies Datum nicht ein.

3) Vgl. S. 41 A. 2. 
erwiesen, daB die von Delehaye zugrunde gelegte S-Form diese Hochschätzung nicht verdient: meist ist in $\mathrm{F}$ oder $\mathrm{C}$ eine ausführlichere und bessere Regeste erhalten. ${ }^{1}$ ) S stellt eine bereits durch den Metaphrasten beeinfluBte Rezension dar. Dabei verdient es Beachtung, daB $\mathrm{S}$ konstant den Klosternamen $\tau \tilde{\omega} \nu$ ' $A \gamma \alpha v \rho \tilde{\omega} v$ in $\tau \tilde{\omega} v A \dot{v} \gamma \alpha \alpha^{\prime} \rho v$ verändert. Sollte hier die Translation des Edessenums vom Jahre 944 einwirken?

Für die Geschichte des Synaxars von Interesse ist die Notiz bei dem Mönch Methodios (um 1261), der zum Beweis der Anerkennung des Arsakios und des Attikos als rechtmäBiger Patriarchen auf die

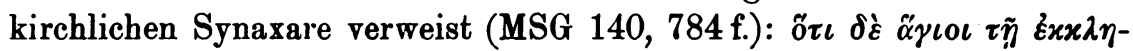

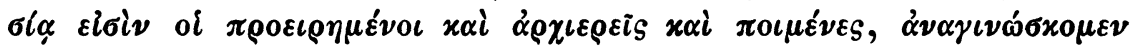

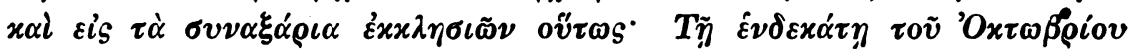

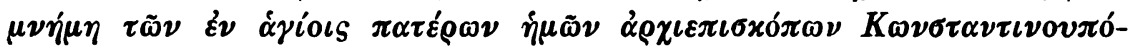

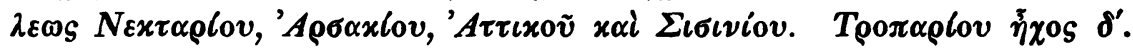

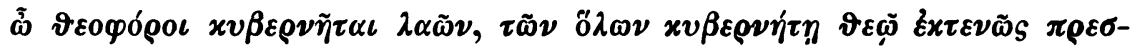

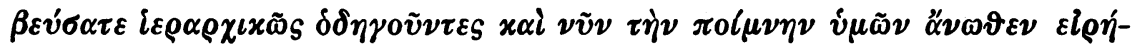
$\nu \eta \nu \alpha i \tau \dot{\eta} \sigma \alpha \sigma \vartheta \varepsilon \quad \tau \alpha \tilde{\tau} S \quad \psi v \chi \alpha \tilde{i}_{S} \dot{\eta} \mu \tilde{\omega} \nu$.

Der Mönch Methodios hatte also c. 1261 ein Synaxarion mit Troparien vor sich. Dabei scheiden sich gerade an dieser Stelle deutlich die Rezensionen; $\mathrm{HPOC}^{*}$ haben obige vier Namen; in $\mathrm{F}^{*} \mathrm{G}$ ist Arsakios durch Akakios ersetzt, in $\mathrm{S} *$ tritt Akakios neben Arsakios, in $\mathrm{M}^{*}$ ist Attikos fortgelassen, in $M$ dazu Arsakios wegradiert. In $\mathrm{B}^{*}$ fehlt die ganze Kommemoration.

StraBburg.

v. Dobschitz.

1) Vgl. S. 59 A. $3.4 ; 69$ A. 3 ; 70 A. $2 ; 7:$ A. 1 ; 75 A. $3.4 ; 77$ A. $6 ; 87$ A. 2; 88 A. 2 ; 93 A. 2. 